\title{
Implementação de um módulo Ethernet 10/100Mbps com interface Avalon para o processador Nios II da Altera
}

\author{
Ricardo Menotti
}

Orientador: Prof. Dr. Eduardo Marques

Dissertação apresentada ao Instituto de Ciências Matemáticas e de Computação como parte dos requisitos para a obtenção do título de Mestre em Ciências da Computação e Matemática Computacional.

USP - São Carlos

Abril de 2005 
Aos meus pais 


\section{Agradecimentos}

A Deus, por me dar a capacidade necessária para realização desse trabalho e por todas as graças recebidas.

Aos meus pais, José e Elda, pelo apoio, carinho e dedicação que sempre tiveram com os filhos, aos meus irmãos, Rodrigo e Regiane. A Claudia, pela compreensão e pelo apoio em todos os momentos.

Ao meu orientador, Prof. Dr. Eduardo Marques, pelos conselhos e pela ajuda, sem os quais este trabalho não teria sido concluído.

Aos companheiros de república, Mário, Reginaldo e Rogério, pela ajuda prestada, pelos conselhos e pela paciência.

A todos que de alguma forma contribuíram para a conclusão deste trabalho, em especial aos companheiros do LCR.

Ao CNPq pelo apoio financeiro. 
Labor improbus omnia vincit.

(Schottus, Adagia 306) 


\section{Resumo}

O presente trabalho apresenta a implementação de um core de rede Ethernet 10/100Mbps com interface para o barramento Avalon para utilização em conjunto com o processador Nios II da Altera. A tecnologia Ethernet foi implementada em computação reconfigurável e utilizou-se como base um módulo disponível na Internet denominado OpenCores MAC 10/100. O projeto foi desenvolvido para ser aplicado em sistemas embarcados, mais especificamente para o uso em um robô móvel em desenvolvimento no Laboratório de Computação Reconfigurável do ICMC/USP. O core foi incorporado à biblioteca da ferramenta SoPC Builder da Altera, visando uma fácil integração do mesmo em outros projetos. Foram utilizadas as ferramentas Quartus II e ModelSim para o desenvolvimento e testes do sistema, além de dois kits Nios versão Stratix para a validação do projeto, sendo as placas interligadas ponto-a-ponto sem a utilizaçao de transceivers analógicos. 


\section{Abstract}

This work presents the implementation of a network Ethernet 10/100Mbps core with interfaces to Avalon bus for using with the Nios II processor from Altera. The Ethernet technology was implemented in reconfigurable computing and was based in the OpenCores MAC 10/100 available on Internet. The project was developed for embedded systems applications, more specifically for a mobile robot in development at Reconfigurable Computing Laboratory from ICMC/USP. The core was incorporated to SoPC Builder tool's library from Altera, aiming to facilitate the integration with others projects. To development and system tests were used Quartus II and ModelSim, and two Nios Development kit Statix Edition for project validation. The boards were linked peer-to-peer, without use analog transceivers. 


\section{Lista de Figuras}

1.1 Ambiente para Projeto e Implementação de Controle Evolucionário Embarcado de Robôs Móveis Reconfiguráveis . . . . . . . . . . . . . . . . . . . 16

1.2 Interligação dos FPGAs com o barramento AMBA . . . . . . . . . . . . 17

1.3 Bridge para a ligação $802.3 / 802.11$ (Netgear, 2003) . . . . . . . . . . . . . 17

2.1 Relação do Ethernet com o modelo de referência OSI . . . . . . . . . . . . . . 21

2.2 Composição do frame Ethernet . . . . . . . . . . . . . . . . . . . . 22

2.3 Utilização de um switch para criação de duas LANs Ethernet separadas . . . . 24

2.4 Frames nos padrões DIX e IEEE 802.3 . . . . . . . . . . . . . . . 25

2.5 Diagrama de blocos do transceiver LXT971A (Intel, 2002) . . . . . . . . . 36

3.1 Computação reconfigurável comparada às soluções de hardware e sofware . . . 38

3.2 Relações de mercado de lógica digital (Hamblen e Furman, 2001) . . . . . . . 39

3.3 Estrutura básica de um FPGA . . . . . . . . . . . . . . . . . . . . . . 39

3.4 Utilização de LUTs para implementação de funções lógicas . . . . . . . . . . . . 40

3.5 Circuito de uma LUT de três entradas . . . . . . . . . . . . . . . . . . 41

3.6 Tecnologia TriMatrix da Altera . . . . . . . . . . . . . . . . . 42

3.7 Estrutura geral dos blocos de DSP (Altera, 2003d) . . . . . . . . . . . . . 42

3.8 Diagrama de blocos dos FPGAs da família Stratix . . . . . . . . . . . . . . 43

3.9 Estrutura dos Logic Array Blocks (LABs) . . . . . . . . . . . . . . . . . . 45

3.10 Utilização de lógica customizada para definir novas instruções no Nios (Altera, 2002d) . . . . . . . . . . . . . . . . . 46

3.11 Kit de desenvolvimento e placa em destaque . . . . . . . . . . . . . . . . 47

3.12 Adicionando componentes ao SoPC Builder . . . . . . . . . . . . . . . 49

3.13 Funcionamento da ferramenta SoPC Builder (Altera, 2002e) . . . . . . . . 50

3.14 Excalibur Apex Edition e Nios Ethernet . . . . . . . . . . . . . . 51

3.15 Altera 10/100 Ethernet MAC MegaCore (Altera, 2002c) . . . . . . . . . . . 52

3.16 Wipro's IEEE 802.3 Ethernet MAC Layer Synthesizable Core (Wipro, 2004) 53 
4.1 Projeto da placa auxiliar conectada ao kit Nios Stratix . . . . . . . . . . . . . 56

4.2 Conector utilizado para construção da uma placa com rede Ethernet . . . . . . 56

4.3 Esquema elétrico dos protetores magnéticos . . . . . . . . . . . . 56

4.4 Kit de desenvolvimento da Microtronix (Microtronix, 2005) . . . . . . . . 57

4.5 Diagrama de blocos do transceiver 78Q2120C (TDK, 2003) . . . . . . . . . 57

4.6 Inclusão do core Ethernet no SoPC . . . . . . . . . . . . . . . . . . . 58

4.7 Diagrama de blocos do core Ethernet para o Avalon . . . . . . . . . . . . . 59

4.8 Sistema montado para validação do projeto . . . . . . . . . . . . . . . 62

4.9 Diagrama de blocos do sistema de validação . . . . . . . . . . . . . . . . . . 62

4.10 Diagrama de blocos do SoC implementado . . . . . . . . . . . . . . 63

4.11 Programa para envio de pacotes com conteúdo seqüencial . . . . . . . . . . 65

4.12 Programa recebendo os pacotes Ethernet e mostrando o conteúdo . . . . . . . . 66

A.1 Gravação do registrador TX_BD_NUM para 1 buffer de transmissão . . . . . . 76

A.2 Gravação do registrador MODER . . . . . . . . . . . . . . . . . . . 77

A.3 Lendo os tamanhos mínimo e máximo de pacotes . . . . . . . . . . . . . 77

A.4 Configuração de um buffer para transmissão . . . . . . . . . . . . . . . . . 78

A.5 Configuração do ponteiro de um buffer de transmissão . . . . . . . . . . . . 78

A.6 Configuração da máscara de interrupções . . . . . . . . . . . . . . . . . . . . 79

A.7 Leitura do descritor para conferência . . . . . . . . . . . . . . . . . . 79

A.8 Gravação do bit WR do descritor . . . . . . . . . . . . . . . . . . 80

A.9 Leitura do descritor para conferência . . . . . . . . . . . . . . . . 80

A.10 Gravação do bit RD, informado que o buffer está pronto . . . . . . . . . . . . . 81

A.11 Leitura do descritor para conferência . . . . . . . . . . . . . . . . . 81

A.12 Interface mestre busca dados na memória . . . . . . . . . . . . . . . . . 82

A.13 Configuração da máscara de interrupções . . . . . . . . . . . . . . . . . . 82

A.14 Gravação do registrador TX_BD_NUM para 118 buffers de transmissão . . . . . 83

A.15 Gravação do registrador MODER . . . . . . . . . . . . . . . . 83

A.16 Lendo os tamanhos mínimo e máximo de pacotes . . . . . . . . . . . . . 84

A.17 Habilitando a interrupção para o descritor de recepção . . . . . . . . . . . . . . . 85

A.18 Configuração do ponteiro de um buffer de recepção . . . . . . . . . . . . . . 85

A.19 Leitura do descritor para conferência . . . . . . . . . . . . . . . . . 86

A.20 Gravação do bit WRAP do descritor . . . . . . . . . . . . . . . . . . . 86

A.21 Leitura do descritor para conferência . . . . . . . . . . . . . . . . . . 87

A.22 Gravação do registrador MODER, habilitando a recepção . . . . . . . . . . . . 87

A.23 Interface mestre grava dados na memória . . . . . . . . . . . . . . 88

A.24 Endereços consecutivos são utilizados . . . . . . . . . . . . . . . . . . . 88 


\section{Lista de Tabelas}

2.1 Tempos máximos de backoff em um sistema 10 Mbps . . . . . . . . . . . . 31

3.1 Quantidade de recursos dos dispositivos da família Stratix (Altera, 2003d) . . . 43

4.1 Recursos utilizados do dispositivo EP1S10F780C6 . . . . . . . . . . . . 64

A.1 Principais sinais do barramento Wishbone apresentados nas simulações . . . . 75 


\section{Lista de Abreviaturas}

AHB Advanced High-Performance Bus

AMBA Advanced Microcontroller Bus Architecture

ARP Address Resolution Protocol

ASCII American Standard Code for Information Interchange

ASIC Application-Specific Integrated Circuit

ASSP Application-Specific Standard Product

BGA Ball Grid Array

BLAM Binary Logarithmic Arbitration Method

CMOS Complementary Metal Oxide Semiconductor

CRC Cyclic Redundancy Check

CSMA/CD Carrier Sense Multiple Access / Collision Detect

DIX DEC-Intel-Xerox

DSP Digital Signal Processing

EBCDIC Extended Binary Coded Decimal Interchange Code

EDA Electronic Design Automation

FCS Frame Check Sequence

FIFO First-In First-Out

FIR Finite Impulse Response

FPGA Field-Programmable Gate Array

HDL Hardware Description Language

ICMC Instituto de Ciências Matemáticas e de Computação

IDE Integrated Development Environment

IFG Interframe Gap

IIR Infinite Impulse Response

IOE Input/Output Element

IP Intellectual Property

ISO International Organization Standardization

LAB Logic Array Block 


$\begin{array}{ll}\text { LAN } & \text { Local Area Network } \\ \text { LCR } & \text { Laboratório de Computação Reconfigurável } \\ \text { LE } & \text { Logic Element } \\ \text { LLC } & \text { Logic Link Control } \\ \text { LUT } & \text { Lookup Table } \\ \text { LU } & \text { Lógica de Usuário } \\ \text { LVPECL } & \text { Low Voltage Positive Emitter Coupled Logic } \\ \text { MAC } & \text { Media Access Control } \\ \text { MII } & \text { Media Independent Interface } \\ \text { OSI } & \text { Open Systems Interconnection } \\ \text { OUI } & \text { Organizationally Unique Identifier } \\ \text { PARC } & \text { Xerox Palo Alto Research Center } \\ \text { PROM } & \text { Programmable Read-Only Memory } \\ \text { RevMII } & \text { Reverse Media Independent Interface } \\ \text { SFD } & \text { Start Frame Delimiter } \\ \text { SoC } & \text { System on Chip } \\ \text { SoPC } & \text { System on a Programmable Chip } \\ \text { USP } & \text { Universidade de São Paulo } \\ \text { VLSI } & \text { Very Large Scale Integration } \\ & \end{array}$




\section{Sumário}

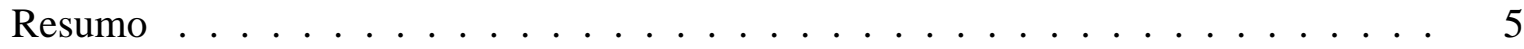

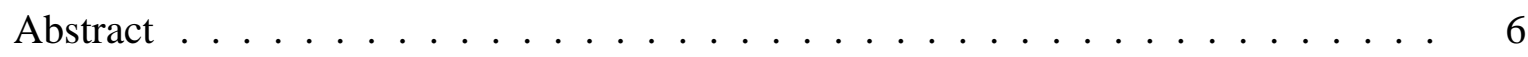

Lista de Figuras . . . . . . . . . . . . . . . . . . . . 8

Lista de Tabelas . . . . . . . . . . . . . . . . . . . . . . . . 9

Lista de Abreviaturas . . . . . . . . . . . . . . . . . . . 10

1 Introdução e Justificativa 14

1.1 Organização do Trabalho . . . . . . . . . . . . . . . . . . . . . . . 17

2 A Tecnologia Ethernet 19

2.1 Introdução . . . . . . . . . . . . . . . . . . . . . . . . . . . . . . 19

2.2 O frame Ethernet e as regras de transmissão . . . . . . . . . . . . . . . . . 24

2.2.1 Os campos do frame Ethernet . . . . . . . . . . . . . . . . 25

2.2.2 Regras do protocolo MAC . . . . . . . . . . . . . . 28

2.3 Detecção de colisão e backoff . . . . . . . . . . . . . . . . . . . 30

2.3.1 Captura do canal Ethernet . . . . . . . . . . . . . 31

2.4 O Ethernet o os protocolos de rede . . . . . . . . . . . . . . 32

2.5 Modo full-duplex e controle de fluxo . . . . . . . . . . . . . . . . . . 33

2.6 O transceiver LXT971A da Intel . . . . . . . . . . . . . . . . . . . . . 34

3 Computação Reconfigurável $\quad 37$

3.1 Introdução . . . . . . . . . . . . . . . . . . . 37

3.2 A família de FPGAs Stratix . . . . . . . . . . . . . . . . . . . . 41

3.3 Ferramentas . . . . . . . . . . . . . . . . . . . . . 44

3.4 FPGA \& Ethernet . . . . . . . . . . . . . . . . . . . 50

3.4 .1 Kit Nios Ethernet . . . . . . . . . . . . . . . . 51

3.4 .2 Altera MegaCore . . . . . . . . . . . . . . . . . 51

3.4.3 Wipro Ethernet MAC Layer Synthesizable Core . . . . . . . . . . . . 52

3.4 .4 OpenCores EthMac . . . . . . . . . . . . . . . . 52 
4 Implementação e Resultados

$4.1 \mathrm{O}$ componente Ethernet . . . . . . . . . . . . . . . . 58

4.2 Sistema de validação . . . . . . . . . . . . . . . . . . 61

5 Conclusões $\quad 67$

5.1 Trabalhos futuros . . . . . . . . . . . . . . . . . . 69

Referências Bibliográficas $\quad 74$

$\begin{array}{ll}\text { A Simulações } & \mathbf{7 5}\end{array}$

A.1 Transmissão de dados . . . . . . . . . . . . . . . . . . . . 75

A.2 Recepção de dados . . . . . . . . . . . . . . . . . . . . . 79 


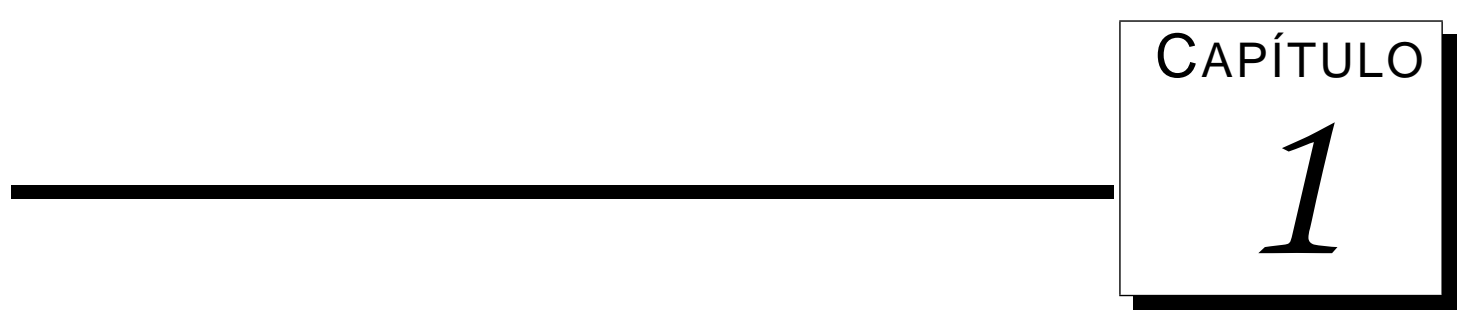

\section{Introdução e Justificativa}

A tecnologia da informação está próxima de outra revolução, impulsionada pelo aumento da capacidade de processamento e pelo declínio dos custos da computação e dos dispositivos de comunicação. Na década de 60 a tecnologia da informação era dominada pelos mainframes e caracterizada pelo poder computacional e armazenamento dos dados de forma centralizada. Os avanços tecnológicos tornaram possível o aparecimento dos minicomputadores na década de 70 e dos PCs na década de 80, que atualmente dominam o mercado. Atualmente, informações são embutidas em diversos dispositivos físicos como celulares e PDAs, interligados por intermédio de redes. Sem considerar os equipamentos menos notados pelo usuário final, como aqueles embutidos em automóveis, aviões e outros que possuem cada vez mais microprocessadores interligados (Estrin et. al., 2001). Com o passar do tempo os dispositivos estão se tornando mais rápidos, menores e mais densos, permitindo que se desenvolva aplicações mais complexas em um único chip, dando origem aos chamados System on a Chip (SoC).

Com a integração de várias funções em um mesmo chip, não há mais a presença de um barramento interligando periféricos, mas sim uma arquitetura interna ao chip. Tal integração sugere projetos baseados em módulos. A abordagem de desenvolvimento em módulos ou macros, facilita o desenvolvimento e a verificação do hardware projetado. Para que as diversas 
macros de um sistema possam ser reutilizadas, foram criados barramentos on-chip, padronizando a comunicação entre elas (Nicolescu et. al., 2002; Roychoudhury et. al., 2003). Para suportar as necessidades dos SoC esses barramentos precisam ser flexíveis e robustos. Entre os barramentos usados para esse fim se destacam o Advanced Microcontroller Bus Architecture (AMBA) (ARM, 1999), Avalon (Altera, 2003a) e CoreConnect (IBM, 1999).

A computação reconfigurável tem sido empregada no desenvolvimento de SoC, originando os chamados System on a Programmable Chip (SoPC). Segundo Berger (2002), o hardware reconfigurável tem potencial para redefinir completamente o processo de criação de sistemas embarcados. Baseado no projeto ARMOSH ${ }^{1}$, o Laboratório de Computação Reconfigurável (LCR) do Instituto de Ciências Matemáticas e de Computação da Universidade de São Paulo (USP) vem desenvolvendo um novo ambiente para projeto e implementação de um sistema de controle evolucionário embarcado para robôs móveis reconfiguráveis dinamicamente, baseado em Field-Programmable Gate Array (FPGA) mostrado na Figura 1.1.

Nesse ambiente, os diversos módulos são interligados pelo AMBA. Esse barramento pode interligar tanto Application-Specific Integrated Circuits (ASICs) quanto FPGAs utilizadas no robô, como mostra a Figura 1.2.

Este projeto de pesquisa descreve a utilização de um módulo de rede Ethernet baseado em computação reconfigurável (destacado na Figura 1.1). Esse módulo, denominado daqui em diante core Ethernet ou simplesmente core, poderá ser aplicado ao robô utilizando uma bridge (Netgear, 2003) como apresentado na Figura 1.3, estabelecendo assim comunicação sem fio. Qualquer outro SoPC que necessite de comunicação em um ambiente de rede Ethernet, como um robô fixo, também poderá fazer uso dele. Com o produto deste projeto pretende-se atender a necessidade de comunicação, indispensável em sistemas embarcados quando se deseja compartilhar recursos ou trabalhar de forma cooperativa (Nett e Schemmer, 2003; Verbauwhede e Chang, 2002).

Atualmente, a tecnologia Ethernet é a mais utilizada nas Local Area Networks (LANs) em todo o mundo, segundo Spurgeon (2000), e está começando a ser utilizada em ambientes industriais para comunicação de tempo real (Song et. al., 2002). A quantidade de redes instaladas

\footnotetext{
${ }^{1}$ Aprendizado de Robôs Móveis via Software e Hardware, financiado pela FAPESP (processo no 2000/02959-3)
} 


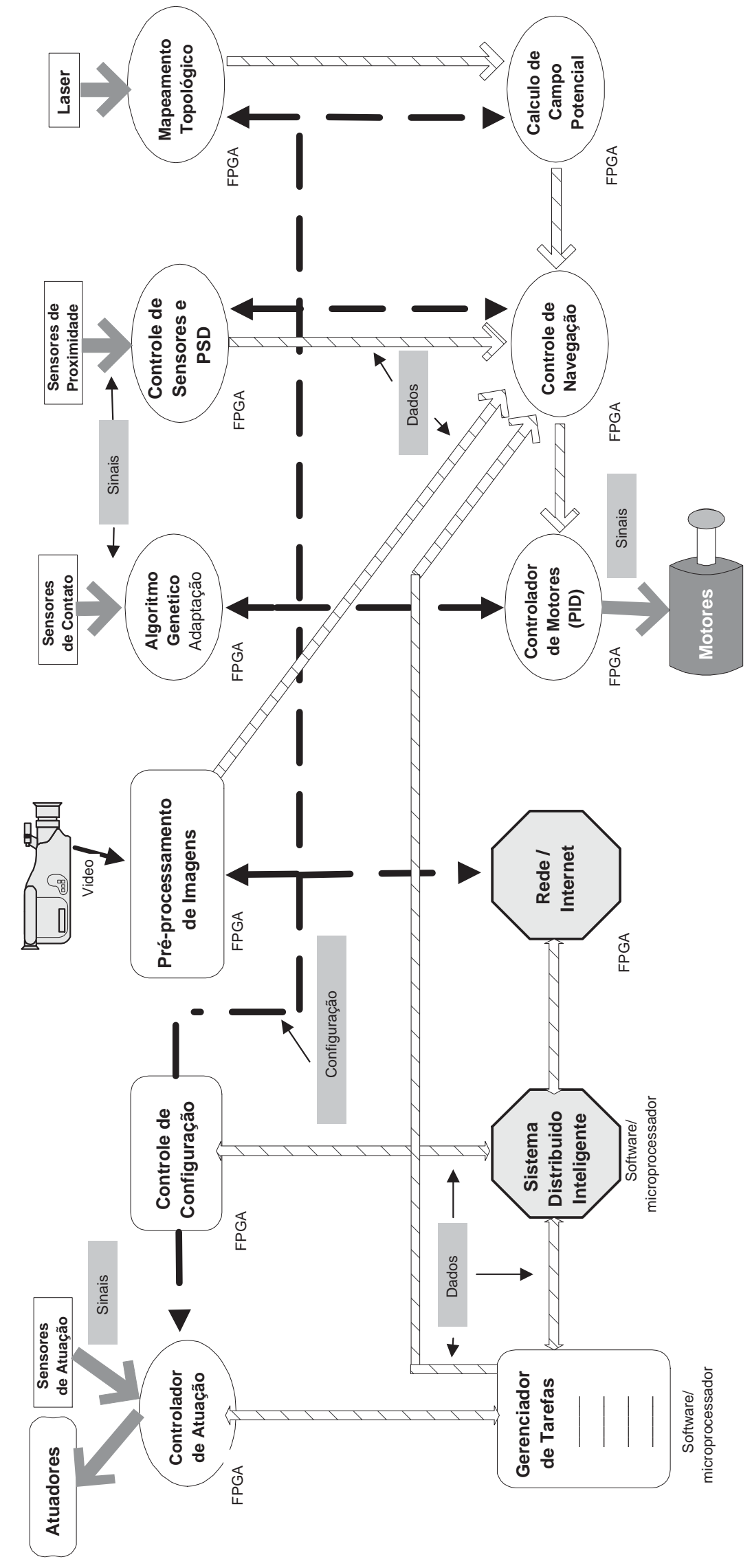




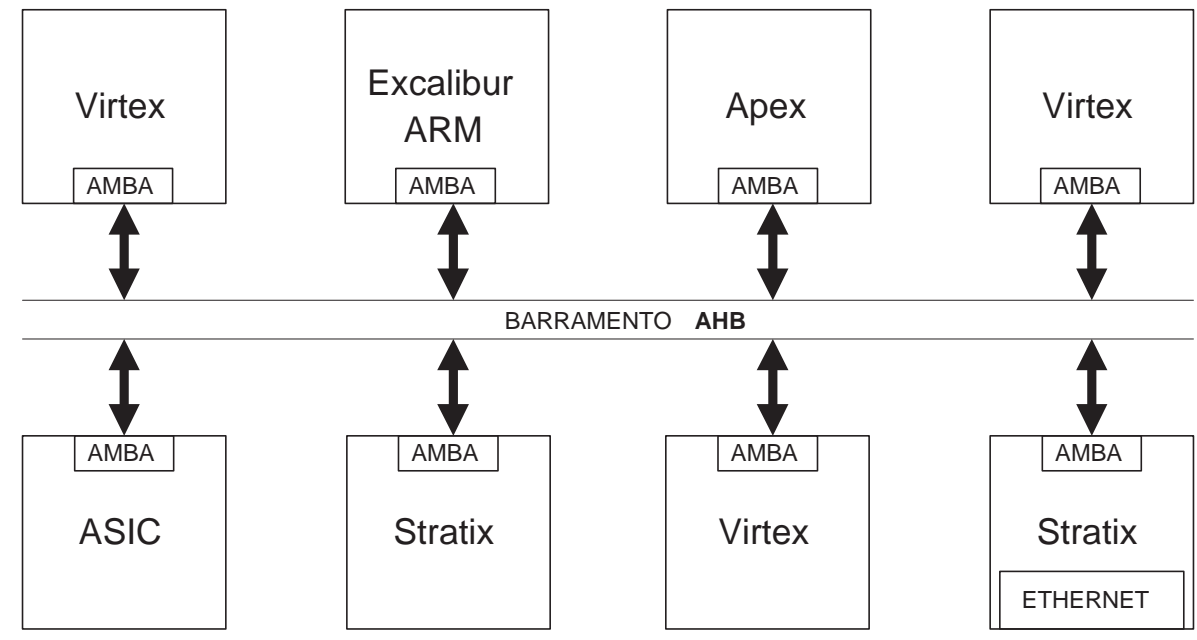

Figura 1.2: Interligação dos FPGAs com o barramento AMBA

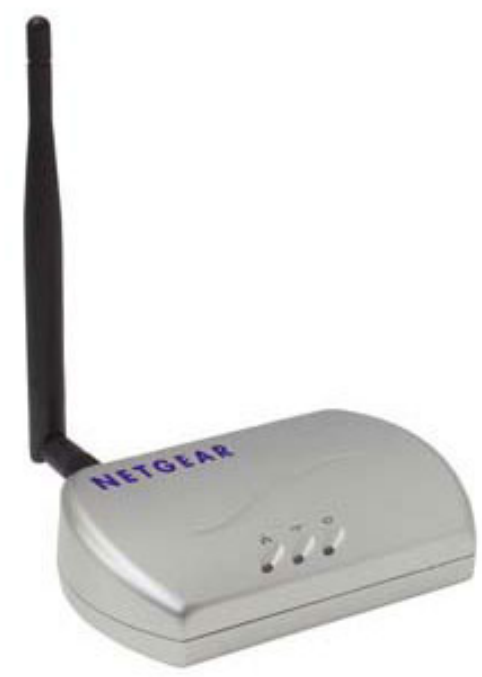

Figura 1.3: Bridge para a ligação 802.3/802.11 (Netgear, 2003)

atualmente justificou o estudo e desenvolvimento dessa tecnologia em computação reconfigurável, permitindo sua utilização em diversas aplicações de robótica e em redes de sistemas embarcados como em aplicações automobilísticas, agricultura de precisão e sistemas de defesa nacional (Estrin et. al., 2001). A tecnologia FPGA permite a implementação de redes de alta velocidade (Altera, 2002b,f). Além disso, acredita-se que esta implementação contribui para trabalhos futuros com protocolos wireless.

\subsection{Organização do Trabalho}

O restante deste trabalho encontra-se organizado da seguinte forma: 
- O Capítulo 2 apresenta uma visão geral da tecnologia Ethernet, descrevendo a estrutura de seu frame, o funcionamento do protocolo MAC e do algoritmo de backoff. Ainda no Capítulo 2 é brevemente apresentado o chip que faz a interface do FPGA com a mídia do Ethernet efetivamente, descrevendo suas principais características e recursos;

- O Capítulo 3 contém uma introdução sobre computação reconfigurável e seus objetivos, além de descrever a plataforma de desenvolvimento do projeto baseada na família de FPGAs Stratix da Altera e nas ferramentas Quartus II, SoPC Builder e ModelSim. São apresentadas ainda algumas soluções existentes para se conectar sistemas embarcados às redes Ethernet;

- O Capítulo 4 descreve a implementação do trabalho, o sistema de validação e apresenta algumas sugestões para trabalhos futuros.

- O Apêndice A apresenta simulações realizadas com a ferramenta ModelSim. 


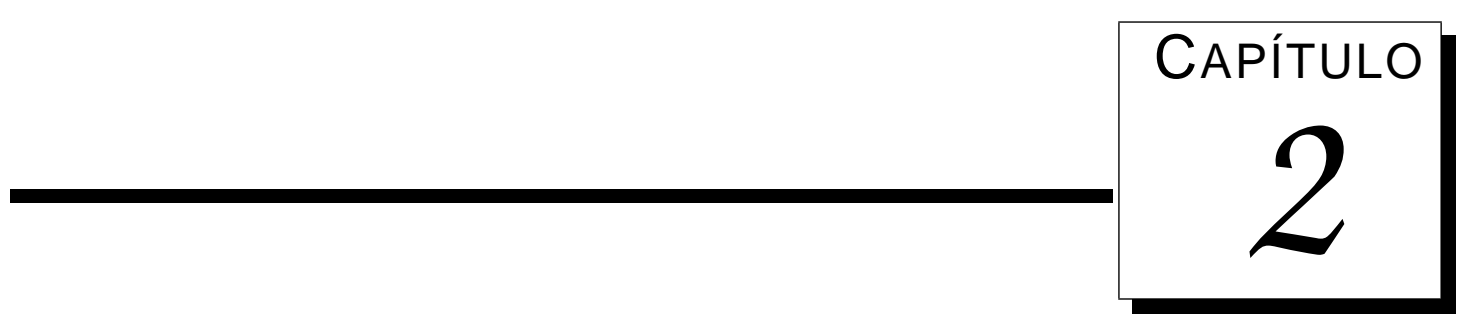

\section{A Tecnologia Ethernet}

Este capítulo apresenta a tecnologia Ethernet, que foi utilizada no desenvolvimento deste projeto, implementada em hardware reconfigurável. São descritos os principais componentes dessa tecnologia e seus modos de operação. O capítulo apresenta também uma descrição de um transceiver que deve ser utilizado entre o FPGA e a mídia física efetivamente.

\subsection{Introdução}

O modelo de referência denominado Open Systems Interconnection (OSI) apresentado pela International Organization Standardization (ISO) descreve como organizar hardware e software para operarem na formação de redes (Bertsekas e Gallager, 1992; Comer, 2000; Naugle, 1994).

Esse modelo descreve sete camadas de funções de rede. As mais inferiores tratam de como os bits circulam em uma LAN e as mais superiores tratam de notações mais abstratas, como por exemplo, a segurança dos dados e forma de apresentação deles ao usuário. Segue uma descrição sucinta de cada camada:

1. Camada Física: padrões elétricos, mecânicos e controles funcionais dos circuitos que conectam à mídia física;

2. Camada de Enlace: responsável pela transmissão e recepção de pacotes (frames) entre as 
estações e detecção de erros nestes frames;

3. Camada de Rede: provê comunicação entre as estações com mais alto nível, independentemente das camadas anteriores. Possui recursos de roteamento dos pacotes;

4. Camada de Transporte: pode prover comunicação confiável entre as estações por intermédio de controle de fluxo e seqüenciamento de pacotes, garantindo a entrega dos dados, embora essas características não estejam presentes em todos os protocolos dessa camada;

5. Camada de Seção: estabelece comunicações confiáveis entre as estações por intermédio de seções. Estão presentes nessa camada as traduções de nomes para endereços de rede;

6. Camada de Apresentação: responsável pela formatação dos dados em formatos como o American Standard Code for Information Interchange (ASCII) e o Extended Binary Coded Decimal Interchange Code (EBCDIC). Pode também permitir recursos de criptografia de dados;

7. Camada de Aplicação: permite que aplicações se comuniquem pela rede, fornecendo mecanismos de alto nível;

É importante ressaltar que o OSI é apenas um modelo teórico de referência, e segundo Comer (2002) esse modelo não é amplamente desenvolvido e apoiado.

O padrão Ethernet está relacionado às duas camadas mais inferiores do modelo OSI, conforme demonstra a Figura 2.1. Ele foi apresentado pela primeira vez em 1976 por Robert Metcalfe (Spurgeon, 2004) que na época trabalhava para o Xerox Palo Alto Research Center (PARC). Atualmente é o padrão mais usado no mundo para LAN e supera em vendas as outras tecnologias com uma grade margem (Spurgeon, 2000).

O sistema consiste na utilização de um canal de comunicação compartilhado entre as partes envolvidas. Cada uma delas deve monitorar o meio físico antes de transmitir para verificar se ele não está sendo usado. Caso ocorra colisão, ou seja, dois dispositivos transmitirem ao mesmo tempo, o sistema deve detectá-la e retransmitir a informação em um tempo escolhido aleatoriamente (Metcalfe e Boggs, 1976). Esse algoritmo é chamado Carrier Sense Multiple Access / Collision Detect (CSMA/CD). 


\begin{tabular}{|c|c|c|c|}
\hline Camada 7 & Aplicação & \multirow{2}{*}{$\begin{array}{c}\text { Subcamada (LLC) } \\
\text { Controle de Ligação Lógica }\end{array}$} & \\
\hline Camada 6 & Apresentação & & \\
\hline Camada 5 & Seção & \multirow{2}{*}{$\begin{array}{l}\text { Subcamada (MAC) } \\
\text { Controle de Acesso a Mídia }\end{array}$} & \\
\hline Camada 4 & Transporte & & \\
\hline Camada 3 & Rede & Subcamada & \\
\hline Camada 2 & Enlace & Sinalização Física & \\
\hline Camada 1 & Física & Especificação da Mídia & \\
\hline
\end{tabular}

Figura 2.1: Relação do Ethernet com o modelo de referência OSI

O sistema Ethernet é constituído basicamente de quatro componentes:

- O quadro (frame), formado por um conjunto de bytes organizados por um padrão e que é utilizado para trafegar os dados na rede;

- O protocolo de controle de acesso à mídia (media access control protocol), que consiste em um conjunto de regras embutidas em cada interface Ethernet, permitindo que vários computadores acessem o meio compartilhado de forma adequada;

- Os componentes de sinalização (signalling components), que são dispositivos eletrônicos que enviam e recebem sinais sobre o canal Ethernet;

- O meio físico (physical medium), formado por cabos e outros hardwares usados para transmitir o sinal digital entre os computadores ligados à rede.

Na constituição do sistema Ethernet, o principal componente é o frame (Figura 2.2), os demais componentes servem apenas para carregar os frames de um dispositivo a outro (Spurgeon, 2000). A Seção 2.2 traz uma descrição mais detalhada de cada componente do quadro Ethernet. No modo half-duplex, utilizado originalmente, um sistema de entrega em broadcast é utilizado, de modo que os pacotes são capturados por todos os dispositivos conectados a rede. Atualmente, muitos dispositivos são conectados diretamente a porta de uma switch e não compartilham o meio físico com outros dispositivos, podendo operar em modo full-duplex, cuja descrição também se encontra na Seção 2.2. 


\begin{tabular}{|c|c|c|c|c|c|}
\hline 64 bits & \multicolumn{2}{|c|}{48 bits } & 48 bits & 16 bits & \multicolumn{2}{c|}{46 a 1500 bytes } & bits \\
\hline Preâmbulo & $\begin{array}{c}\text { Endereço } \\
\text { Destino }\end{array}$ & $\begin{array}{c}\text { Endereço } \\
\text { Origem }\end{array}$ & $\begin{array}{c}\text { Tipo/ } \\
\text { Tamanho }\end{array}$ & Dados & $\begin{array}{c}\text { Seqüência } \\
\text { de Checagem }\end{array}$ \\
\hline
\end{tabular}

Figura 2.2: Composição do frame Ethernet

O modo de operação half-duplex, descrito no padrão Ethernet original, utiliza o protocolo Media Access Contol (MAC) que consiste em um conjunto de regras usadas para arbitrar o acesso à mídia compartilhada.

Cada frame Ethernet é enviado por meio do canal de sinal compartilhado e todas as interfaces ligadas ao canal capturam os bits do sinal e interpretam o segundo campo do frame apresentado na Figura 2.2, o qual contém o endereço de destino. A interface compara esse endereço com o seu endereço unicast de 48 bits, ou com algum endereço multicast, desde que esteja habilitada a reconhecer tal endereço. As interfaces de rede que reconhecerem o endereço continuam com o processo de leitura do frame enquanto as demais o descartam.

Um endereço unicast único é atribuído a cada interface Ethernet em sua fabricação. Endereços multicast permitem que um único frame Ethernet seja recebido por um grupo de estações. Um caso especial de endereço multicast é conhecido como endereço de broadcast, o qual possui todos os 48 bits em nível lógico 1. Todas as interfaces de rede capturam os pacotes enviados com esse destino e encaminham para o software de rede do computador.

Após a transmissão de um frame, todas as estações da rede que possuem informações aguardando para serem enviadas podem competir igualmente pela oportunidade de enviar o próximo frame. Isso torna o acesso ao meio compartilhado justo para que nenhuma estação bloqueie o canal de comunicação definitivamente. O algoritmo CSMA/CD embutido em cada interface de rede Ethernet é responsável por esse controle.

A parte do protocolo denominada carrier sense verifica se cada interface precisa aguardar até que não haja sinal no canal antes de transmitir. Se outra interface está transmitindo há um sinal no canal, o que define a condição é chamada de carrier $^{1}$. Todas as outras interfaces devem

\footnotetext{
${ }^{1}$ Normalmente, um carrier é definido como um sinal de freqüência contínua assim como o sinal usado para modular os sinais de rádio AM ou FM. Não há sinal de carrier contínuo no Ethernet, então "carrier" representa somente a presença de tráfego na rede
} 
aguardar até que o sinal cesse e o meio volte a ficar ocioso antes de tentar transmitir.

Com multiple access, todas as interfaces têm a mesma prioridade ao transmitirem um frame na rede e todas elas podem tentar acessar o canal ao mesmo tempo. Caso duas ou mais interfaces comecem a transmitir simultaneamente elas detectam a colisão do sinal (colision detect). Cada uma delas escolhe um tempo aleatório de retransmissão antes de fazer uma nova tentativa, em um processo chamado backoff. A colisão é absolutamente comum no sistema Ethernet e o tempo aleatório de retransmissão serve para evitar que os frames colidam novamente na retransmissão.

Para que o sistema MAC funcione corretamente é necessário que cada interface consiga responder a qualquer outra em um tempo estritamente controlado. O tempo de sinal do Ethernet é baseado na quantidade de tempo gasto para que o sinal trafegue de um lado ao outro da rede e volte. Esse tempo é denominado round-trip time. No modo half-duplex esse tempo máximo deve ser rigidamente controlado para garantir que todas as estações da rede consigam receber os sinais de todas as outras no tempo necessário para o sistema MAC.

Aumentar o tamanho de um segmento de rede significa aumentar o tempo que um sinal precisa para percorrê-lo. As especificações do Ethernet incluem tamanhos máximos de segmentos e quantidades máximas de segmentos e repetidores utilizados em uma rede e variam de acordo com o tipo de mídia utilizada (cabo coaxial, cabo par-trançado, fibra ótica). Isso garante que o round-trip time correto seja mantido.

O sistema Ethernet foi desenvolvido para ser facilmente expandido de acordo com as necessidades do local. Para facilitar a extensão dos sistemas Ethernet half-duplex foram desenvolvidos os chamados repeater hubs ou simplesmente hubs que são equipamentos com diversas portas Ethernet. Cada porta do hub liga um segmento de rede Ethernet aos outros formando uma única LAN, também chamado domínio de colisão.

Outro tipo de hub é o chamado switching hub ou simplesmente switch. Esse equipamento usa o endereço de destino de 48 bits do sistema Ethernet para tomar decisões no encaminhamento do frame de uma porta a outra. Como apresentado na Figura 2.3, cada porta do switch provê uma conexão para uma mídia Ethernet que funciona como uma LAN completamente separada. 

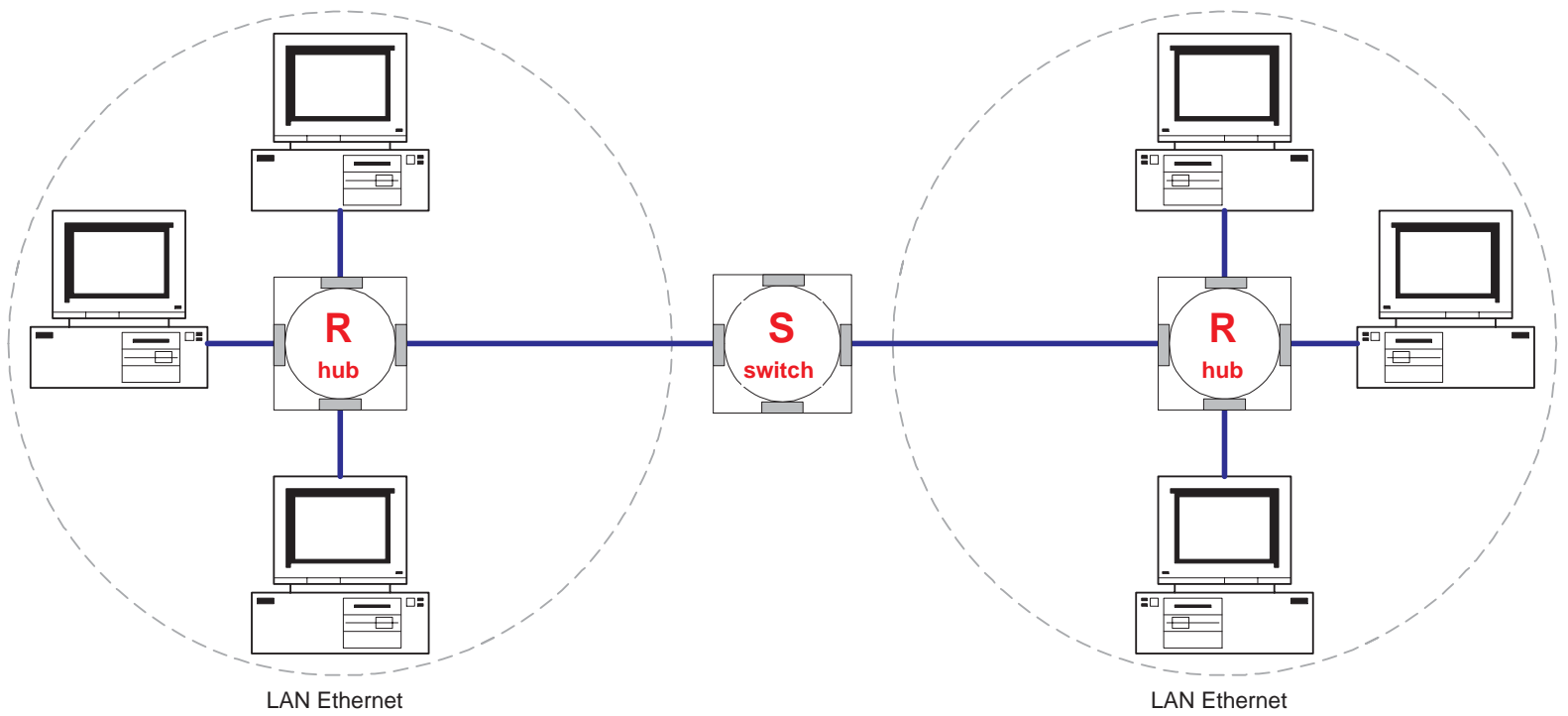

Figura 2.3: Utilização de um switch para criação de duas LANs Ethernet separadas

Enquanto um $h u b$ apenas conecta segmentos de uma mesma LAN Ethernet, um switch interliga diferentes LANs. As regras para cálculo do round-trip time de cada LAN aplicam-se até a porta do switch, permitindo então que sejam interligadas diversas LANs mantendo as especificações.

Em resumo, o protocolo denominado Media Access Control (MAC) é o responsável por permitir que cada estação da rede possa competir pelo meio físico de maneira equilibrada. Uma vez que não há um controle central, cada estação precisa operar de forma independente utilizando o mesmo protocolo MAC, que funciona como um conjunto de regras do Ethernet. Para entender o funcionamento desse protocolo é necessária a compreensão dos seguintes tópicos:

- Estrutura do frame e regras para transmissão;

- Funcionamento da detecção de colisão;

- Utilização dos frames Ethernet pelos protocolos de rede.

\subsection{O frame Ethernet e as regras de transmissão}

As especificações do Ethernet determinam tanto como um frame é composto como quando uma estação está autorizada a transmitir um frame. O sistema Ethernet é usado para transmitir os frames que levam dados das aplicações de um computador a outro. A organização dos frames então é o ponto central de todo o sistema. 
Primeiramente o frame foi definido no padrão DEC-Intel-Xerox (DIX) e depois foi redefinido pelo padrão IEEE 802.3 o qual é o padrão oficial. A principal diferença entre os dois padrões está no campo "tipo", que no padrão 802.3 foi definido como um campo de tamanho do frame, utilizando um mecanismo que permite que os dois tipos de frames coexistam em uma mesma rede. Padrões mais recentes do IEEE 802.3 modificaram esse campo para operar com tipo ou tamanho dependendo da utilização. A Figura 2.4 mostra os frames nos dois padrões.

\begin{tabular}{|l||c|c|c|c|c|}
\hline \multicolumn{1}{|c|}{64 bits } & 48 bits & 48 bits & 16 bits & 46 a 1500 bytes & bits \\
\hline Preâmbulo & $\begin{array}{c}\text { Endereço } \\
\text { Destino }\end{array}$ & $\begin{array}{c}\text { Endereço } \\
\text { Origem }\end{array}$ & $\begin{array}{c}\text { Tipo/ } \\
\text { Tamanho }\end{array}$ & Dados & $\begin{array}{c}\text { Seqüência } \\
\text { de Checagem }\end{array}$ \\
\hline \\
unicast/multicast \\
Frame no padrão DIX
\end{tabular}

\begin{tabular}{|c|c|c|c|c|c|c|c|}
\hline 56 bits & 8 bits & 48 bits & 48 bits & 16 bits & 46 a 1500 bytes & bits \\
\hline Preâmbulo & SFD & $\| \begin{array}{c}\text { Endereço } \\
\text { Destino }\end{array}$ & $\begin{array}{c}\text { Endereço } \\
\text { Origem }\end{array}$ & $\begin{array}{c}\text { Tipo/ } \\
\text { Tamanho }\end{array}$ & Dados & $\begin{array}{c}\text { Seqüência } \\
\text { de Checagem }\end{array}$ \\
\hline $\begin{array}{l}\text { administração local/global } \\
\text { unicast/multicast }\end{array}$
\end{tabular}

Frame no padrão IEEE 802.3

Figura 2.4: Frames nos padrões DIX e IEEE 802.3

\subsubsection{Os campos do frame Ethernet}

Uma descrição detalhada de cada campo do frame Ethernet é aqui apresentada, além de esclarecer as diferenças entre os padrões em alguns dos campos.

\subsubsection{Preâmbulo}

O frame começa com um preâmbulo de 64 bits, permitindo que as interfaces que operam a 10 Mpbs sincronizem o recebimento antes que campos de dados importantes cheguem até elas. Assim as interfaces podem descartar alguns bits até que o sincronismo seja estabelecido sem prejudicar a integridade dos dados.Os sistemas Fast Ethernet (100 Mbps) e Gigabit Ethernet (1000 Mbps) possuem uma codificação de sinal mais complexa que não necessita desse preâmbulo, pois não são perdidos dados no início do recebimento. No entanto, esses sistemas utilizam esse campo para manter a compatibilidade com os sistemas Ethernet anteriores. 
No padrão DIX esse campo é composto por oito octetos de bits que se alternam entre $1 \mathrm{e}$ 0 (possuem o formato 10101010) sendo que o último octeto termina em 1 (possui o formato 10101011). No padrão IEEE o preâmbulo é idêntico, porém o último octeto é chamado de start frame delimiter (SFD).

\subsubsection{Endereço de Destino}

Cada interface Ethernet possui um endereço único de 48 bits. O campo "endereço de destino" pode, então, conter: o endereço de uma interface, um endereço multicast que identifica uma ou mais interfaces que estejam habilitadas a receber ou o endereço de broadcast padrão. Cada interface conectada a rede recebe os frames pelo menos até o campo de endereço de destino. Se o endereço não for o seu próprio ou um endereço de multicast que ela esteja apta a receber, ou o endereço de broadcast, então ela ignora o restante do frame.

No padrão DIX o primeiro bit desse campo enviado pela mídia é usado para distinguir um endereço físico de um endereço de multicast. Se esse bit for 0, trata-se de um endereço unicast e o frame em questão tem apenas um destino. Caso contrário, o endereço de destino do frame é um endereço multicast. O padrão IEEE adiciona significância especial ao segundo bit desse campo, o qual é usado para distinguir entre uma interface administrada localmente e uma interface administrada globalmente. Se esse segundo bit for 0 , a interface é administrada globalmente e o endereço foi atribuído pelo seu fabricante. Sistemas administrados localmente possuem o segundo bit em 1 e são raramente usados uma vez que a maioria das interfaces Ethernet possuem um endereço atribuido pelo fabricante. Em redes Token Ring é comum encontrar endereços administrados localmente (3COM, 1996, 1998; IBM, 2001; Spurgeon, 2000).

No sistema Ethernet os endereços físicos são escritos em 12 dígitos hexadecimais agrupados em pares e transmitidos da esquerda para a direita. No entanto, cada octeto de bits é transmitido do bit menos significativo para o mais significativo. ${ }^{2}$

\subsubsection{Endereço de Origem}

O próximo campo do frame é o endereço de origem que representa o endereço físico da interface de origem do frame. Esse campo não é interpretado pelo protocolo MAC, mas é

\footnotetext{
${ }^{2}$ Um endereço Ethernet representado pela string 00:10:4B:C8:63:7B é enviado na seguinte sequiência de bits: 000000000000100011010010000100111100011011011110
} 
enviado para os protocolos de mais alto nível. O padrão DIX estabelece que uma interface Ethernet não pode mudar seu endereço de origem. No padrão IEEE não há nenhuma restrição a esse respeito e a maioria das interfaces em uso atualmente permitem tal mudança, possibilitando que administradores de redes ou softwares de rede modifiquem o endereço físico, se necessário.

Para obter o endereço físico, utilizado no endereço de origem dos frames, o fabricante da interface precisa solicitar um identificador único denominado Organizationally Unique Identifier (OUI) junto a IEEE. O OUI possui 24 bits e constitui a primeira parte do endereço físico da interface fabricada e pode ser útil para identificar o fabricante ou resolver problemas na rede.

\subsubsection{Cabeçalho VLAN}

Embora esse campo de 4 bytes não apareça na Figura 2.4, ele pode ser inserido entre os campos endereço de origem e tamanho/tipo. Alguns switch hubs utilizam desse campo para formar LANs virtuais entre os dispositivos conectados a elas. A adição desse campo faz com que o tamanho máximo de um frame passe de 1518 bytes para 1522 bytes, porém isso não é problema já que o IEEE constatou que as interfaces são capazes de receber frames com esse tamanho. Uma interface não preparada para receber frames com cabeçalho VLAN os interpreta como um frame de tipo desconhecido e descarta-os (Seifert, 2000).

\subsubsection{Tipo ou Tamanho}

O campo seguinte pode ser tanto um campo de tipo, como um campo de tamanho, dependendo do padrão. No padrão DIX esse campo representa sempre o tipo de protocolo de mais alto nível, cujos dados estão contidos no frame. Por exemplo, um frame DIX que encapsula um pacote IPv4 contem o valor hexadecimal 0800 no campo "tipo".

No padrão IEEE esse campo é denominado tipo/tamanho, pois pode conter uma das duas coisas dependendo de seu valor. Se este for numericamente menor ou igual a 1500 ele indica o tamanho do campo de dados automaticamente preenchido, caso não atinja o tamanho mínimo de 46 bytes. Se o valor do campo for igual ou maior que 1536, ele é usado como campo de tipo especificado originalmente no padrão DIX. 


\subsubsection{Dados}

O campo "dados" deve conter de 46 bytes a 1500 bytes. No padrão DIX o protocolo de rede é responsável por fornecer no mínimo 46 bytes para a construção no frame. Já no padrão IEEE, embora esse campo tenha os mesmo limites de tamanho do padrão DIX, existe um protocolo denominado IEEE 802.2 Logic Link Control (LLC) que encapsula os protocolos de rede. O LLC é responsável por fornecer os 46 bytes mínimos, necessários para a construção do campo de dados do frame (IEEE, 2002; Tanenbaum, 2003).

\subsubsection{Seqüência de Checagem}

O último campo do frame Ethernet, em ambos os padrões, é o frame check sequence (FCS), também chamado de cyclic redundancy check (CRC). É um campo de 32 bits e sua função é verificar a integridade de todos os outros campos com exceção do preâmbulo. Este campo é calculado na interface de origem por meio de um CRC polinomial dos demais campos e depois conferido nas interfaces de destino. O CRC é utilizado por ter boa capacidade de detecção de erros, gerar um pequeno overhead e por ser de fácil implementação. O coeficiente $x^{31}$ é enviado no primeiro bit do campo e o coeficiente $x^{0}$ no último (Comer, 2001).

\subsubsection{Regras do protocolo MAC}

Como já mencionado anteriormente, as regras descritas nesta seção a respeito do protocolo MAC referem-se apenas ao modo de operação half-duplex, considerando que o sistema Ethernet trabalha em uma mídia compartilhada. Uma interface operando neste modo precisa seguir os seguintes passos para transmitir um frame:

- Quando um sinal começa a ser transmitido no canal chamamos esta condição de carrier;

- Se uma interface deseja transmitir um frame, esta deve aguardar até que o canal esteja ocioso, indicado por ausência de carrier;

- Quando o canal se torna ocioso, a interface aguarda por um pequeno período usado como intervalo entre os frames e denominado interframe gap (IFG), e então começa a transmitir o frame; 
- Caso a transmissão seja efetuada por mais de uma interface simultaneamente, estas detectama colisão e reprogramam a transmissão do frame.

As regras para a transmissão de um frames são as seguintes:

1. Se não há carrier e o tempo de ociosidade do canal é maior ou igual ao IFG, o frame pode ser transmitido imediatamente. Se a interface deseja transmitir vários frames deve aguardar um período igual ao IFG entre cada frame. O IFG é utilizado para oferecer um pequeno tempo de recuperação entre um frame e outro e é baseado no tempo necessário para transmitir 96 bits. Esse tempo é de 9,6 microssegundos para redes Ethernet $10 \mathrm{Mbps,}$ 960 nanossegundos para 100 Mbps e 96 nanossegundos para redes Gigabit Ethernet;

2. Se há carrier, a interface deve aguardar até que o canal fique ocioso para então transmitir, respeitando sempre o IFG;

3. Se a interface detectar uma colisão durante a transmissão, esta deve continuar a transmitir pelo menos 32 bits. Caso a colisão tenha acontecido logo no começo de transmissão, a interface deve transmitir todo o preâmbulo, além destes 32 bits, chamados collision enforcement jam signal. Esse procedimento é utilizado para que todas as interfaces consigam detectar a colisão ocorrida e, conseqüentemente consigam tratá-la;

(a) Após enviar os 32 bits de jam a interface deve aguardar um tempo escolhido aleatoriamente e voltar ao ítem 1. Esse procedimento é chamado backoff. O tempo aleatório permite que as interfaces envolvidas na colisão escolham tempos diferentes, evitando novas colisões;

(b) Se na próxima tentativa de transmissão ocorrer uma nova colisão o procedimento de backoff é executado novamente, mas desta vez o tempo utilizado na escolha aleatória é aumentado. Tal heurística tenta diminuir as chances de ocorrência de uma nova colisão e fornece um mecanismo de ajuste de carga da rede;

4. Uma vez transmitidos 512 bits de um frame (sem incluir o preâmbulo) sem que ocorra colisão, diz-se que a interface adquiriu o canal de comunicação. Em um sistema Ethernet funcionando corretamente não deve haver colisão após a aquisição do canal. O tempo 
necessário para a aquisição do canal (transmissão dos 512 bits) é denominado slot time. Para que o frame tenha no mínimo 512 bits é necessário que o campo de dados tenha no mínimo 46 bytes. Após a transmissão do frame a interface deve zerar seu contador de colisões, usado para gerar o tempo de backoff. Caso esta encontre uma nova colisão no próximo frame ela irá iniciar os cálculos de backoff novamente.

Embora os sinais trafeguem rapidamente no canal de comunicação, eles levam um tempo finito para se propagar por todo o canal. Quanto maiores forem os cabos usados no sistema Ethernet, maior o tempo de propagação do sinal. Os tamanhos máximos de cada segmento de rede são cuidadosamente designados para que os tempos essenciais do sistema sejam preservados. O sistema Ethernet original, que operava com cabos coaxiais, permitia a utilização de um segmento com até 2800 metros. Já os segmentos Ethernet que utilizam par trançado têm um comprimento máximo muito menor, apenas 100 metros, não por questões de tempo de propagação, mas por limitações de qualidade do sinal.

\subsection{Detecção de colisão e backoff}

A detecção de colisão e o procedimento de backoff são recursos importantes no protocolo MAC no Ethernet, já que as colisões são parte normal do protocolo e são tratadas de forma rápida e automaticamente. As colisões não causam perda dos dados no sistema Ethernet, pois toda transmissão de um frame que encontra uma colisão é realizada novamente.

O mecanismo de detecção de colisão é dependente da mídia utilizada. Um segmento de rede Ethernet, seja ele de fibra ótica ou de cabo par trançado, possui vias independentes de recepção e transmissão. A colisão é detectada na presença de atividade em ambas as vias. Em sistemas de cabos coaxiais as colisões são detectadas por intermédio do monitoramento da tensão ${ }^{3}$ média, que aumenta caso duas ou mais interfaces transmitam ao mesmo tempo.

Colisões normais ocorrem durante os primeiros 512 bits de transmissão do frame. Após este tempo, a colisão é considerada um erro grave e é denominada late collision. Esse erro indica um problema no sistema de rede, já que o frame é descartado e a interface não retransmite. $\mathrm{O}$ software deve detectar a ausência da informação e solicitar a retransmissão, causando um atraso

\footnotetext{
${ }^{3} \mathrm{DC}$ - corrente contínua
} 
significante. Mesmo uma pequena quantidade de colisões atrasadas podem comprometer o desempenho da rede e devem ser corrigidas o quanto antes possível. As colisões atrasadas podem ocorrer em função de interferências nos cabos da rede. Outra causa provável é a configuração incorreta das interfaces. Se uma interface está operando em modo full-duplex ela desabilita o protocolo CSMA/CD e envia os frames quando desejar. Um interface neste modo, operando com outras interfaces em modo half-duplex, causa colisões atrasadas, já que não monitora o canal antes de transmitir.

Após uma colisão, o tempo de espera para a retransmissão deve ser múltiplo do tempo de transmissão de 512 bits, que é de 512 nanossegundos a 100 Mbps e 51.2 microssegundos a 10 Mbps. O algoritmo de backoff utiliza a seguinte fórmula para calcular o inteiro $r$, usado para multiplicar o slot time e gerar o tempo de espera: $0 \leq r<2^{k}$, sendo $k$ o número de tentativas de transmissão ou o número 10, o que for menor. A Tabela 2.1 mostra os tempos que podem ocorrer na operação para o Ethernet 10 Mbps.

Tabela 2.1: Tempos máximos de backoff em um sistema 10 Mbps

\begin{tabular}{|c|c|c|}
\hline Tentativas & Intervalo & Tempo \\
\hline \hline 1 & $0 . .1$ & $0 . .51,2 \mu \mathrm{s}$ \\
\hline 2 & $0 . .3$ & $0 . .153,6 \mu \mathrm{s}$ \\
\hline 3 & $0 . .7$ & $0 . .358,4 \mu \mathrm{s}$ \\
\hline 4 & $0 . .15$ & $0 . .768 \mu \mathrm{s}$ \\
\hline 5 & $0 . .31$ & $0 . .1,59 \mathrm{~ms}$ \\
\hline 6 & $0 . .63$ & $0 . .3,23 \mathrm{~ms}$ \\
\hline 7 & $0 . .127$ & $0 . .6,5 \mathrm{~ms}$ \\
\hline 8 & $0 . .255$ & $0 . .13,1 \mathrm{~ms}$ \\
\hline 9 & $0 . .511$ & $0 . .26,2 \mathrm{~ms}$ \\
\hline $10-15$ & $0 . .1023$ & $0 . .52,4 \mathrm{~ms}$ \\
\hline
\end{tabular}

Como o expoente $k$ atinge no máximo o número 10, o intervalo do inteiro $r$ é de 0 até o limite de 1023, o que sugere um limite de 1024 estações em um sistema Ethernet half-duplex. Após 16 tentativas a interface descarta o frame. Neste caso, considera-se que a rede está sobrecarregada ou danificada.

\subsubsection{Captura do canal Ethernet}

Embora o protocolo Ethernet seja confiável, de baixo overhead e já tenha provado seu valor em milhões de redes instaladas, ele não é perfeito. O melhor exemplo disso é um efeito chamado 
captura do canal.

Quando várias interfaces estão transmitindo um uma rede Ethernet, é esperado que ocorram colisões. Com exceção da interface que está transmitindo, todas as outras que tentaram transmitir têm seus contadores de colisão diferentes de zero. Assim, esta interface terá vantagem sobre as outras interfaces em sua próxima transmissão e a cada colisão os contadores das outras interfaces são incrementados, facilitando a captura do canal por parte da interface com contador menor. Isso só ocorre se a interface puder transmitir uma grande quantidade de dados de forma rápida e contínua, o que não é um cenário muito comum.

Durante anos o problema de captura do canal foi estudado, pois causa uma queda no desempenho do sistema. Um mecanismo denominado Binary Logarithmic Arbitration Method (BLAM) (Molle, 1994) foi desenvolvido para resolver o problema de captura do canal, modificando as regras do backoff, mas mantendo a compatibilidade com as interfaces existentes. $\mathrm{O}$ IEEE criou um projeto chamado $802.3 \mathrm{w}$ para estudar a implementação do método, mas não foi padronizado por diversos motivos, principalmente pela quantidade de interfaces já desenvolvidas em todo o mundo. A implementação de Ethernet em hardware reconfigurável permite que se modifique o algoritmo utilizado dinamicamente.

\subsection{O Ethernet o os protocolos de rede}

Para a comunicação, os protocolos de redes utilizam o seu próprio sistema de endereçamento, como o de 32 bits usando no Internet Protocol (IPv4). O software de rede baseado no protocolo IP conhece o seu endereço e é capaz de ler também o endereço Ethernet da interface utilizada. No entanto, para a comunicação com outros computadores, o software precisa obter o endereço Ethernet destes. Para isso o TCP/IP utiliza o Address Resolution Protocol (ARP) (Plummer, 1982), enviando um pacote em broadcast para solicitar o endereço Ethernet da interface que possui o endereço IP desejado. Esse pacote é recebido por todas as interfaces da LAN, mas é respondido apenas pelo possuidor do IP procurado, que informa seu endereço Ethernet em resposta à solicitação. A nova versão do protocolo IP (IPv6) utiliza multicast para a resolução de IP, ao invés de broadcast, evitando que computadores não habilitados com o protocolo IP recebam os pacotes IP ARP. 
Os dados transmitidos na rede são transportados no campo de dados do frame Ethernet e estruturados em protocolos de mais alto nível (como o TCP/IP) para estabelecer conexões entre os computadores. Uma vez que os protocolos de mais alto nível são independentes do Ethernet, é possível interligar em uma mesma LAN diversos computadores com diferentes protocolos. O sistema Ethernet apenas transporta os dados contidos no frame sem se importar com o seu conteúdo em um processo chamado encapsulamento de protocolo ou multiplexação de dados.

O sistema original de multiplexação do Ethernet é baseado no uso do campo "tipo" do frame. O software de rede insere o valor correspondente ao protocolo de mais alto nível transportado no frame. A estação ou computador que recebe esse frame utiliza o campo "tipo" para demultiplexar o frame. Sistemas TCP/IP utilizam o campo "tipo" para realizar tal finalidade. No entanto, existem protocolos como o AppleTalk que utilizam o padrão IEEE 802.2 LLC (IEEE, 1985), pois foram criados após a padronização.

\subsection{Modo full-duplex e controle de fluxo}

Full-duplex é um modo de operação opcional do Ethernet que permite comunicação simultânea entre um par de estações. A ligação entre as interfaces é ponto-a-ponto, fornecendo vias independentes de transmissão e recepção, comumente realizadas com cabos de par trançado ou fibra ótica. Por possuir a capacidade de transmissão e recepção simultânea, esse modo pode dobrar a largura de banda do sistema. Nesse modo de operação não é necessária a utilização do algoritmo CSMA/CD; a interface pode transmitir a qualquer momento, ignorando o sinal de carrier. Não há acesso múltiplo à mídia uma vez que a interface tem um canal dedicado para transmissão, o que implica também na ausência de colisões.

Embora esse modo de operação tenha potencial para dobrar a velocidade de um segmento de rede, isso geralmente não ocorre, pois os protocolos de rede trabalham de forma a enviar uma informação e aguardar uma confirmação ou resposta. Por outro lado, um switch operando no modo full-duplex permite a comunicação simultânea entre diversos pares de computadores.

Um switching hub tem memória limitada, principalmente em função dos custos e, portanto, possui uma capacidade limitada de armazenar frames para serem transmitidos posteriormente. Diversas formas não padronizadas foram criadas por fabricantes para controlar o fluxo de da- 
dos do Ethernet, como por exemplo transmitir um sinal de carrier impedindo que as outras interfaces transmitam. Esse recurso funciona apenas para o modo half-duplex, já que no modo full-duplex a interface ignora o sinal de carrier recebido. Para o controle de fluxo no modo full-duplex é utilizado um protocolo opcional denominado MAC Control, que fornece mecanismos para controlar em tempo real a transmissão e recepção de frames em um sistema Ethernet.

Os frames do protocolo MAC Control são identificados pelo valor 0x8808 em seu campo “tipo" e possuem o tamanho mínimo que é de 46 bytes. Os dois primeiros bytes do campo de dados são códigos de operação utilizados pelo protocolo MAC Control. Como não há um mecanismo de transporte seguro, o protocolo de nível supertior (rede) tem que considerar que os frames podem ser perdidos, descartados, danificados ou atrasados.

Uma das operações do protocolo MAC Control é a de PAUSE, identificada pelo código de operação 0x0001. Apenas interfaces configuradas para operar em modo full-duplex podem enviar frames de PAUSE. Para isso a interface deve utilizar o endereço de multicast 01-80-C2-00-00-01 que é reservado exclusivamente para esse propósito, simplificando a operação, pois não é necessário conhecer o endereço da interface de destino.

O frame de PAUSE possui o opcode (já mencionado) e o tempo da pausa nos 2 bytes seguintes, que é medido em unidades de tempo necessário para se transmitir 512 bits na rede. A faixa de valores possíveis para esta pausa vai de 0 a 65.535 unidades. Com esse mecanismo é possível que uma interface solicite que a outra pare de transmitir por um determinado tempo, fornecendo controle de fluxo no modo full-duplex.

\subsection{O transceiver LXT971A da Intel}

O LXT971A é um transceiver compatível com o padrão IEEE 802.3 para operar com aplicações de 100 Mbps e 10 Mbps (100BASE-TX e 10BASE-T respectivamente) e que possui uma interface Low Voltage Positive Emitter Coupled Logic (LVPECL) para operação com fibra ótica em aplicações 100 Mbps (100BASE-FX). A comunicação com o controlador MAC é feita por intermédio de uma interface denominada Media Independent Interface (MII) descrita no padrão IEEE 802.3u. A Figura 2.5 mostra o diagrama de blocos do LXT971A. Como se pode notar, a construção de um transceiver é complexa e envolve circuitos analógicos, fugindo 
do escopo deste trabalho. O chip é construído com a tecnologia Complementary Metal Oxide Semiconductor (CMOS) e portanto é alimentado com 3.3 volts (Intel, 2002).

Este transceiver pode operar nos modos full-duplex e half-duplex e possui um mecanismo de detecção de velocidade e do modo utilizado. O mecanismo é descrito também no padrão IEEE e denomina-se auto negociação. Além disso, ele utiliza uma função de deteção paralela que lhe permite operar com equipamentos que não suportam auto negociação. É possivel também utilizar transceivers de outros fabricantes como o AM79C874 da AMD (AMD, 2001), o 78Q2120C da TDK (TDK, 2003) e o BCM5221 da Broadcom (Broadcom, 2001). Embora os transceivers Ethernet em geral sejam chips relativamente baratos, sua aquisição não é simples, uma vez que não existem muitas indústrias no Brasil que necessitem de tal material, além da dificuldade de se construir placas com chips de encapsulamentos modernos como o Ball Grid Array (BGA). Isto dificulta a construção de uma placa de Printed Circuit Board (PCB) com tais chips. 
O)

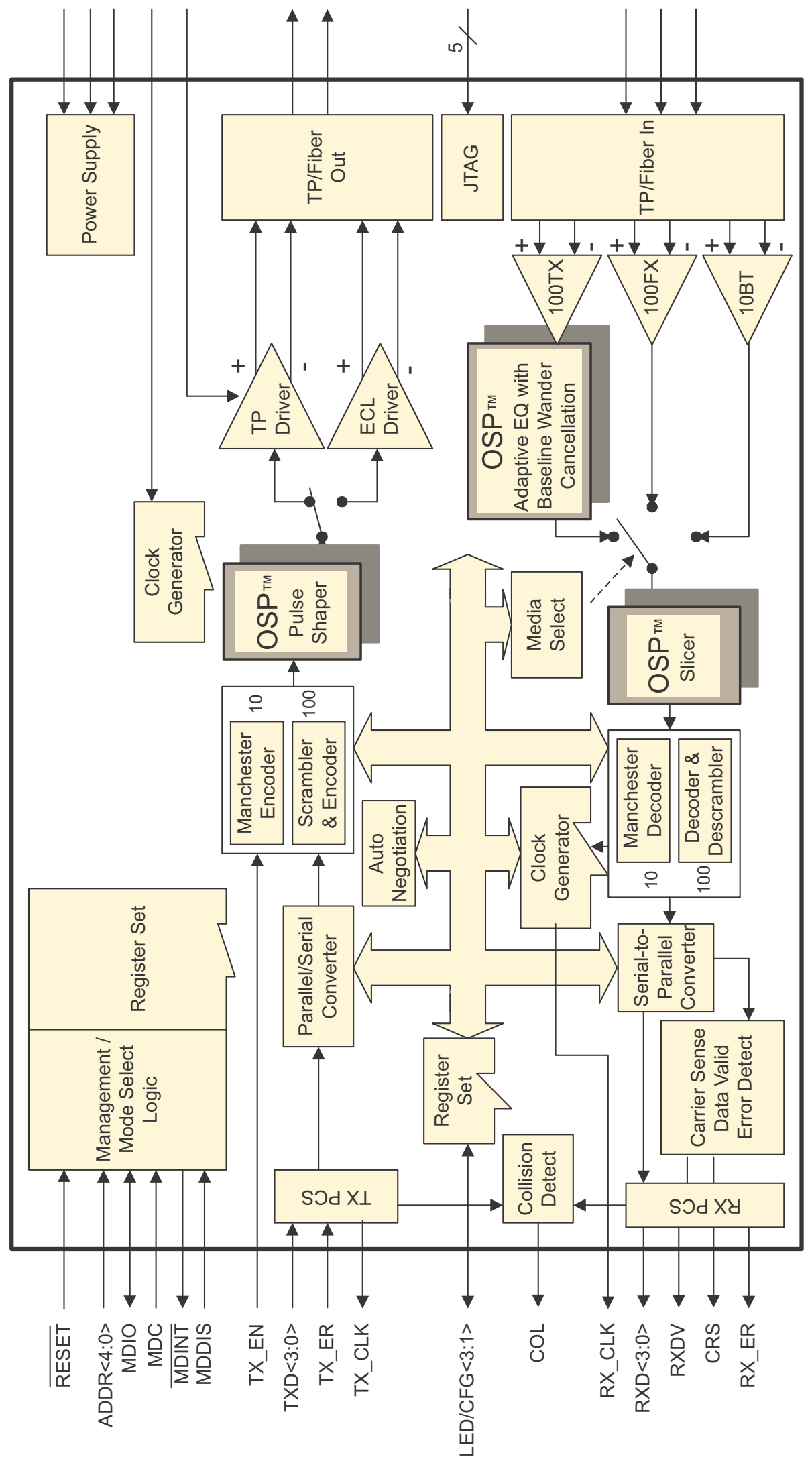

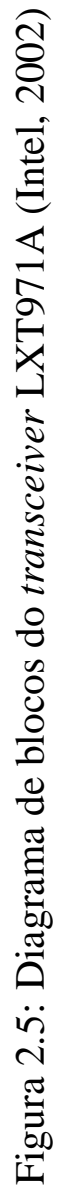




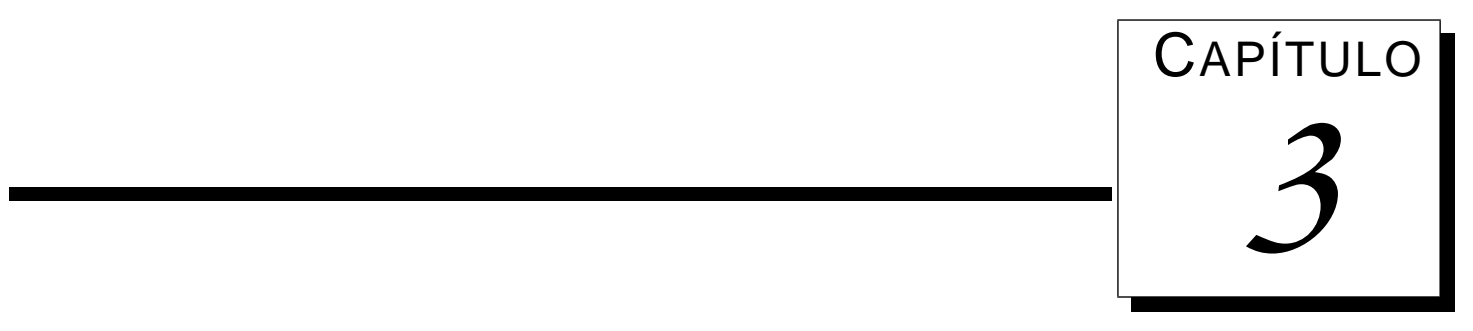

\section{Computação Reconfigurável}

Na computação há basicamente dois métodos para a execução de algoritmos. O primeiro, é baseados em hardware construído especificamente para executar a tarefa (ASIC), e por esse motivo a realiza com eficiência e rapidez. No entanto, o circuito fabricado é pouco flexível, não podendo ser alterado após sua fabricação. O segundo método é baseado em software executado em microprocessadores, constituindo uma solução muito mais flexível, pois é possível alterar as instruções do programa e consequentemente sua funcionalidade sem alterar o hardware do microprocessador. Apesar da flexibilidade, o método baseado em software apresenta uma grande desvantagem de desempenho, pois o processador precisa buscar cada instrução na memória, decodificá-la e depois executá-la (Compton e Hauck, 2002). Este capítulo apresenta uma introdução à computação reconfigurável que une a flexibilidade do software ao desempenho do hardware. Além disso, é descrita a plataforma de desenvolvimento do projeto.

\subsection{Introdução}

O objetivo da computação reconfigurável é preencher o espaço que há entre o software e o hardware, atingindo um desempenho muito maior que a da solução por software, enquanto mantém um nível de flexibilidade maior que a do hardware, como mostra a figura Figura 3.1. 
Os FPGAs têm mostrado acelerar uma variedade de aplicações, como por exemplo as de criptografia de dados (Elbirt et. al., 2001, 2000). Além disso, os dispositivos reconfiguráveis podem aproveitar melhor sua densidade uma vez que utilizam a mesma área do chip para realizar tarefas diferentes (DeHon, 2000).
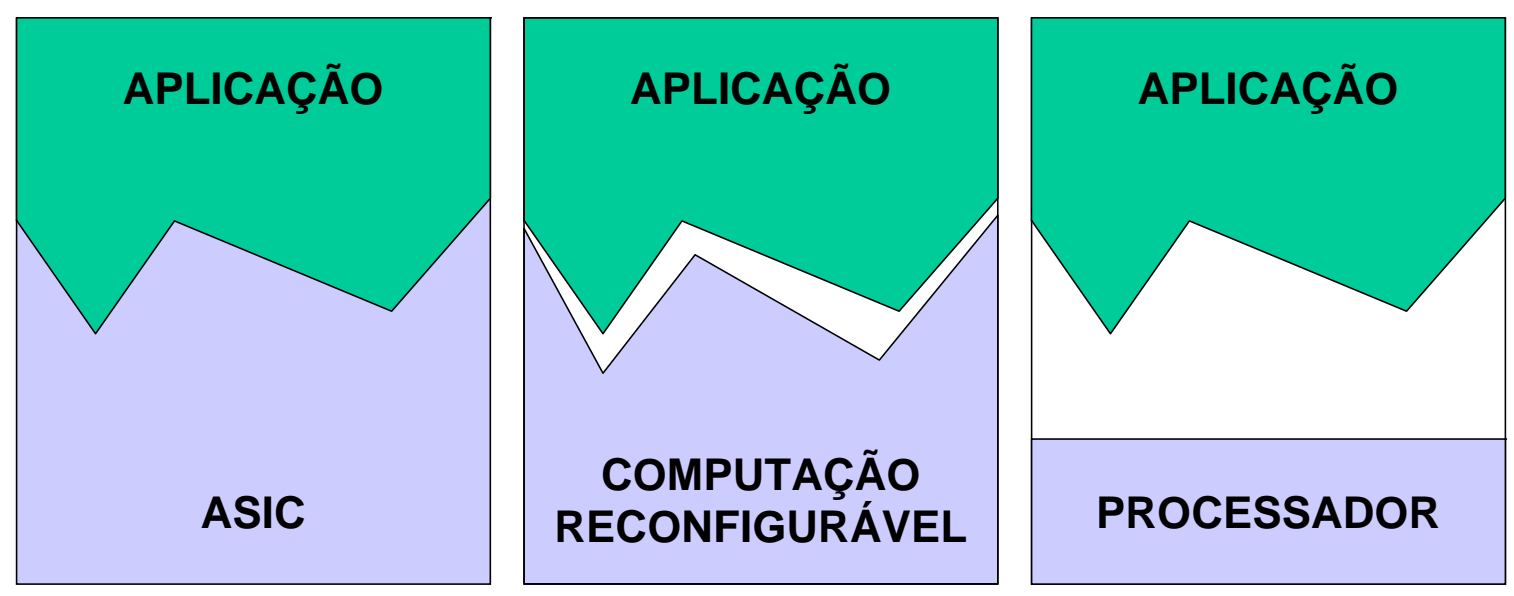

Figura 3.1: Computação reconfigurável comparada às soluções de hardware e sofware

Embora os FPGAs tenham suas vantagens quanto ao custo de engenharia e ao tempo de desenvolvimento comparado aos ASICs, projetos desenvolvidos com tecnologia Very Large Scale Integration (VLSI) como processadores e memórias RAM utilizadas nos PCs apresentam maior velocidade, densidade e complexidade, mas precisam ser produzidos em um volume muito maior devido aos custos de produção. A Figura 3.2 demonstra a relação das FPGAs com os ASICs e projetos VLSI (Hamblen e Furman, 2001).

Dispositivos reconfiguráveis como os FPGAs são formados por um arranjo de células configuráveis, também chamado de bloco lógico, que podem ser utilizados para a implementação de funções lógicas. Um FPGA possui três tipos principais de recursos: blocos lógicos, blocos de entrada e saída, e chaves de interconexão programáveis, mostrados na Figura 3.3. Os blocos lógicos formam um arranjo bidimensional e as chaves de interconexão são organizadas como canais de roteamento horizontais e verticais, entre as linhas e colunas de blocos lógicos. Cada um desses canais possui chaves também programáveis, que permitem conectar os blocos lógicos de maneira conveniente, segundo a necessidade de cada algoritmo (Compton, 1999; Murgai et. al., 1995; Oldfield e Dorf, 1995).

A forma mais utilizada de se construir o bloco lógico é por meio de lookup table (LUT), que 


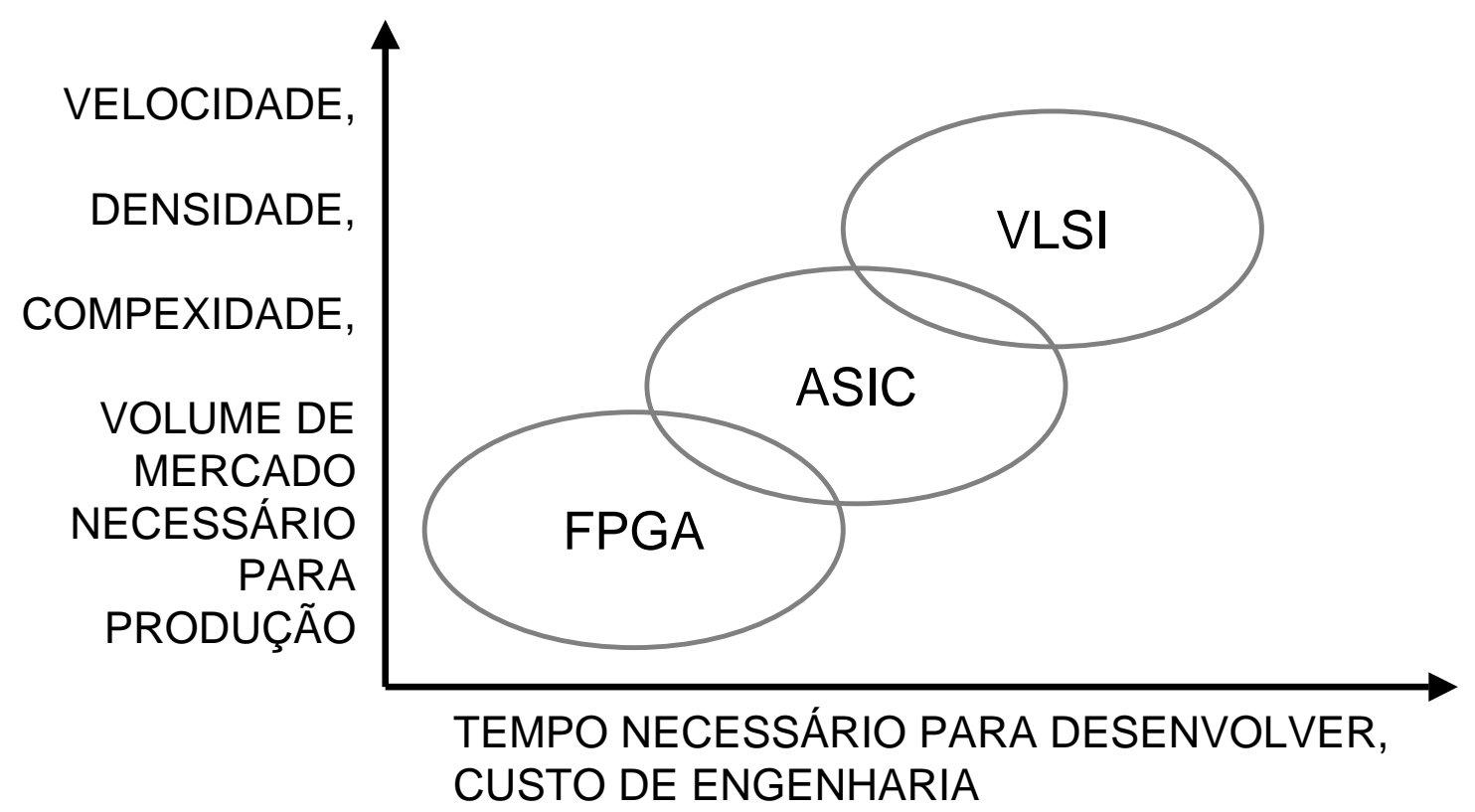

Figura 3.2: Relações de mercado de lógica digital (Hamblen e Furman, 2001)

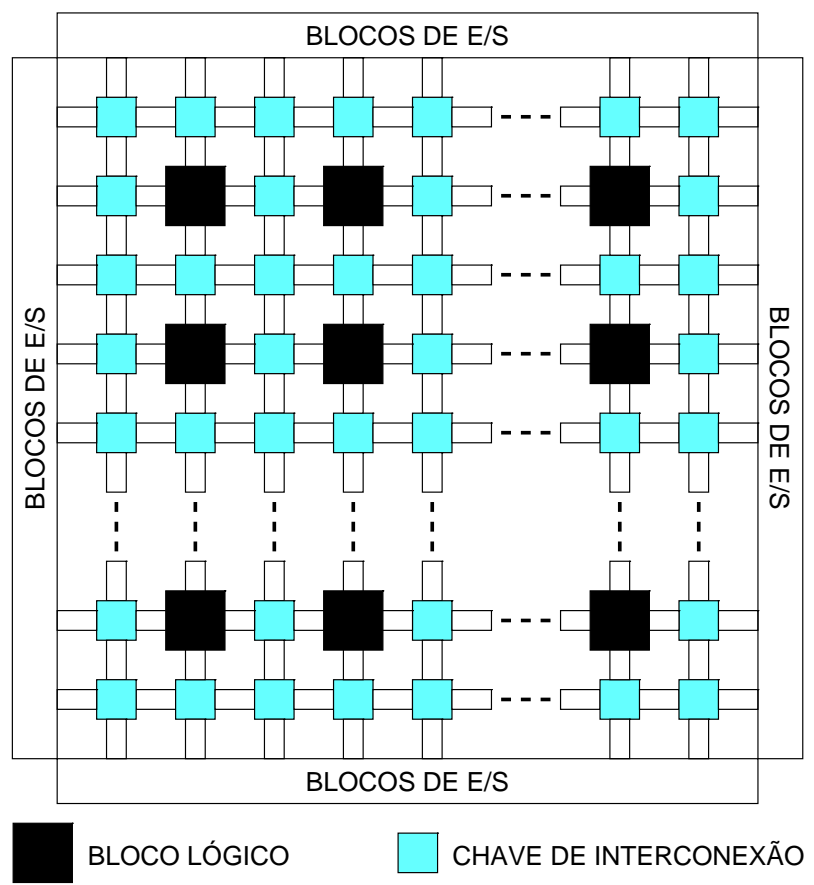

Figura 3.3: Estrutura básica de um FPGA

contém células de armazenamento usadas para implementar uma pequena função lógica. Cada célula é capaz de armazenar um bit que pode ser a saída da função dependendo da entrada, conforme Figura 3.4(a). É possível criar LUTs de vários tamanhos, sendo que o tamanho é 
definido pela quantidade de entradas. Como a tabela verdade de uma função de duas variáveis tem quatro linhas, é possível implementar qualquer função de duas variáveis com uma LUT de quatro células. As variáveis de entrada da LUT são utilizadas como entradas de seleção de multiplexadores, determinando qual célula deve fornece a saída do circuito. A Figura 3.4(c) mostra a utilização de uma LUT para implementar a função da Figura 3.4(b).

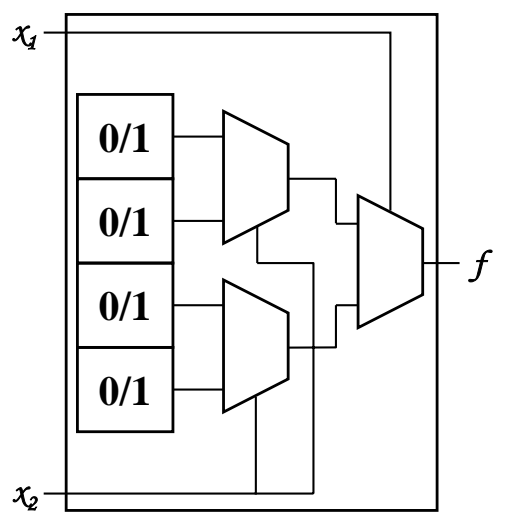

(a) Circuito de uma LUT

\begin{tabular}{cc|c}
$x_{1}$ & $x_{2}$ & $f_{1}$ \\
\hline 0 & 0 & 1 \\
0 & 1 & 0 \\
1 & 0 & 0 \\
1 & 1 & 1
\end{tabular}

(b) $f_{1}=\bar{x}_{1} \bar{x}_{2}+x_{1} x_{2}$

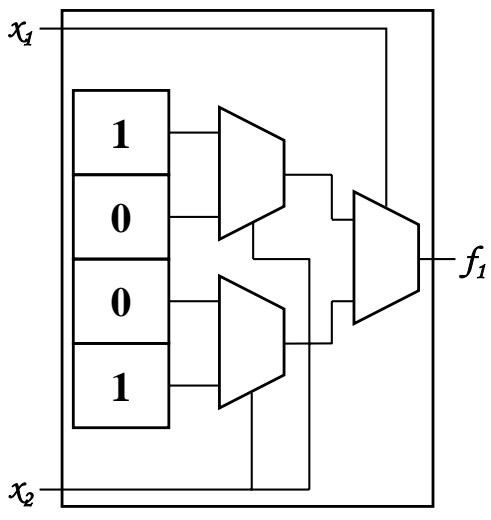

(c) Conteúdo das células

Figura 3.4: Utilização de LUTs para implementação de funções lógicas

A Figura 3.5 mostra uma LUT de três entradas, que possui oito células de armazenamento de acordo com a tabela verdade de uma função de três entradas. As FPGAs comerciais normalmente possuem LUTs de quatro ou cinco entradas e normalmente incluem elementos extra como flip-flops em seus blocos lógicos (Bout e E., 1999). Existem diversas tecnologias de programação para FPGAs, sendo que as mais comuns são baseadas em LUTs voláteis, carregadas por intermédio de programmable read-only memorys (PROMs) quando o circuito é ligado.

Os FPGAs foram introduzidos pela empresa Xilinx Inc. no ano de 1985 (Chan e Mourad, 1994), consistem em dispositivos lógicos programáveis que suportam a implementação de circuitos lógicos relativamente grandes (Brown e Vranesic, 2000, 2003; Xilinx, 2005), como a família Stratix II (Altera, 2004a) da Altera com até 180K elementos lógicos (LEs), permitindo a construção de sistemas extremamente complexos em um único chip, os chamados System On a Programmable Chip (SoPC). 


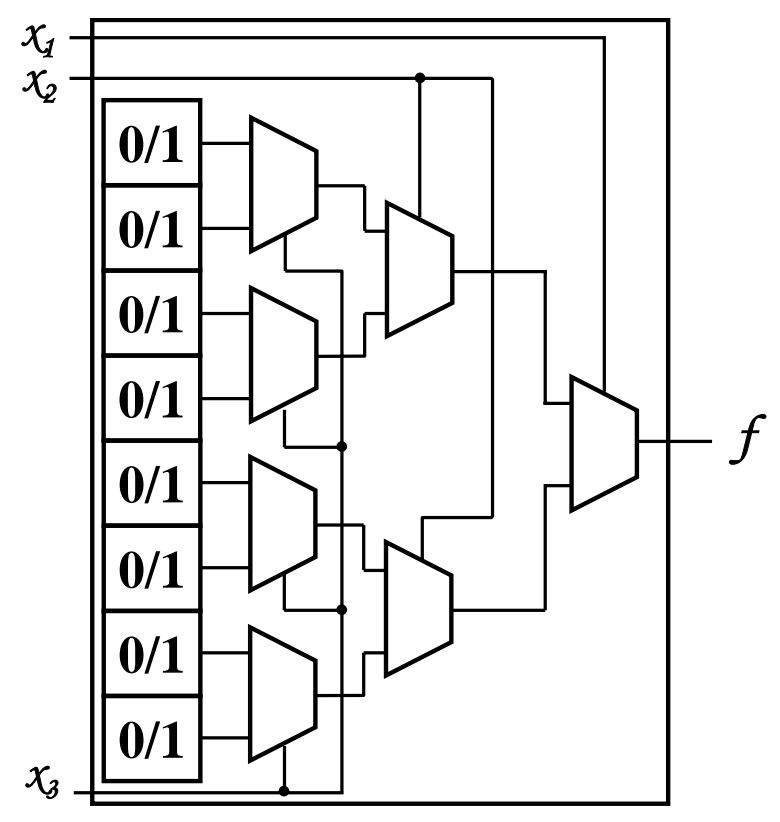

Figura 3.5: Circuito de uma LUT de três entradas

\subsection{A família de FPGAs Stratix}

Os dispositivos da família Stratix implementam a lógica customizada por meio de uma arquitetura bidimensional. Uma série de interconexões em linhas e colunas com velocidades e tamanhos variáveis interligam os Logic Array Blocks (LABs), blocos de Digital Signal Processing (DSP) e blocos de memória. Os LABs são vetores formados por 10 elementos lógicos (LEs) e estão dispostos em linhas e colunas no dispositivo. Os LEs são pequenas estruturas capazes de implementar, com eficiência, funcões lógicas de usuário.

As FPGAs dessa família possuem blocos de memória internos com três tamanhos diferentes, segundo a tecnologia TriMatrix da Altera (Figura 3.6). Os blocos M512 RAM são memórias simple dual-port de 512 bits mais paridade (576 bits) que podem ser acessadas no modo single-port ou simple dual-port de até 18 bits, a até $318 \mathrm{MHz}$. Elas são agrupadas em colunas entre certos LABs e podem ser utilizadas em pequenas funções como aplicações first-in first-out (FIFO). Os blocos M4K RAM são memórias true dual-port de 4K bits, mais paridade (4.608 bits), que podem ser acessadas nos modos single-port, simple dual-port ou true dual-port de até 36 bits, a até $291 \mathrm{MHz}$, e também se localizam agrupadas em colunas entre certos LABs. Os blocos M-RAM são memórias true dual-port de 512K mais paridade (589.824 bits) que podem ser acessados nos modos single-port, simple dual-port ou true dual-port de até 144 bits, a até 
$269 \mathrm{MHz}$, e encontram-se no FPGA aos pares ou individualmente.

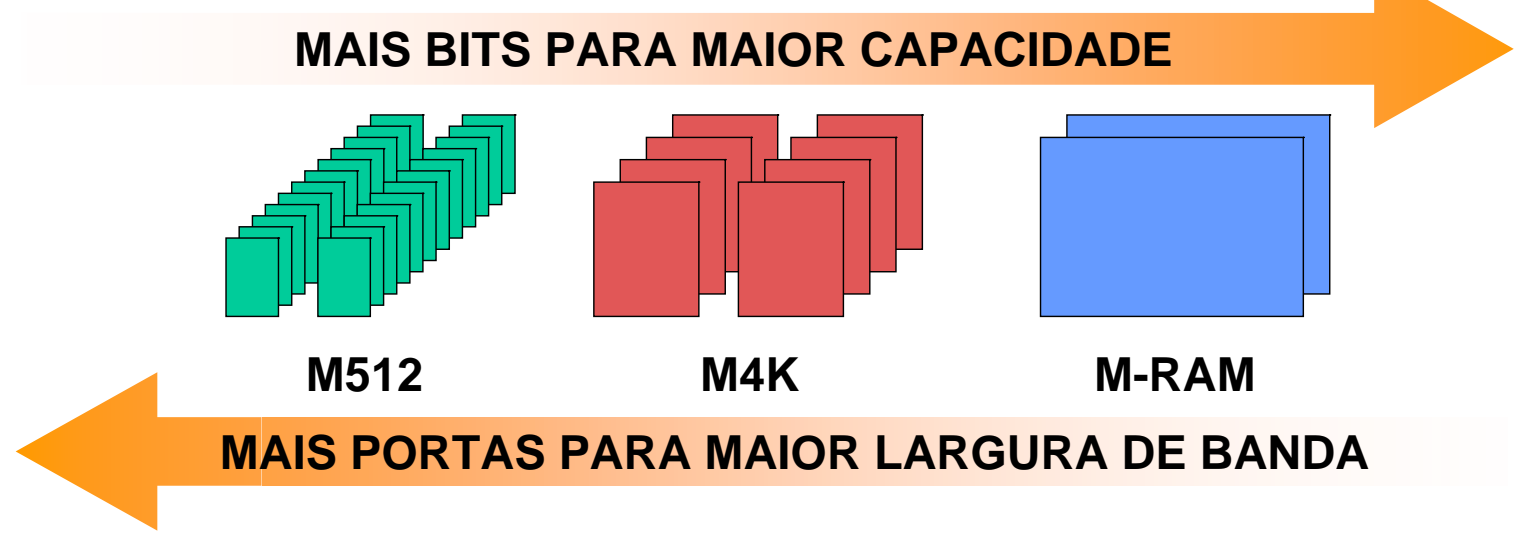

Figura 3.6: Tecnologia TriMatrix da Altera

Cada bloco de DSP pode implementar até oito multiplicadores completos de 9x9 bits ou quatro de $18 \times 18$ bits ou ainda um de 36x36 bits com recursos de soma e subtração. A estrutura geral dos blocos de DSP é mostrada na Figura 3.7. Esses blocos possuem ainda registradores de deslocamento de 18 bits para aplicações como filtros Finite Impulse Response (FIR) e Infinite Impulse Response (IIR). Esses blocos estão agrupados em duas colunas no FPGA. A quantidade de blocos DSP, M512 RAM, M4K RAM e M-RAM variam juntamente com o número de colunas e linhas de acordo com cada dispositivo desta família, conforme a Tabela 3.1.

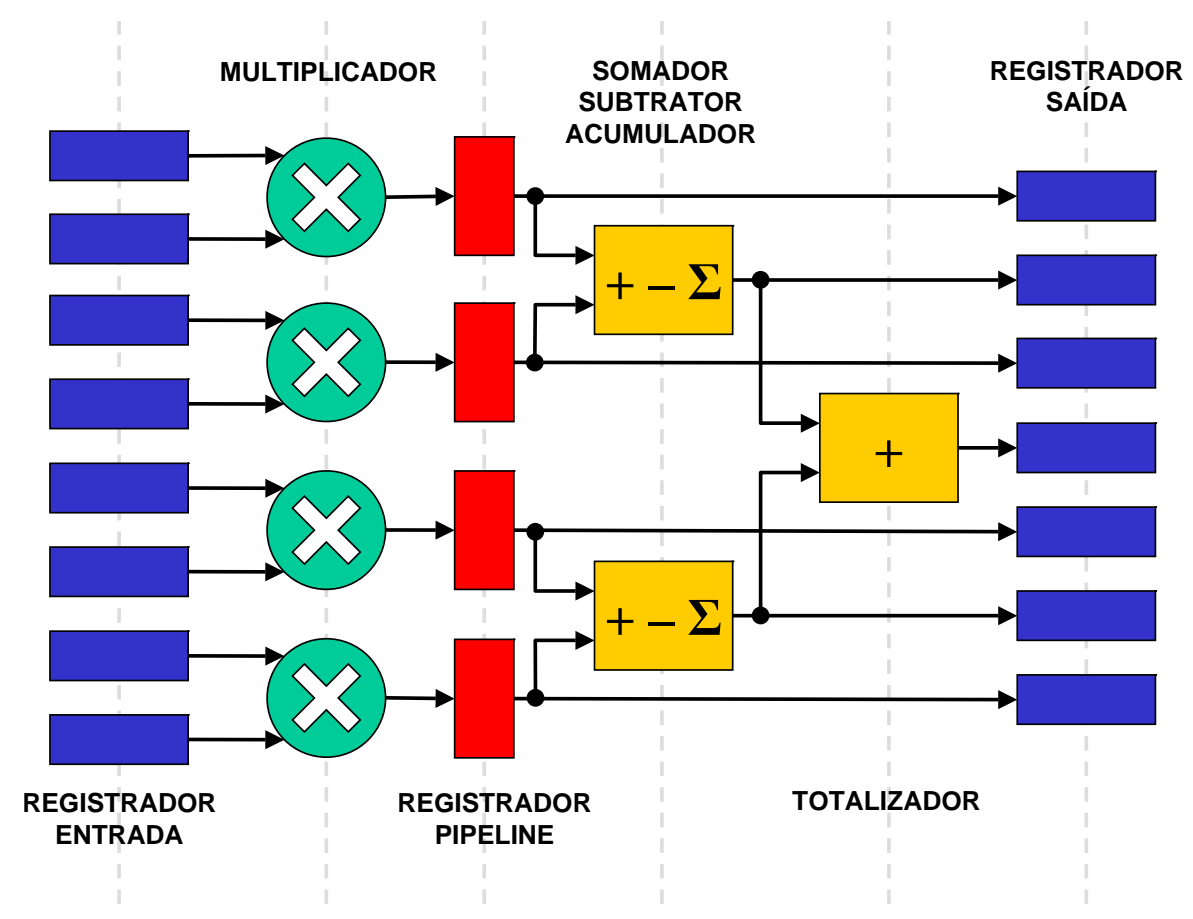

Figura 3.7: Estrutura geral dos blocos de DSP (Altera, 2003d) 
Tabela 3.1: Quantidade de recursos dos dispositivos da família Stratix (Altera, 2003d)

\begin{tabular}{|c|c|c|c|c|c|c|}
\hline Dispositivos & $\begin{array}{c}\text { M512 RAM } \\
\text { Coluna/Bloco }\end{array}$ & $\begin{array}{c}\text { M4K } \\
\text { Coluna/Bloco }\end{array}$ & $\begin{array}{c}\text { M-RAM } \\
\text { Bloco }\end{array}$ & $\begin{array}{c}\text { Bloco DSP } \\
\text { Coluna/Bloco }\end{array}$ & $\begin{array}{c}\text { LAB } \\
\text { Coluna }\end{array}$ & $\begin{array}{c}\text { LAB } \\
\text { Linha }\end{array}$ \\
\hline \hline EP1S10 & $4 / 94$ & $2 / 60$ & 1 & $2 / 6$ & 40 & 30 \\
\hline EP1S20 & $6 / 194$ & $2 / 82$ & 2 & $2 / 10$ & 52 & 41 \\
\hline EP1S25 & $6 / 224$ & $3 / 138$ & 2 & $2 / 10$ & 62 & 46 \\
\hline EP1S30 & $7 / 295$ & $3 / 171$ & 4 & $2 / 12$ & 67 & 57 \\
\hline EP1S40 & $8 / 384$ & $3 / 183$ & 4 & $2 / 14$ & 77 & 61 \\
\hline EP1S60 & $10 / 574$ & $4 / 292$ & 6 & $2 / 18$ & 90 & 73 \\
\hline EP1S80 & $11 / 767$ & $4 / 364$ & 9 & $2 / 22$ & 101 & 91 \\
\hline
\end{tabular}

Elementos de entrada e saída (IOEs), localizados nas extremidades das linhas e colunas de LABs, alimentam cada pino de E/S do dispositivo. Cada elemento possui um buffer bidirecional de E/S e seis registradores para registrar sinais de entrada, saída e saída-habilitada. Os pinos da FPGA suportam diversos padrões de E/S e quando utilizados com clock dedicado podem operar com memórias externas em padrões como o DDR SDRAM e QDR SRAM. A Figura 3.8 mostra o diagrama de blocos dos dispositivos da família Stratix.

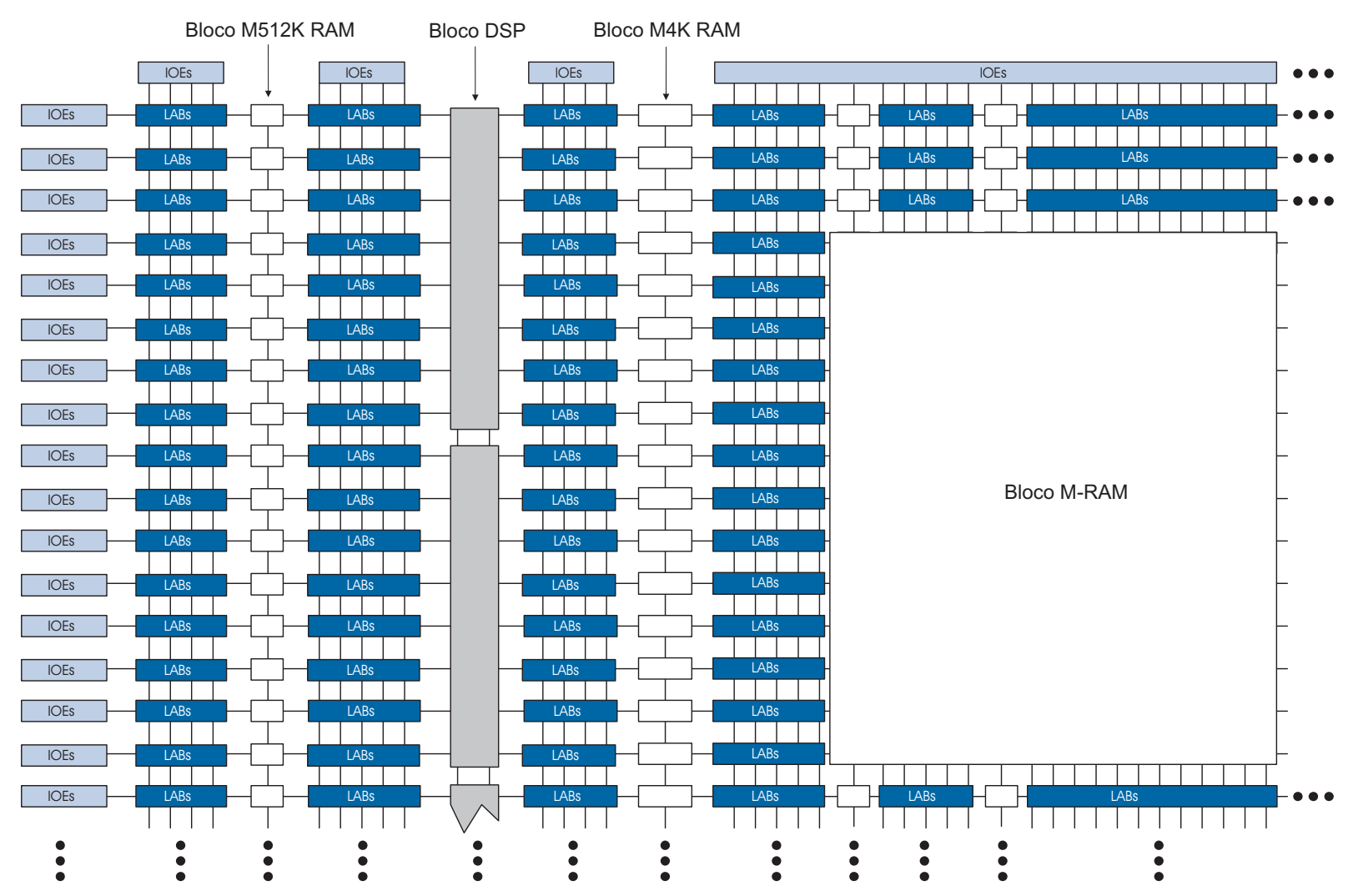

Figura 3.8: Diagrama de blocos dos FPGAs da família Stratix

Cada LAB consiste em 10 elementos lógicos (LEs), cadeias de carry dos LEs, sinais de con- 
trole do LAB, interconexões locais, cadeia de LUT e linhas de conexão da cadeia de registrador. As interconexões locais transferem sinais entre LEs do mesmo LAB. As conexões das cadeias de LUT transferem a saída dos LUTs de um LE para o adjacente dentro do mesmo LAB. A saída do registrador de um LE é transferida pra o LE adjacente por meio da cadeia de conexões de registradores.

As interconexões locais formam uma arquitetura de três lados, pois podem ser dirigidas às colunas, às linhas e às saídas dos LEs de um mesmo LAB. Essa arquitetura minimiza o uso das interconexões em linha e coluna, permitindo que cada LE seja ligado a outros 30 LEs. A Figura 3.9 mostra a estrutura dos LABs.

\subsection{Ferramentas}

Para o desenvolvimento do projeto, foi utilizado o kit Nios da Altera edição Stratix (Altera, 2003b), mostrado na Figura 3.11(a). O kit contém todas as ferramentas Electronic Design Automation (EDA) necessárias para se criar sistemas de alto desempenho em dispositivos lógicos programáveis.

O Nios é um core de processador Reduced Instruction Set Computer (RISC) embutido, desenvolvido pela Altera para a utilização em FPGAs. Esse processador possui um pipeline de cinco estágios e pode ser utilizado nas versões 16 bits e 32 bits. Baseado na arquitetura Harvard-Modified, sua CPU possui barramentos separados para dados e instruções com uma interface mestre para cada um deles. O processador permite que sejam desenvolvidas instruções customizadas, acelerando algoritmos de tempo crítico com hardware, conforme mostra a Figura 3.10. As lógicas utilizadas para esse fim podem, inclusive, acessar memórias e outros componentes externos ao processador (Altera, 2002a,d). Durante o desenvolvimento do projeto foi lançado o processador Nios II, o qual foi adotado como nova plataforma de desenvolvimento. O processador Nios II apresenta um melhor desempenho, menor utilização de recursos da FPGA e uma integração mais fácil com sistemas operacionais de tempo real (Altera, 2004b). Com a mudança, o projeto não sofreu nenhuma modificação na parte de hardware, já que os processadores utilizam o mesmo barramento. No entanto, toda a parte de software foi modificada, pois até o ambiente de desenvolvimento foi modificado para o novo processador. Todos 


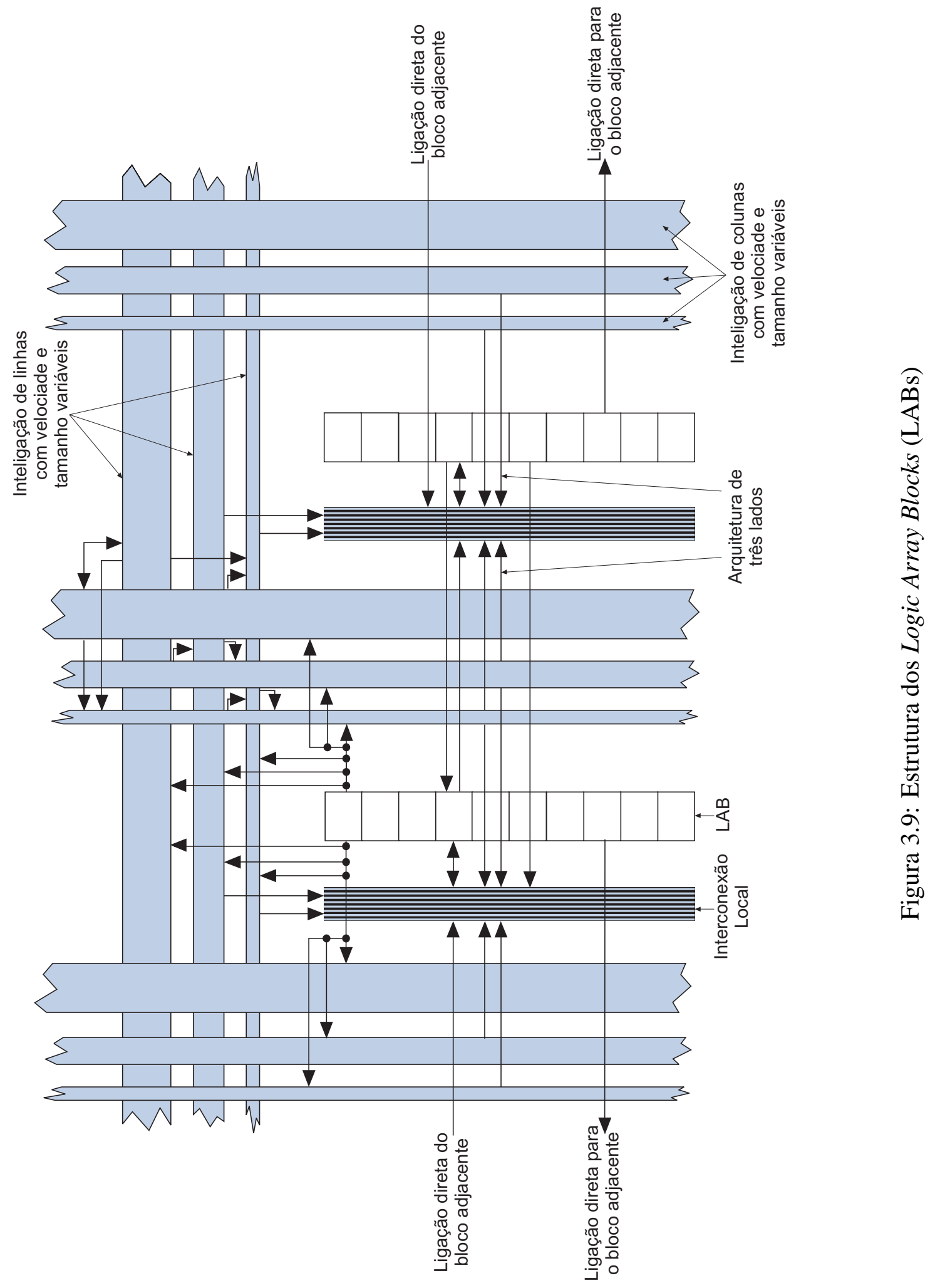

os tutoriais da ferramenta tiveram que ser refeitos para a atualização da tecnologia utilizada.

A placa de desenvolvimento contida no kit é mostrada na Figura 3.11(b). O kit provê uma plataforma de hardware para desenvolvimento de sistemas embarcados baseados em FPGAs da família Stratix da Altera. Os principais componentes da placa são: 


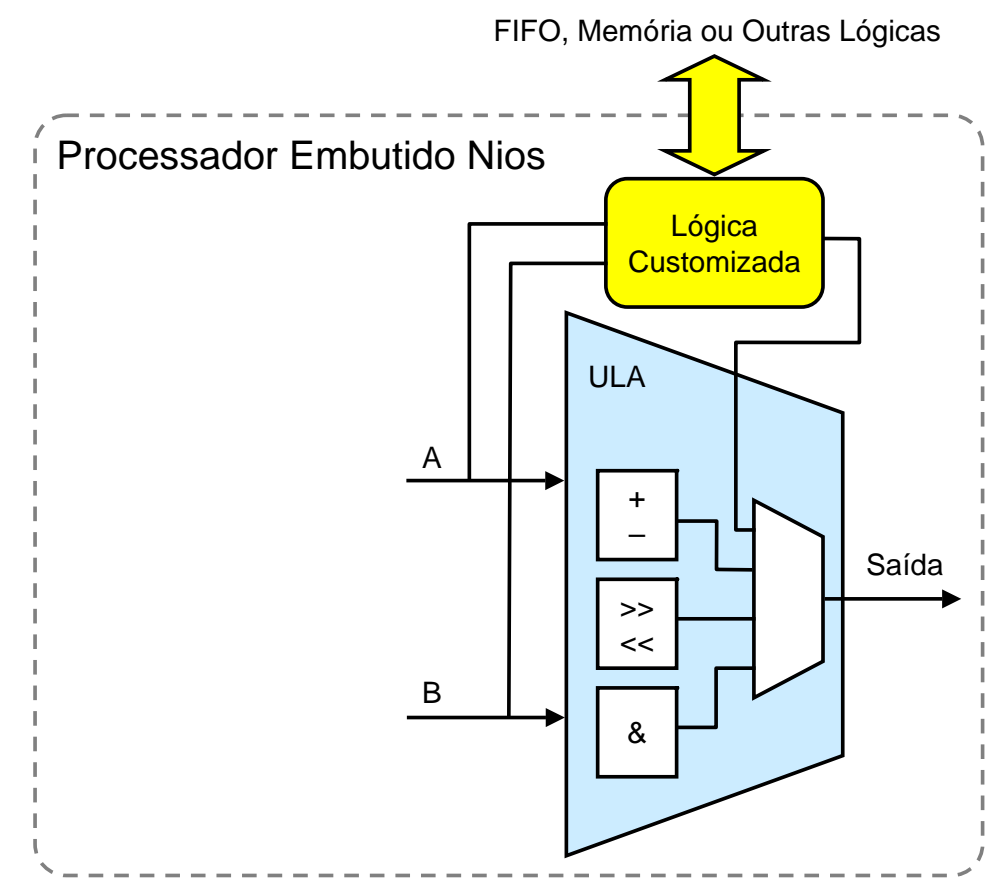

Figura 3.10: Utilização de lógica customizada para definir novas instruções no Nios (Altera, 2002d)

- FPGA Stratix EP1S10F780C6 com 10.570 elementos lógicos e 920 Kbits de memória on-chip;

- 8 Mbytes de memória flash;

- 1 Mbyte de memória RAM estática;

- 16 Mbytes de memória SDRAM;

- Controlador de configuração EPM7128AE, capaz de configurar a FPGA a partir de informações armazenadas na memória flash;

- 2 portas seriais RS-232 com conectores DB9;

- 4 botões ligados aos pinos de E/S da FPGA;

- 8 LEDs ligados aos pinos de E/S da FPGA;

- 2 displays de LED 7 segmentos;

- Oscilador de $50 \mathrm{MHz}$ e conector para utilização de clock externo; 
- Interface Ethernet 10/100 Mbps MAC/PHY LAN91C111 com conector RJ-45;

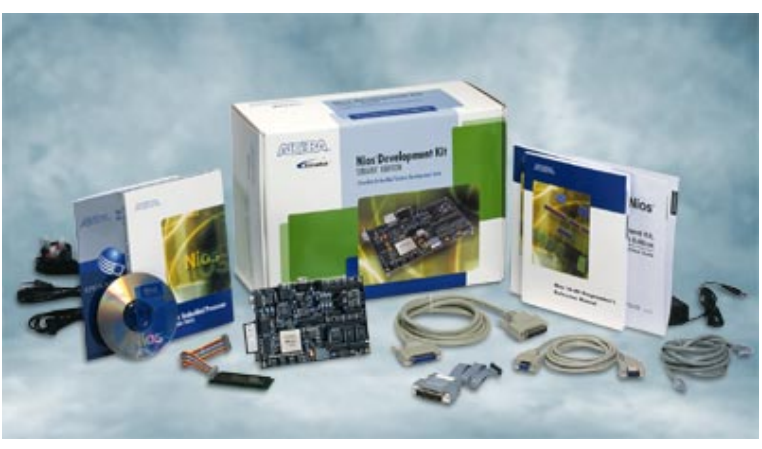

(a)

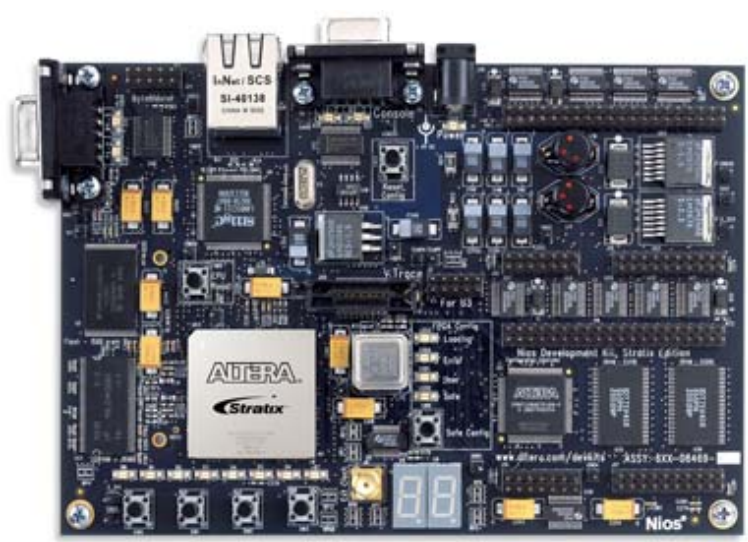

(b)

Figura 3.11: Kit de desenvolvimento e placa em destaque

O projeto foi desenvolvido na linguagem de descrição de hardware Verilog, pois a utilização de Hardware Description Languages (HDLs) trás inúmeros benefícios em relação aos projetos esquemáticos. As HDLs permitem que se faça uma descrição compacta e que se pode editar. As descrições são portadas de uma ferramenta para outra, sem a necessidade de softwares adicionais. Por exemplo, os códigos sintetizados no Quartus II podem ser simulados no ModelSim, sem nenhuma modificação. O trabalho de remover, realocar ou recolocar objetos em um projeto esquemático pode consumir muito tempo se o projeto for muito denso ou complexo (Ciletti, 1999; Coffman, 2000).

Foram utilizadas as seguintes ferramentas durante o desenvolvimento do projeto:

- Altera Quartus II

- Mentor Graphics ModelSim

- Altera SoPC Builder

O Quartus II foi a principal ferramenta utilizada no desenvolvimento deste projeto. Ela oferece suporte para desenvolvimento baseado em HDLs (Verilog e VHDL) ou baseado em esquemáticos gráficos, além de possuir ferramentas integradas para projeto em nível de sistema, 
integrando hardware e software. O ambiente da ferramenta integra projeto, síntese, roteamento e verificação, incluindo interfaces para ferramentas EDA de outros fabricantes.

Para a simulação do projeto foi utilizada a ferramenta ModelSim, da Mentor Graphics, que apresenta integração com as ferramentas da Altera. Por exemplo, é possível configurar um projeto do Quartus II para ser simulado no ModelSim, como uma ferramenta auxiliar. O SoPC Builder é capaz de gerar projetos do ModelSim facilitando a integração das ferramentas.

O SoPC Builder é uma ferramenta da Altera integrada ao Quartus para automatizar a criação de sistemas compostos por diversos cores como processadores, co-processadores, periféricos, memórias e lógicas de usuários baseados em barramentos. A ferramenta suporta atualmente os barramentos Avalon e AMBA Advanced High-Performance Bus (AHB), gerando automáticamente a lógica de interconexão ao barramento especificado. Sua biblioteca de componentes inclui itens como:

- Processadores;

- Microcontroladores Periféricos;

- Digital Signal Processing (DSP) cores;

- Intellectual Property (IP) cores;

- Periféricos de Comunicação;

- Interfaces:

- Memórias (on-chip ou off-chip);

- Barramentos e Pontes;

- Application-Specific Standard Products (ASSPs);

- Application-Specific Integrated Circuits (ASICs);

- Componentes de Software:

- Arquivos header;

- Drivers Genéricos em Linguagem C; 
- Kernels de Sistemas Operacionais;

- Bibliotecas de Middleware.

É possível adicionar novos módulos à biblioteca, denominados lógica de usuário (LU), que podem ser desenvolvidos em Verilog/VHDL ou adquiridos de terceiros na forma de netlist. Existem basicamente três maneiras de se adicionar um componente a um sistema gerado pelo SoPC Builder. A primeira delas, mostrada na Figura 3.12(a), exporta as portas do barramento para fora do sistema, ficando a cargo do projetista a correta conexão das mesmas. A segunda forma, mostrada na Figura 3.12(b), coloca um módulo vazio dentro do sistema, gerando sua lógica de interconexão apenas. Por último, a maneira mostrada na Figura 3.12(c) incorpora o módulo ao sistema, gerando suas interconexões e arquivos de simulação para o módulo.

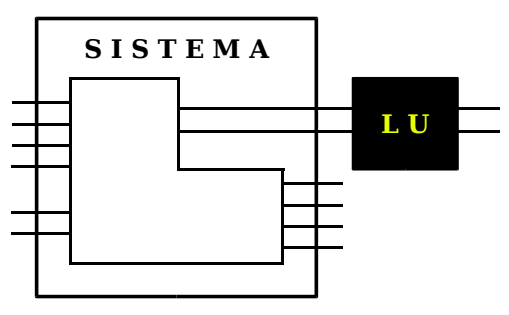

(a)

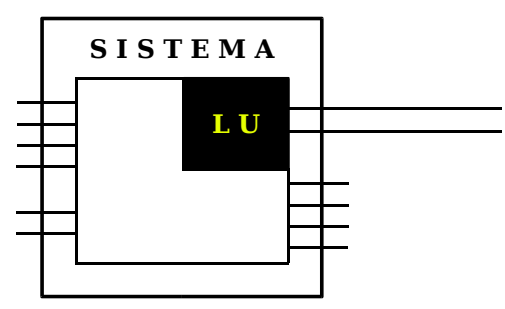

(b)

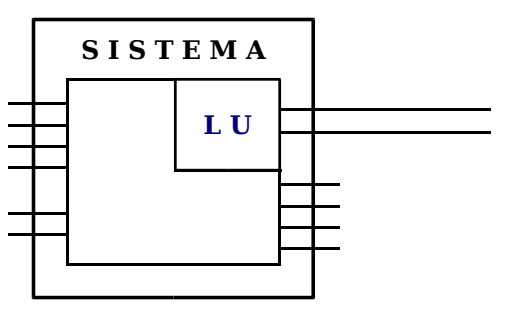

(c)

Figura 3.12: Adicionando componentes ao SoPC Builder

Para armazenar as informações de um sistema, o SoPC Builder utiliza um arquivo com a extensão PTF, que consiste na única fonte de informações sobre cada projeto criado. Usuários que desejam apenas criar projetos com esta ferramenta, utilizando os blocos disponíveis em suas bibliotecas não necessitam sequer tomar conhecimento da existencia desses arquivos. Internamente, a ferramenta é formada por duas partes: uma interface gráfica com o usuário e um gerador de sistemas, que pode inclusive ser invocado por meio de linha de comandos, sem a utilização da interface gráfica. A Figura 3.13 mostra a estrutura de funcionamento da ferramenta.

Existem dois tipos de arquivos PTF: os arquivos de sistema e os arquivos de classe. Os arquivos de sistema são criados individualmente para cada projeto do SoPC Builder e são a ligação entre as duas partes de ferramenta. A interface gráfica é como um editor deste arquivo 


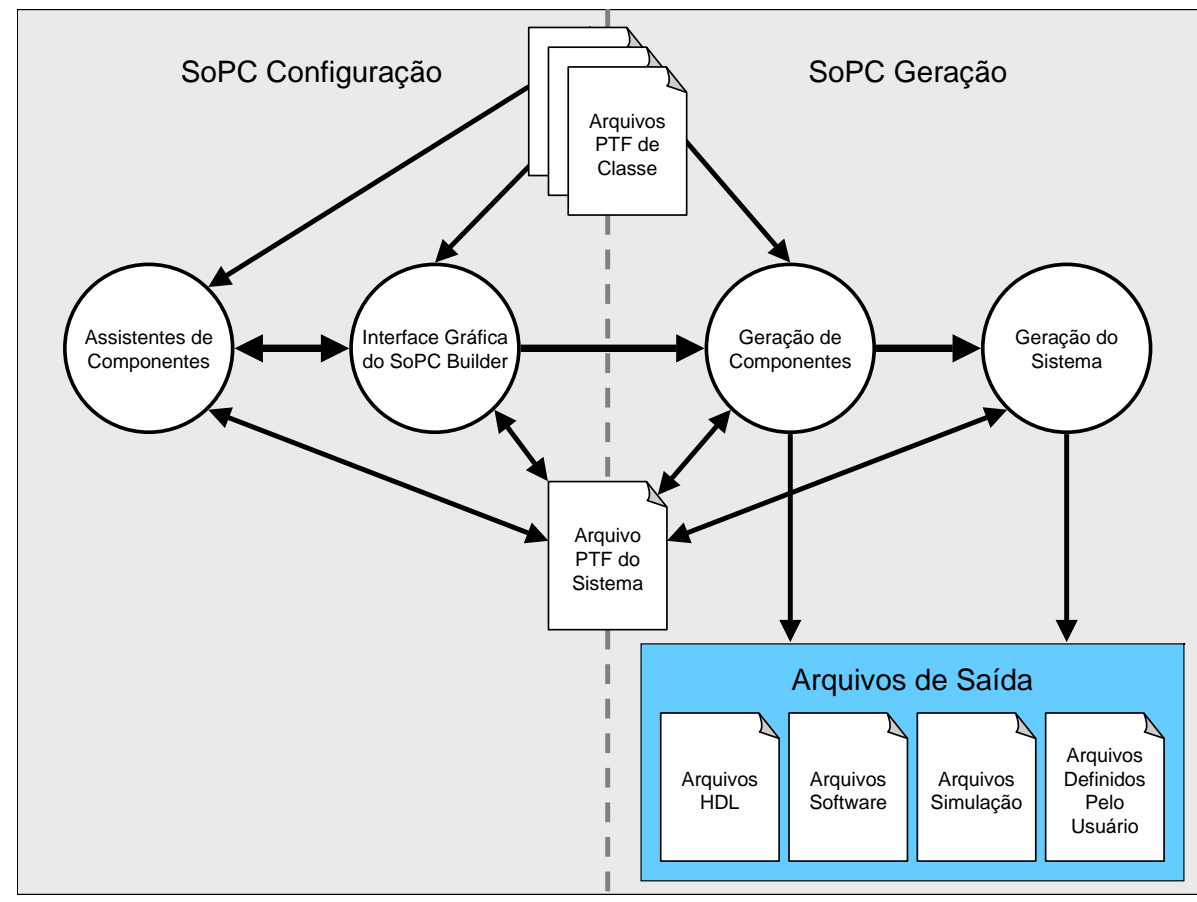

Figura 3.13: Funcionamento da ferramenta SoPC Builder (Altera, 2002e)

e o gerador de sistemas como um compilador. O segundo tipo de arquivo é o class.ptf, que descreve os componentes da biblioteca. Cada componente exibido na interface gráfica possui um arquivo desse tipo. Portanto, para adicionar um novo componente à biblioteca é necessário criar um arquivo de classe.

Um arquivo de sistema armazena todas as informações de um projeto, como por exemplo:

- A lista de todos os módulos do sistema (IP cores);

- Informações de cada módulo, incluindo:

- Conjunto de sinais de interface com o barramento;

- Ligações realizadas pelo usuário;

- Lista dos arquivos HDL necessários para a síntese/simulação do módulo;

- Outra informação específica para o sistema em questão;

\subsection{FPGA \& Ethernet}

Diversas soluções Ethernet têm sido propostas para utilização com sistemas embarcados. Esta seção apresenta algumas soluções neste sentido. 


\subsubsection{Kit Nios Ethernet}

A versão anterior do kit Nios, da Altera, era denominada Excalibur Apex Edition e não possuia interface Ethernet. O kit Nios Ethernet (Altera, 2003c) incorpora à placa de desenvolvimento da linha Excalibur um módulo Ethernet em hardware dedicado, como mosta a Figura 3.14. Este módulo possui um chip LAN91C111 (SMsC, 2003), que opera com o Ethernet. As características implementadas neste projeto são praticamente as mesmas desse ASIC. O fato da Altera ter incorporado o chip LAN91C111 às novas versões de seus kits comprova a importância da comunicação em sistemas embarcados, que antes era obtida apenas com esta placa auxiliar (daughter card).

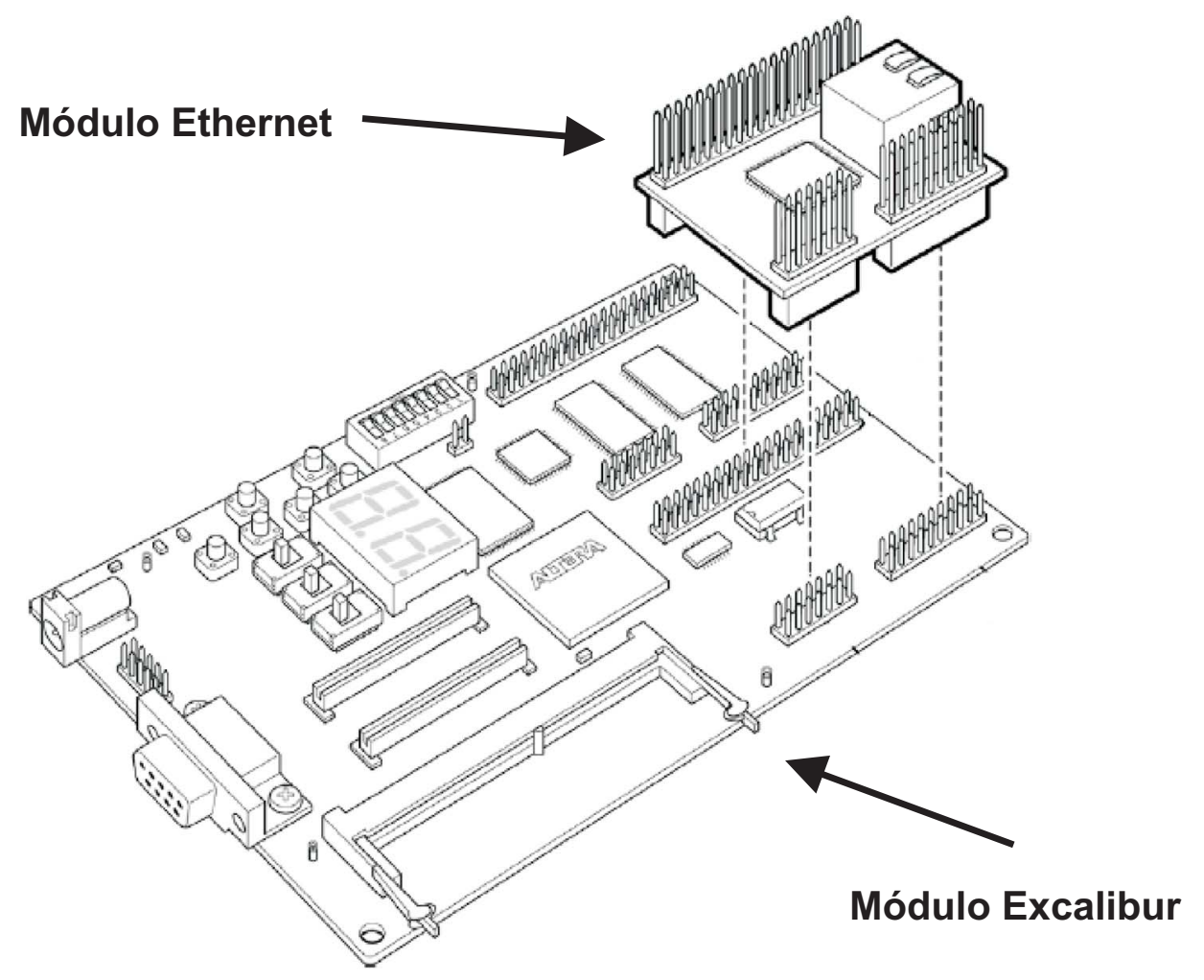

Figura 3.14: Excalibur Apex Edition e Nios Ethernet

\subsubsection{Altera MegaCore}

Atualmente alguns fabricantes dispõem de IP cores similares ao que se pretende desenvolver. O MegaCore da Altera mostrado na Figura 3.15 custa U\$12.995,00 e opera com o barramento AMBA. Esse core é fornecido em forma de netlist, um tipo de código binário. Apenas as partes do MAC assinaladas na Figura 3.15 foram implementadas neste projeto e, com o 
barramento Avalon. A implementação do barramento AMBA AHB foi tema de estudo de uma outra dissertação de mestrado (Queiroz, 2005), no LCR, e pode ser acoplada a este projeto.

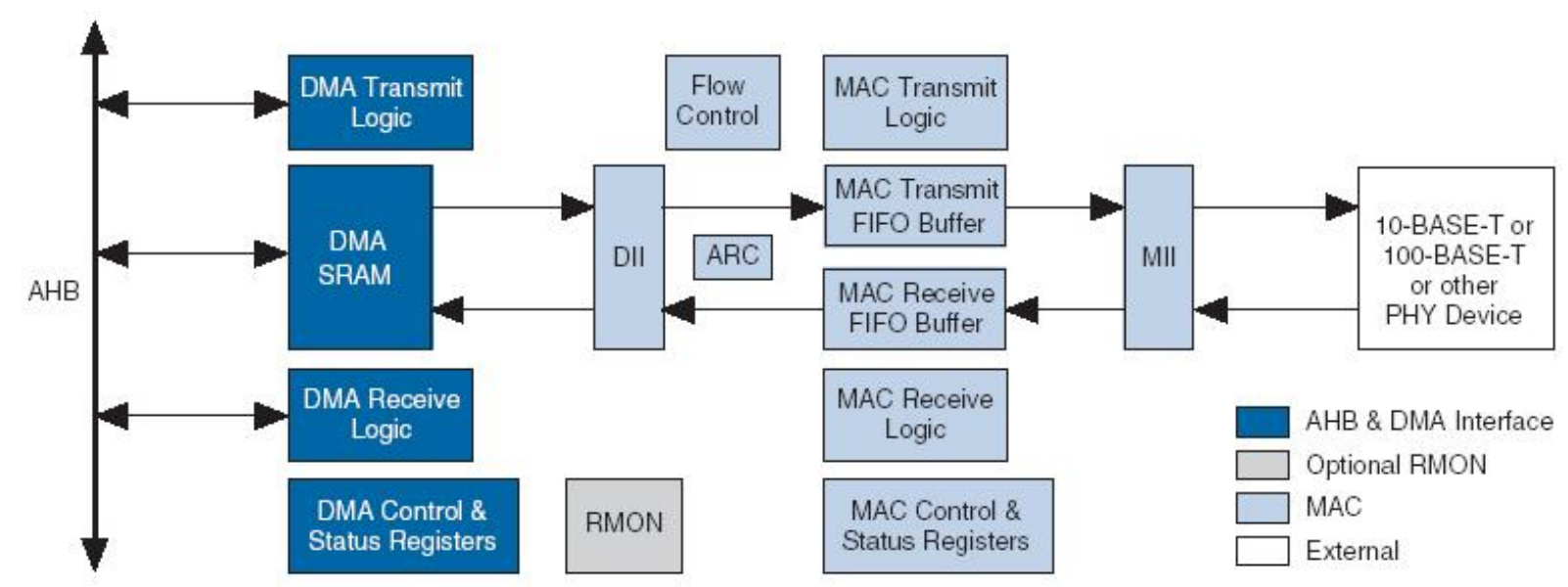

Figura 3.15: Altera 10/100 Ethernet MAC MegaCore (Altera, 2002c)

O MegaCore possui recursos para operar nos modos half-duplex e full-duplex tanto a 10 Mbps como a 100 Mbps e está disponível para a maioria das famílias de FPGA da Altera. O core é dependente da arquitetura da FPGA, pois não é fornecido em código-fonte sintetizável e não pode ser modificado. Em função dessas desvantagens, a Altera está descontinuando esse core e optou por colocar um ASIC em seus novos kits de desenvolvimento.

\subsubsection{Wipro Ethernet MAC Layer Synthesizable Core}

A empresa Wipro Ltd. comercializa o core Ehternet mostrado na Figura 3.16. Esse core possui os recursos mais comuns do padrão Ethernet e uma interface serial para uma PROM que pode ser utilizada para armazenar o endereço físico e dados de configuração. Porém, não oferece implementação de nenhum barramento on-chip. Não foi possível descobrir seu valor de comercialização, pois a empresa não respondeu nenhuma solicitação realizada.

\subsubsection{OpenCores EthMac}

O core EthMac está disponível na Internet no site do grupo OpenCores, que disponibiliza hardware para ser usado de forma livre, assim como os softwares sob licensa GPL. O core possui 10630 linhas de código Verilog e implementa comunicação por meio de um barramento on-chip denominado Wishbone, cujo módulo possui mais de 2500 linhas de código (Mohor, 2002). 


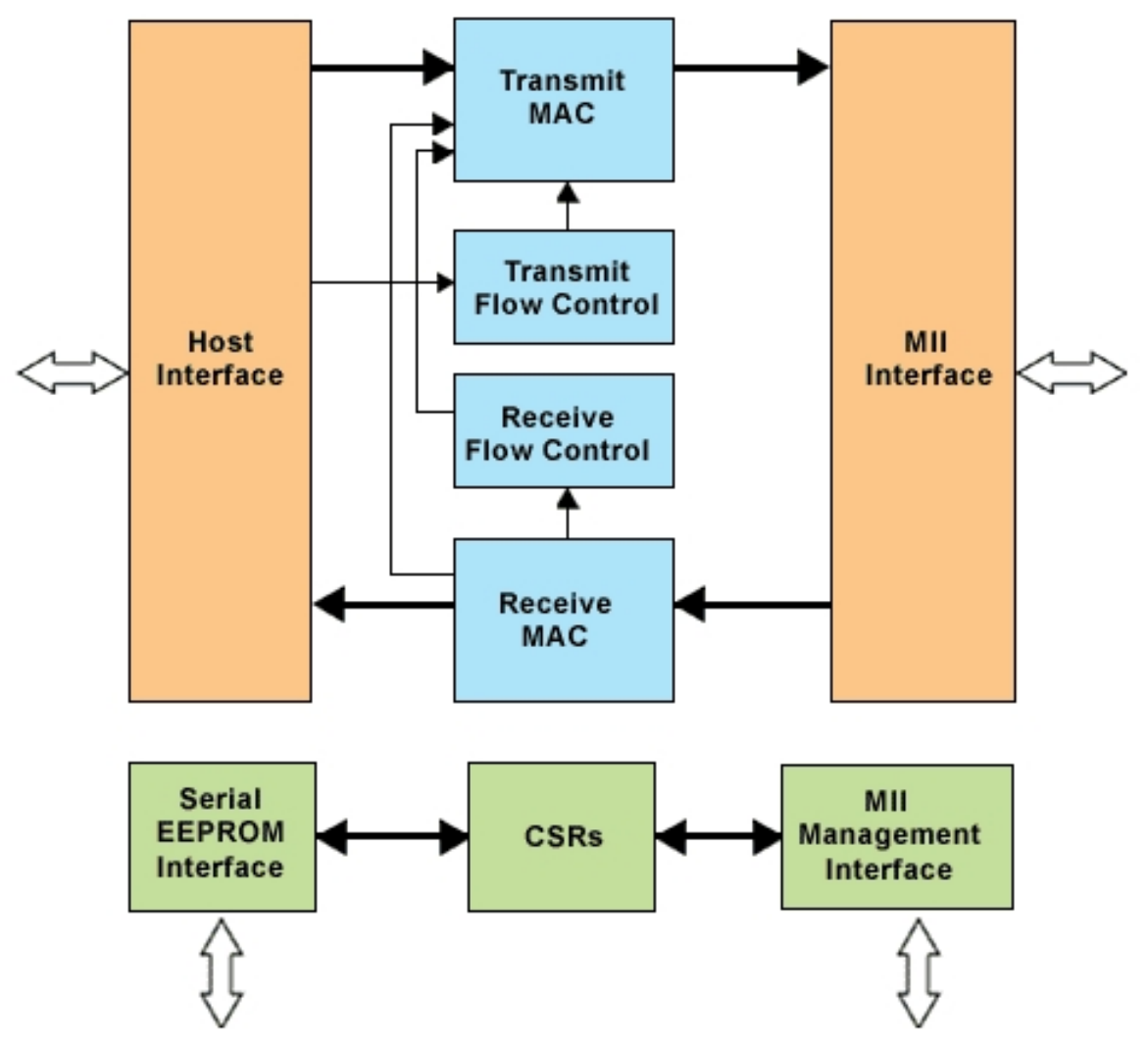

Figura 3.16: Wipro's IEEE 802.3 Ethernet MAC Layer Synthesizable Core (Wipro, 2004)

Os principais módulos deste core são:

- eth_miim.v: faz a interface com o chip PHY externo (transceiver), alterando seus registradores de configuração e coletando informações do chip;

- eth_rxethmac.v: recebe dados do chip PHY externo em nibbles e os transmite para o módulo eth_wishbone em bytes, removendo o preâmbulo e o CRC;

- eth_txethmac.v: recebe dados do módulo eth_wishbone em bytes e os envia para o chip PHY externo em nibbles; possui um sub-módulo para geração de CRC;

- eth_maccontrol.v: realiza o controle de fluxo dos dados quando o core está operando em modo full-duplex a 100 Mbps; a Seção 2.5 descreve a operação de PAUSE utilizada para esse fim;

- eth_macstatus.v: monitora as operacões do hardware registrando a ocorrência de erros como os de CRC, colisão atrasada, entre outros; 
- eth_registers.v: acomoda todos os registradores necessários para o sistema. Cada registrador é instanciado com um parâmetro de largura e outro de valor inicial;

- eth_wishbone.v: faz a interface entre o core e outros elementos como memória e processador por meio do barramento Wishbone; possui duas interefaces (mestre e escravo) para esse propósito.

Este core foi utilizado com ponto de partida deste projeto, conforme descrito no Capítulo 4. 


\section{Implementação e Resultados}

Para o desenvolvimento deste projeto de mestrado foram utilizados os recursos disponíveis no Laboratório de Computação Reconfigurável (LCR) do ICMC/USP. O laboratório possui ferramentas de Electronic Design Automation (EDA) avançadas, essenciais para o desenvolvimento, simulação, síntese e depuração de hardware.

A proposta inicial para validar o projeto foi construir uma placa auxiliar (daughter card), cujo esquema é apresentado na Figura 4.1 contendo um transceiver e um conector RJ-45 para acoplá-la ao kit Nios e conectar a placa a uma rede Ethernet. A aquisição de transceivers e conectores e a construção da placa não foram possíveis, devido ao custo relativamente alto já que os chips disponíveis no mercado atualmente utilizam encapsulamentos extremamente pequenos, impossibilitando sua soldagem de forma manual no laborátorio.

A construção de uma placa FPGA para a utilização com esse core deve incluir um conector como o mostrado na Figura 4.2, que possui LEDs de sinalização e protetores magnéticos embutidos. Caso o conector não possua esses protetores é necessário implementá-los conforme o esquema na Figura 4.3. Atualmente, os fabricantes de FPGA estão lançando kits no mercado prontos para a implementação de MACs, ou seja, com transceivers e conectores acoplados, o que confirma a tendência de se incorporar os componentes de rede Ethernet aos circuitos FPGA. 


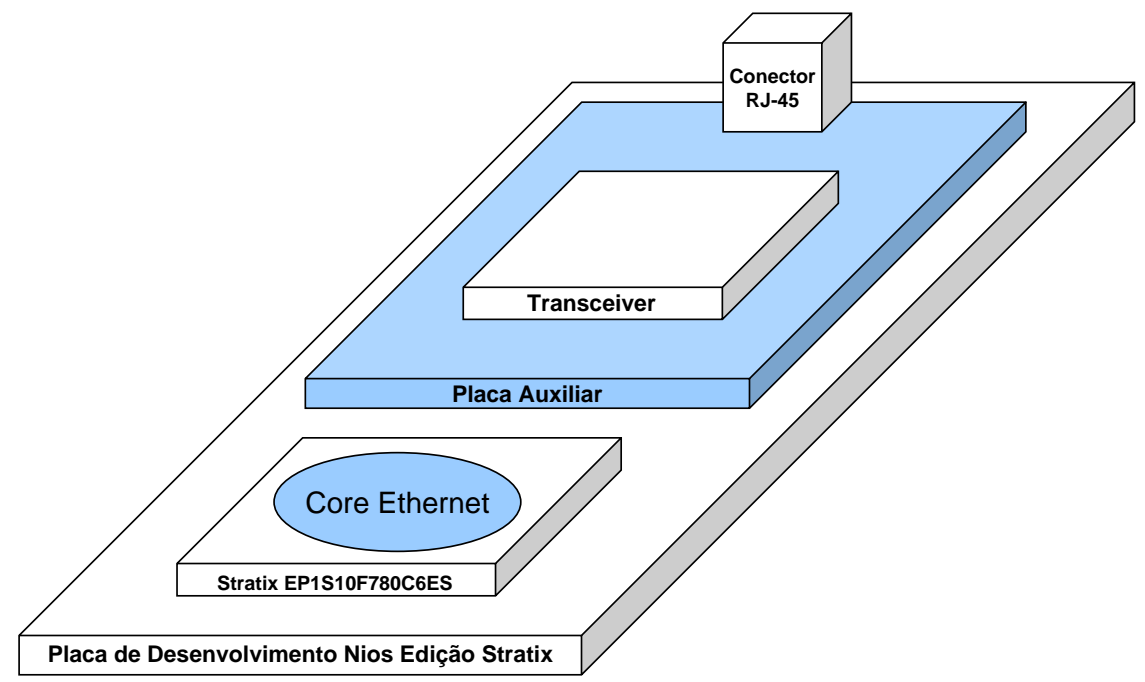

Figura 4.1: Projeto da placa auxiliar conectada ao kit Nios Stratix

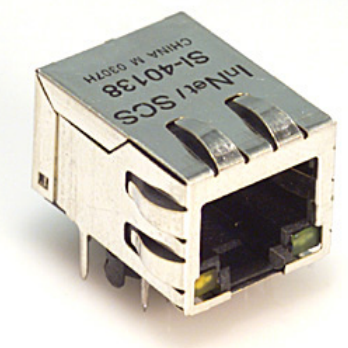

Figura 4.2: Conector utilizado para construção da uma placa com rede Ethernet

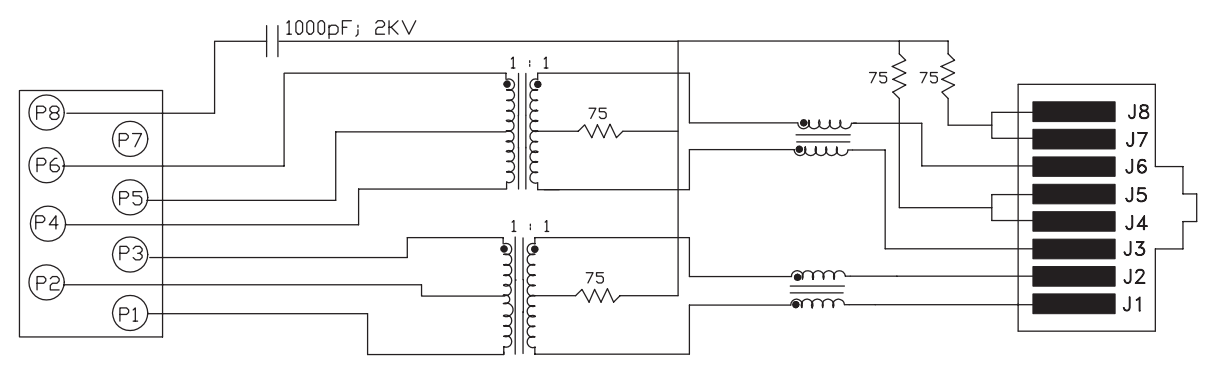

Figura 4.3: Esquema elétrico dos protetores magnéticos

Outra opção de validação seria adquirir o kit comercializado pela empresa Microtronix, mostrado na Figura 4.4. O produto é similar ao kit Nios da Altera; embora possua um FPGA muito inferior, da família Cyclone, acompanha um transceiver 78Q2120C da TDK, cujo diagrama de blocos é mostrado na Figura 4.5, e um conector RJ45 com protetores magnéticos. Esta configuração seria ideal para validação do core, mas a compra e importação do produto não foi possível devido a restrições financeiras. A aquisição do kit ficaria em US\$437,45 mais 
impostos, portanto optou-se por outra opção.

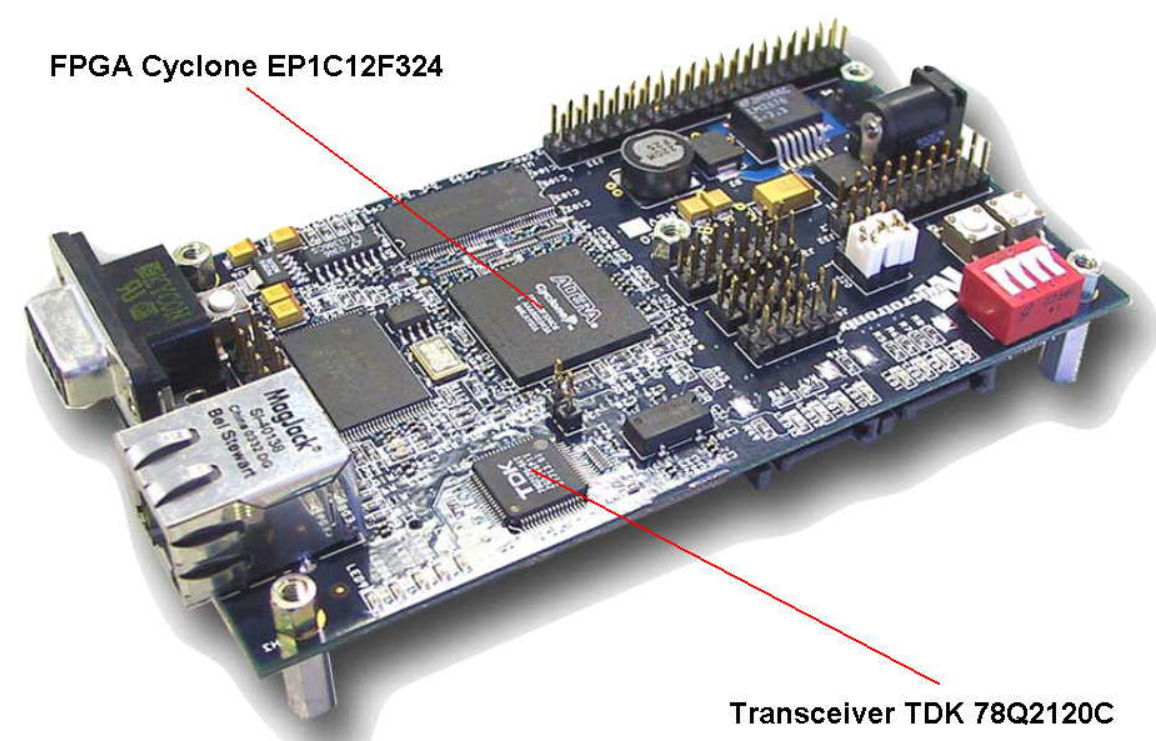

Figura 4.4: Kit de desenvolvimento da Microtronix (Microtronix, 2005)

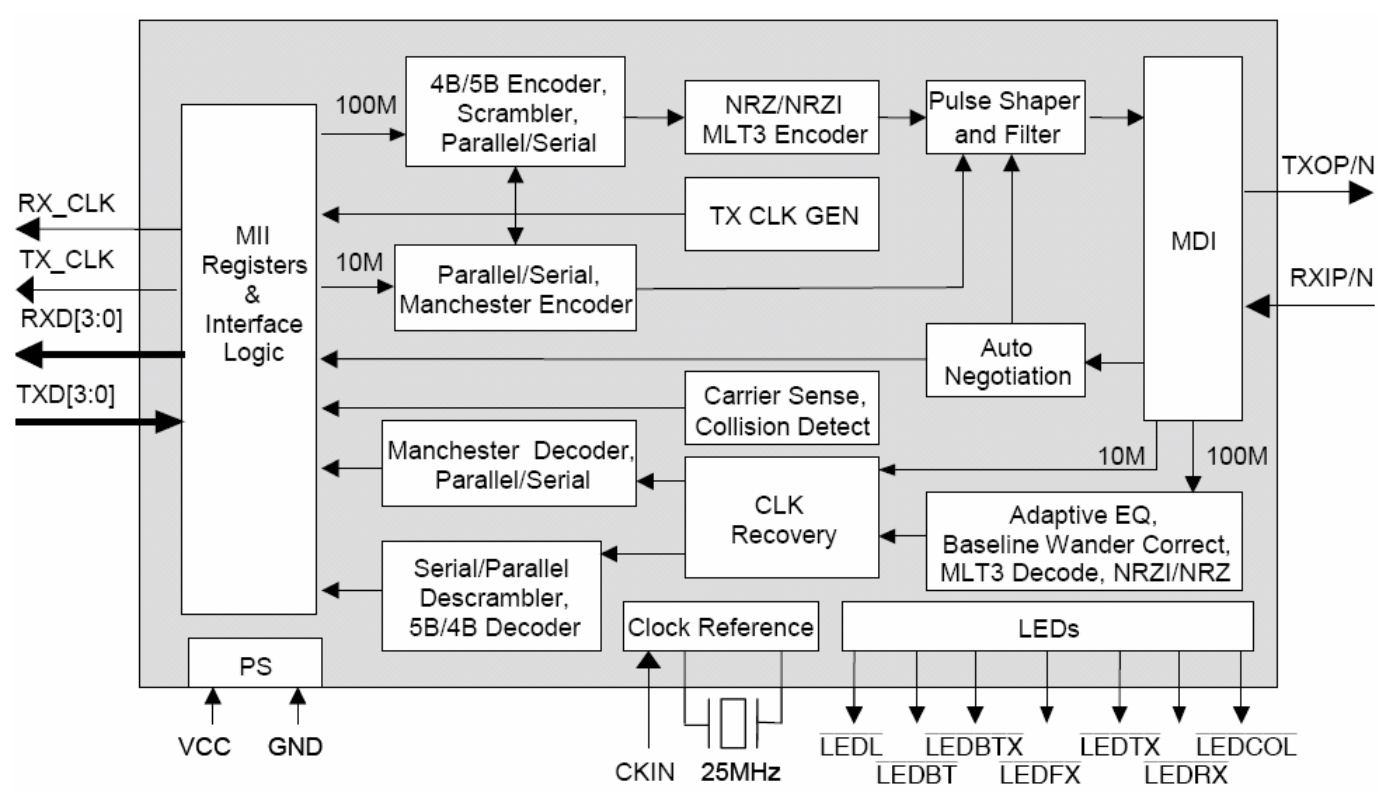

Figura 4.5: Diagrama de blocos do transceiver 78Q2120C (TDK, 2003) 


\subsection{O componente Ethernet}

Para adicionar um componente a biblioteca do SoPC Builder é necessário criar um arquivo de classe com a extensão PTF. Esse arquivo contém informações que determinam como os sinais do componente são conectado ao barramento do $\mathrm{SoC}$, além dos sinais externos a serem exportados. É possível também construir um assistente para a inclusão do componente no sistema, parametrizando informações necessárias em uma interface gráfica. A Figura 4.6 mostra o core Ethernet selecionado na biblioteca do lado esquerdo e ao lado a janela exibida no momento de sua inclusão no sistema.

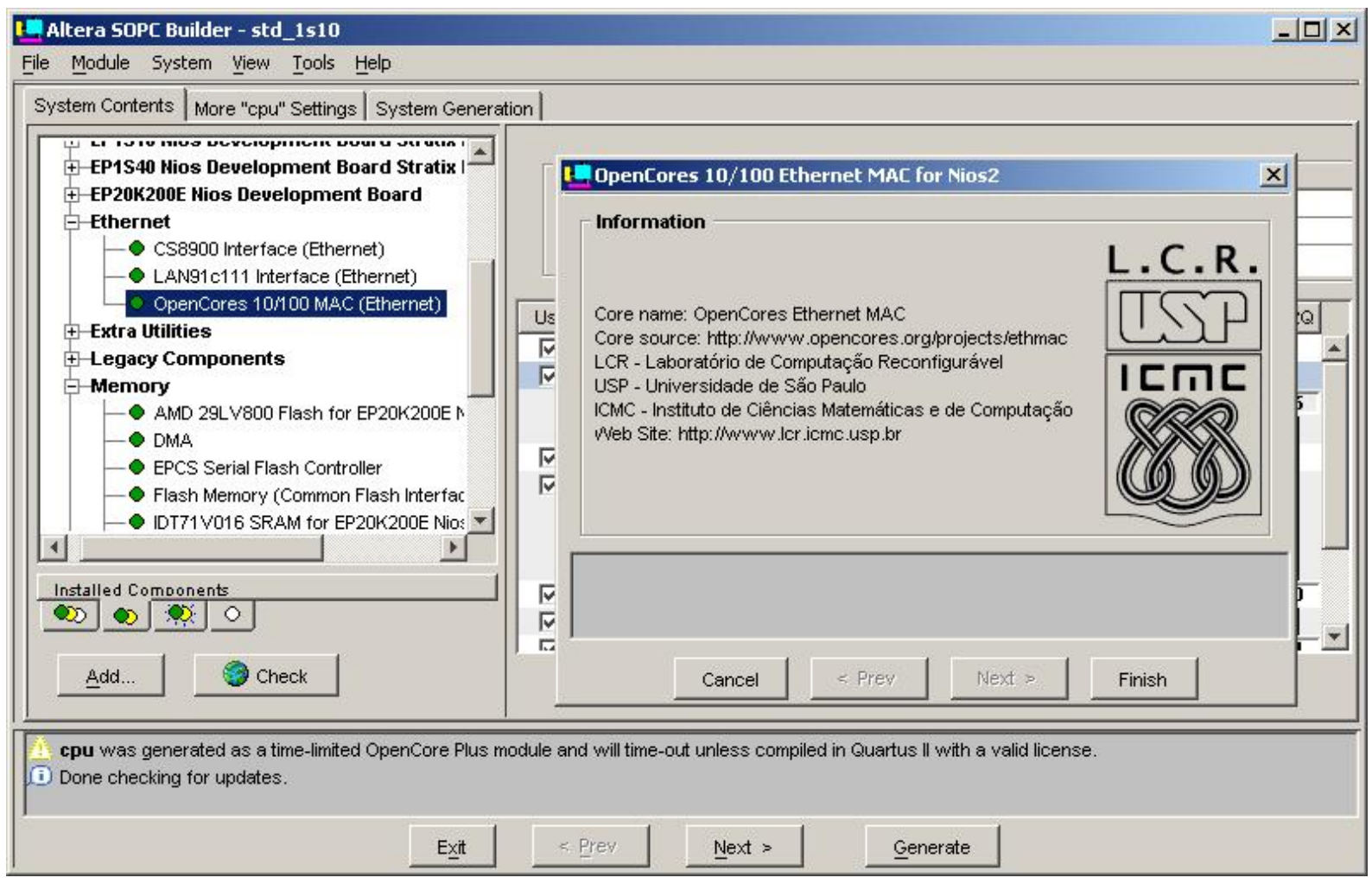

Figura 4.6: Inclusão do core Ethernet no SoPC

O componente foi descrito com a linguagem Verilog, compatível com todas as ferramentas utilizadas. Na Figura 4.7 é apresentado o diagrama de blocos do componente. Os blocos mais internos são instanciados pelos blocos mais externos, até o último arquivo do componente, que deve ser instanciado pelo árbitro do barramento.

O módulo eth_miim.v é responsável pela ligação do core com um transceiver externo. Essa comunicação é realizada por meio de dois sinais: o clock MDC e um sinal bidirecional 


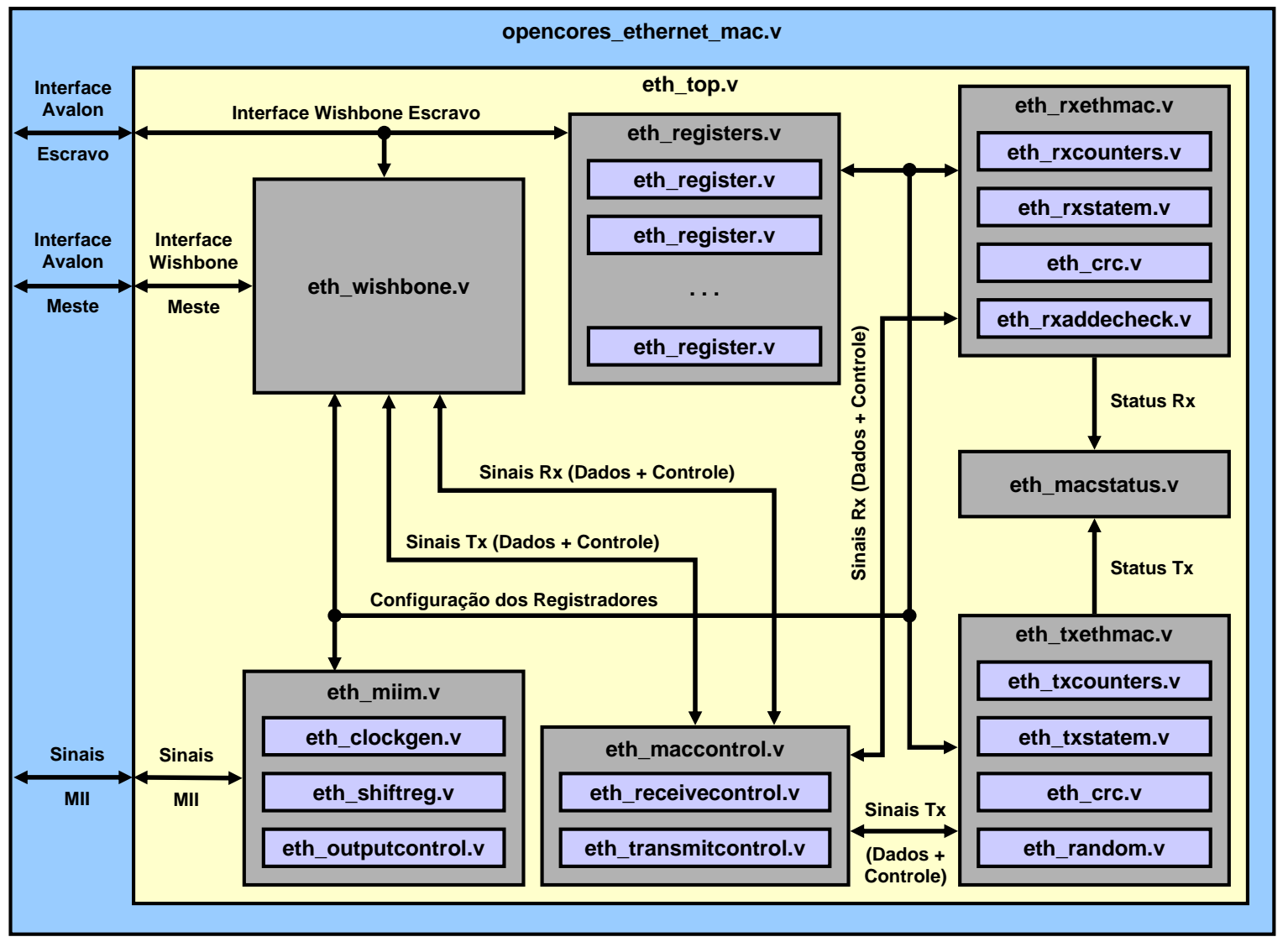

Figura 4.7: Diagrama de blocos do core Ethernet para o Avalon

de dados chamado MDIO. O clock fornecido ao PHY é determinado por um valor armazenado no registrador MIIMODER, cujo valor padrão é 100, ou seja, o transceiver opera com o clock do MAC dividido pelo valor deste registrador. A comunicação com o PHY permite configurar a velocidade de transmissão e o modo de operação da rede, entre outras opções.

Todas as tarefas de recepção de dados são realizadas pelo módulo eth_rxethmac.v. Os dados são recebidos do transceiver em nibbles, agrupados em bytes e transferidos para o módulo de controle do barramento. Antes porém, o preâmbulo é removido, o CRC é verificado e removido e o endereço MAC é comparado para determinar se o dado deve ser aceito ou não. Alguns registradores do core podem interferir na comparação do endereço MAC, como o campo PRO do registrador MODER, que coloca a interface de rede em modo promíscuo, aceitando pacotes de qualquer destino.

As tarefas de transmissão são executadas pelo módulo eth_txethmac.v. Esse módulo recebe dados em bytes e os transfere em nibbles para o transceiver. Entre as tarefas desse módulo estão a geração do preâmbulo e do CRC, e o algoritmo de backoff. Quando uma colisão é detectada, 
a retransmissão é realizada em um tempo aleatório dentro de um limite, que aumenta com o número de colisões.

O módulo eth_maccontrol.v realiza o controle de fluxo que é utilizado apenas no modo 100Mbps full-duplex. Esse controle é realizado com a troca de pacotes PAUSE entre as interfaces de rede. Quando o processador não consegue processar todos os pacotes recebidos ele solicita uma pausa, transmitindo um desses pacotes ao outro lado da conexão. Do mesmo modo, quando a interface de rede recebe uma solicitação de pausa ela suspende a transmissão por um tempo ou até que receba outro comando.

O módulo eth_macstatus.v é reponsável por monitorar as operações de transmissão e recepção e atualizar os descritores de buffer envolvidos na operação. Todos os registradores do core estão no módulo eth_registers.v e possuem 32 bits. Os bits não utilizados são ignorados em operações de escrita e lidos como zeros. Cada registrador é instanciado com dois parâmetros, a largura e o valor padrão, que é utilizado no caso de reset.

A interface com o barramento Wishbone é realizada pelo componente eth_wishbone.v por meio de uma ligação mestre e outra escrava. A interface escrava é utilizada para acessar os registradores e os descritores de buffer, e a interface mestre é utilizada para acessar a memória gravando dados recebidos e lendo dados para transmissão. É neste módulo também que estão os descritores, armazenados em memória interna ao core, e as filas de recepção e transmissão, ligadas aos seus respectivos módulos, sendo que cada fila possui 16 palavras de profundidade.

Os descritores estão localizados na memória interna entre os endereços 0x400 e 0x7FF, num total de 128. Cada descritor possui 8 bytes de largura, 4 para status e 4 para o ponteiro de memória. Eles podem ser utilizados tanto para recepção quanto para transmissão de dados. O número de buffers utilizados para transmissão é definido no registrador TX_BD_NUM e o restante é utilizado para recepção.

O barramento Wishbone consiste em uma metodologia de projeto flexível para utilização em semicondutores. Seu propósito é encorajar o reúso, amenizando os problemas oriundos da integração de componentes em um Soc. Isto é obtido por meio da criação de uma interface comum entre os cores. A integração de componentes sem a utilização de uma interface padronizada é trabalhosa, pois demanda a criação de glue logic para a conexão dos diferentes componentes. 
A arquitetura Wishbone é similar a de um barramento utilizado em microcomputadores, como o Peripheral Component Interconnect (PCI), pois oferece flexibilidade de integração, variedade de ciclos e larguras de dados e permite que produtos desenvolvidos por diversos fabricantes possam ser utilizados juntos. No entanto, barramentos utilizados em microcomputadores são limitados para a utilização em SoC. Eles são desenvolvidos para levar sinais por longos caminhos e seus conectores são altamente indutivos e capacitivos. Nesse aspecto, os SoC são mais simples, rápidos e possuem uma grande quantidade de recursos de interconexão, pois não estão limitados aos encapsulamentos dos circuitos integrados ou pelos conectores mecânicos.

O conjunto de especificações do barramento Wishbone pode ser considerado um subconjunto do barramento Avalon, já que a maior parte de seus recursos é suportada por este barramento. O módulo opencores_ethernet_mac.v foi criado para adaptar os sinais do core ao barramento Avalon. Entre as adaptações necessárias estão o alinhamento de endereços, o sinal de waitreq_n do Avalon, obtido pela combinação dos sinais ack e stb do Wishbone, e o endianness dos dados.

\subsection{Sistema de validação}

Por se tratar de uma aplicação prática, os resultados foram analisados tanto com simulações parciais no software ModelSim, bem como diretamente no hardware montado que está em destaque na Figura 4.8. Foram utilizados dois kits Nios da Altera edição Stratix (Altera, 2003b) para a validação do sistema. Em cada uma das placas foi colocado um processador Nios II com o core Ethernet e estes foram conectados por meio de uma ligação ponto-a-ponto em suas interfaces MII.

Muitos dispositivos de rede utilizam Ethernet como interface principal de dados e necessitam de um transceiver analógico para se conectar à mídia. Se a ligação Ethernet é utilizada para conectar apenas dois dispositivos a mídia não precisa ser compartilhada e o transceiver pode ser evitado (Gusev, 2003). Para a validação do projeto foi desenvolvido um bloco capaz de conectar dois MACs em uma ligação ponto-a-ponto, baseado na proposta de Gusev (2003), conforme apresentado na Figura 4.9. Esse bloco, denominado Reverse Media Independent Interface (RevMII), foi desenvolvido em linguagem Verilog no Quartus II. O bloco é utilizado 


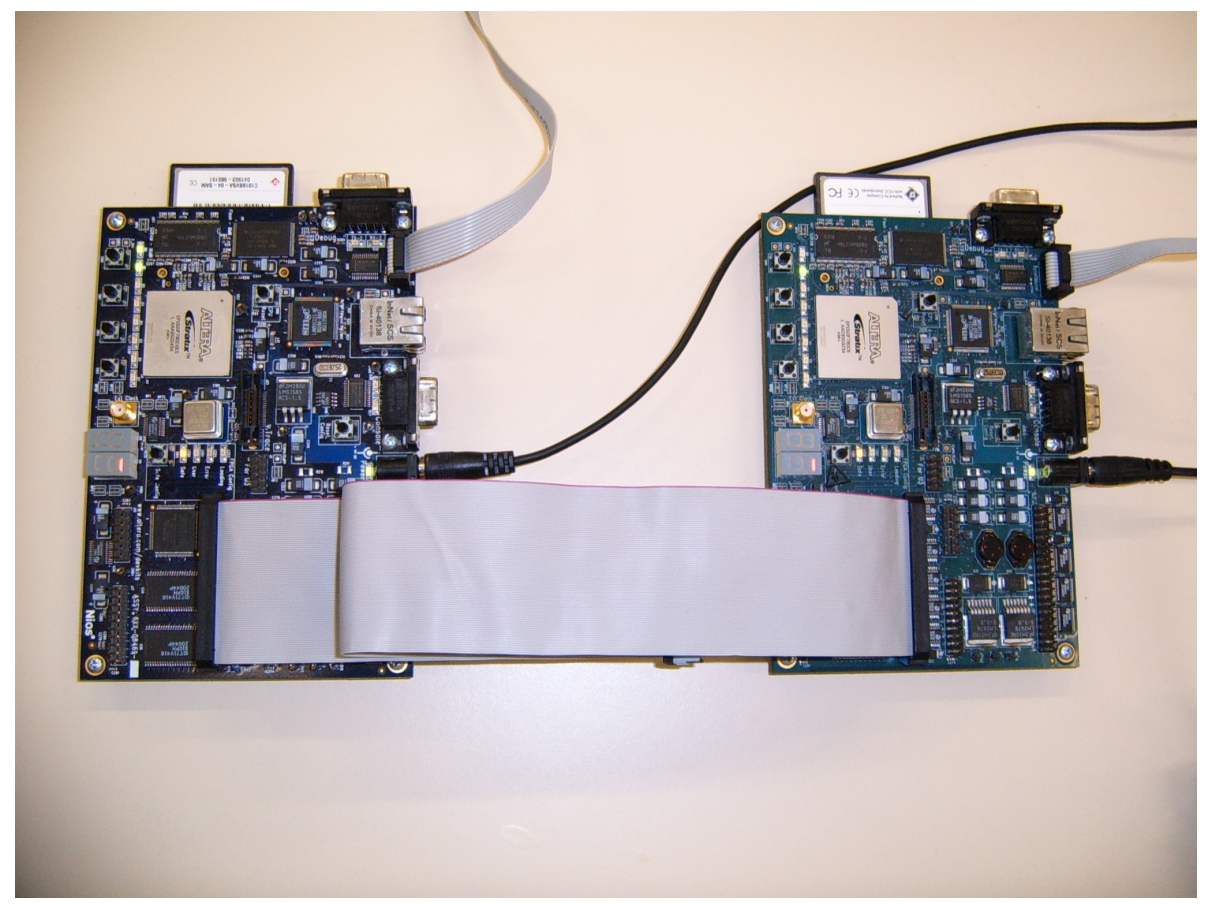

Figura 4.8: Sistema montado para validação do projeto

em uma das placas do sistema de validação, conectando as interfaces Ethernet em uma ligação ponto-a-ponto. Um cabo de 40 pinos, utilizado em discos rígidos, foi conectado aos soquetes de extensão das placas.

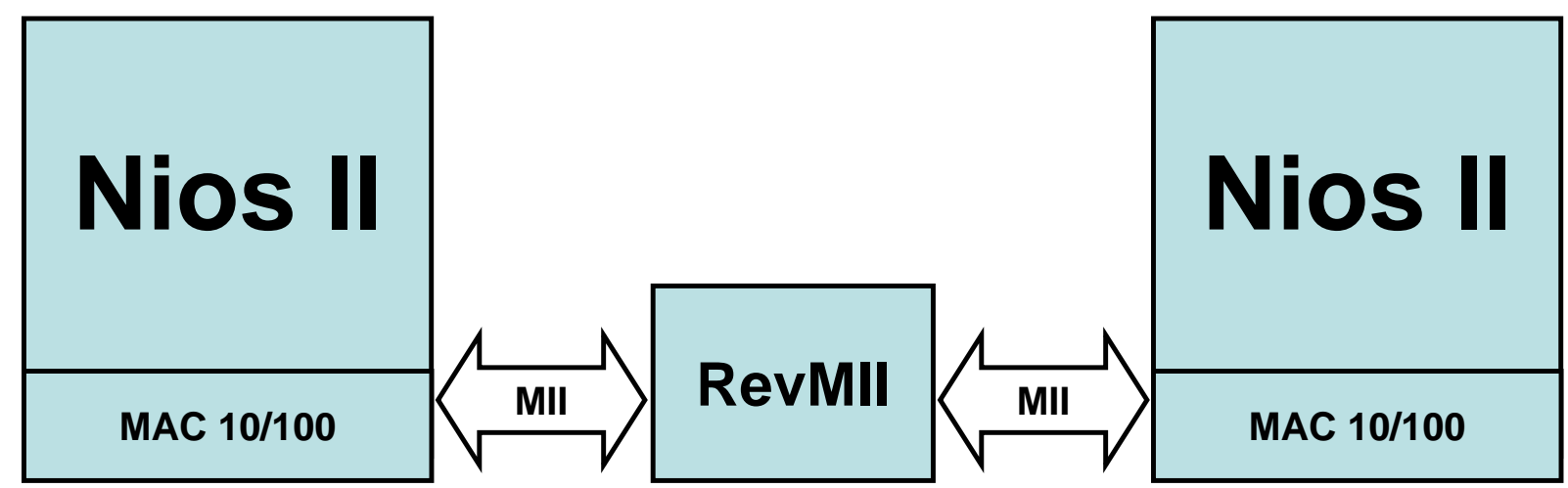

Figura 4.9: Diagrama de blocos do sistema de validação

O procesador utilizado no SoC de cada uma das placas foi o Nios II da Altera, que utiliza o barramento Avalon. A Figura 4.10 mostra o diagrama de blocos de cada processador implementado na FPGA da placa, delimitado por uma linha pontilhada, bem como os componentes de memória RAM e Flash utilizados. O Bloco RevMII está presente em apenas uma das FPGAs, pois possui duas portas MII para conectar os MACs, interligando as placas em rede.

O sistema Nios II implementado no SoPC Builder possui os seguintes componentes: 


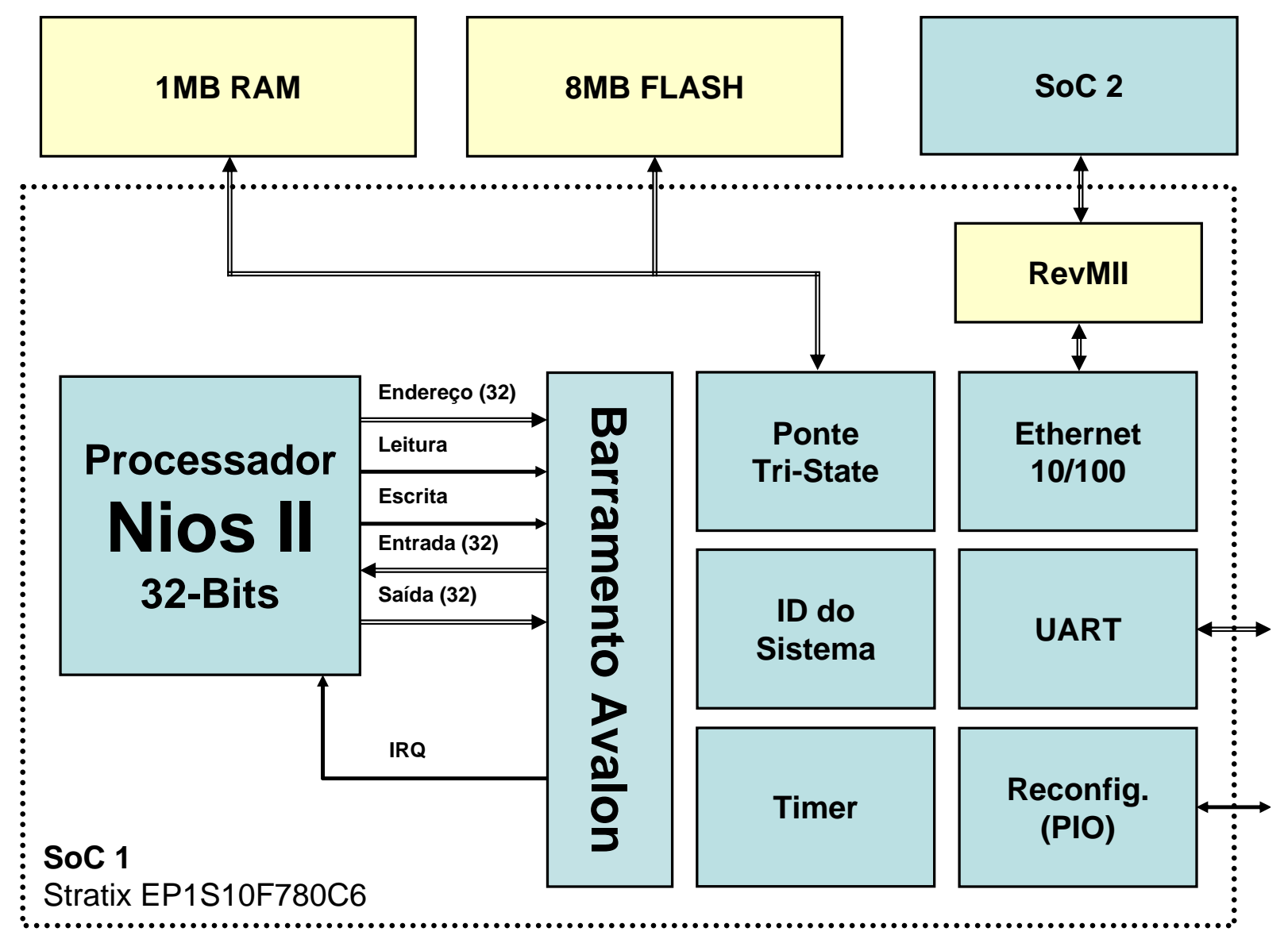

Figura 4.10: Diagrama de blocos do SoC implementado

- cpu - Nios II Processor: foi utilizada a versão standard do processador com cache de instruções de 4 Kbytes e hardware de multiplicação implementado em blocos DSP disponíveis na família Stratix. Foi utilizado o Nível 1 de depuração, que permite uma conexão JTAG para fazer o download do programa na placa e realizar breakpoints por software;

- mac - OpenCores 10/100 MAC: o core conecta-se ao barramento Avalon por meio de duas portas. A porta escrava recebe comandos de controle que são escritos em seus registradores. A porta mestre acessa a memória diretamente para transmitir/receber dados;

- ext_flash - Flash Memory (CFI): interface para memória flash de 8 Mbytes utilizando o padrão CFI (Common Flash Interface), capaz de conectar memórias disponíveis em uma lista ou informando os tempos de acesso de qualquer memória que suporte o padrão. A memória utilizada foi a AMD29LV065D-120R, disponível nos kits utilizados;

- code - IDT71V416 SRAM: interface para dois chips de memória RAM estática, cada um 
com 512 Kbytes;

- sys_clk_timer - Iterval Timer: periférico para controle de tempo utilizado em diversos drivers para controles de timeout e delay;

- reconfig_request_pio - Parallel I/O (PIO): porta bidirecional utilizada pra reconfigurar o sistema. Foi atribuído um botão da placa para realizar a reconfiguração;

- jtag_uart - JTAG UART: esse componente provê comunicação serial entre o PC e o processador Nios II. Foi utilizado um cabo paralelo denominado ByteBlasterMV para a conexão, o qual não é o mais indicado, pois pode apresentar falhas e comunicação intermitente. A Altera recomenda que seja usado o cabo USB Blaster, o qual não estava disponível no laboratório durante o desenvolvimento.

- sysid - System ID Peripheral: ao ser incluído no sistema, este periférico gera uma identificação única e um timestamp que são utilizados posteriormente no desenvolvimento do software. Isso impede que se execute programas desenvolvidos para um sistema em outro sistema diferente;

- ext_ram_bus - Avalon Tri-State Bridge: ponte que possibilita a comunicação do processador com memórias externas à FPGA, disponíveis na placa.

Na Tabela 4.1 estão relacionados os recursos utilizados da FPGA para a implementação do SoC 1. As primeiras linhas representam as quantidades de recursos utilizadas pelo processador, core Ethernet e pelo bloco RevMII, respectivamente. A última linha apresenta a quantidade total de células lógicas, memória e blocos de DSP disponíveis na placa e os percentuais utilizados pelo sistema.

Tabela 4.1: Recursos utilizados do dispositivo EP1S10F780C6

\begin{tabular}{|l|r|r|r|r|r|r|}
\hline Módulo & Células Lógicas & \multicolumn{1}{c|}{ \% } & Bits de Memória & \% & DSP & \% \\
\hline \hline cpu & 1480 & $14,00 \%$ & 45824 & $4,98 \%$ & 8 & $16,67 \%$ \\
\hline mac & 2170 & $20,53 \%$ & 9216 & $1,00 \%$ & 0 & $0,00 \%$ \\
\hline revmii & 10 & $0,09 \%$ & 0 & $0,00 \%$ & 0 & $0,00 \%$ \\
\hline total & 10570 & $34,63 \%$ & 920448 & $5,98 \%$ & 48 & $16,67 \%$ \\
\hline
\end{tabular}


Uma vez montado o hardware de validação do sistema, foram desenvolvidos os programas para os SoCs. O ambiente de desenvolvimento de software da Altera para o processador Nios II é o Eclipse, integrated development environment (IDE) baseada em Java com código fonte aberto. Os programas realizam procedimentos semelhantes aos descritos no Apêndice A para envio e recepção dos pacotes. Nesse apêndice são apresentadas simulações das operações necessárias para a transmissão e recepção de dados.

O programa de envio é mostrado na Figura 4.11. Ele utiliza um único descritor para envio da mesma posição de memoria em repetição. A cada transmissão, o conteúdo da memória é incrementado e o buffer é novamente habilitado para uma nova transmissão. São exibidos na sua console a quantidade de pacotes enviados com sucesso, a quantidade de erros reportados, a interrupção gerada no envio e o conteúdo transmitido.

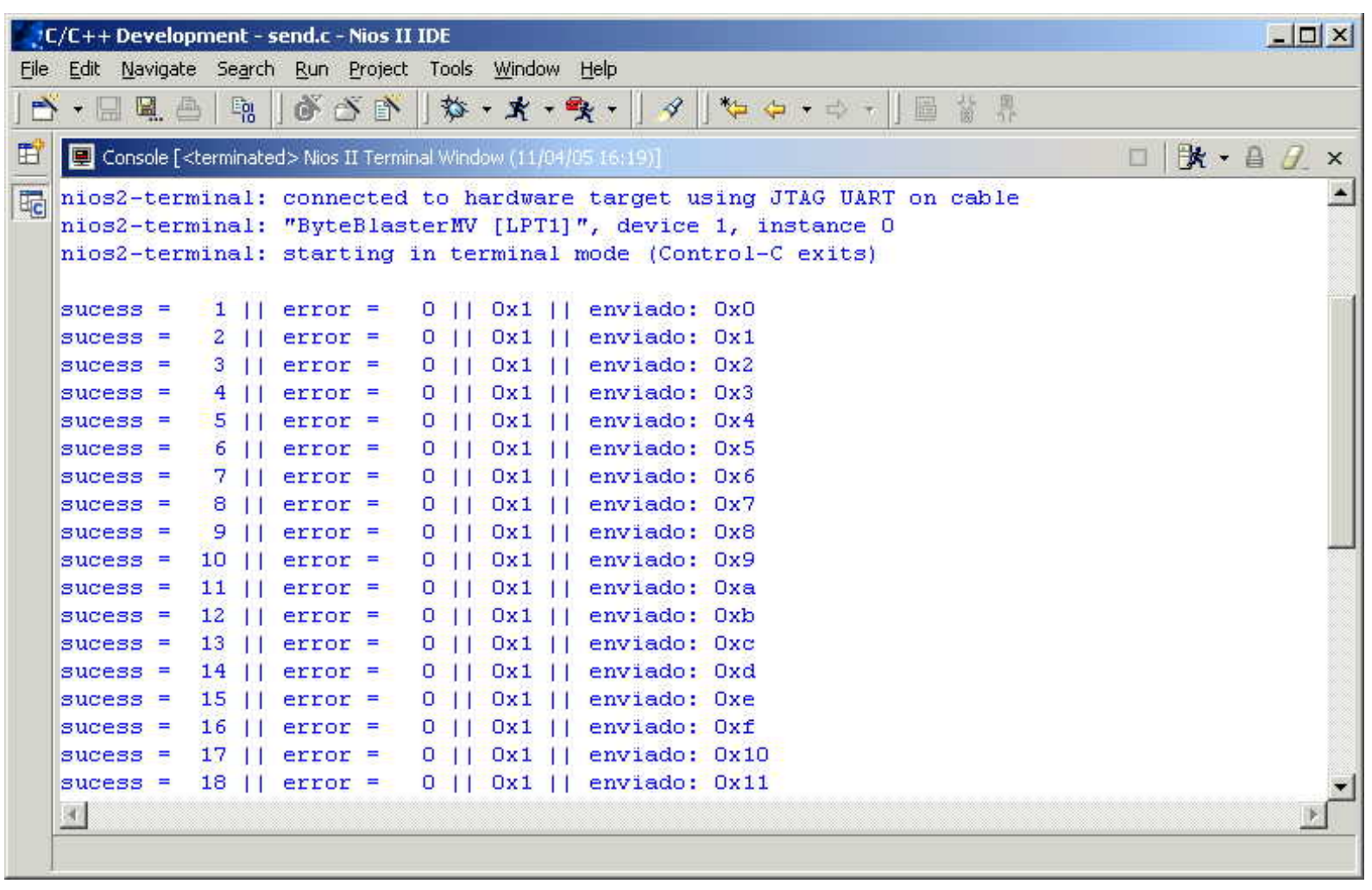

Figura 4.11: Programa para envio de pacotes com conteúdo seqüencial

O programa de recepção utiliza um único buffer e monitora interrupções para detectar pacotes recebidos. Quando um pacote é recebido, seu conteúdo é exibido na console e o buffer liberado novamente para uma nova recepção. Sua console é mostrada na Figura 4.12, listando a quantidade de pacotes recebidos com sucesso, pacotes recebidos com erro, número da inter- 
rupção gerada e o conteúdo do pacote recebido.

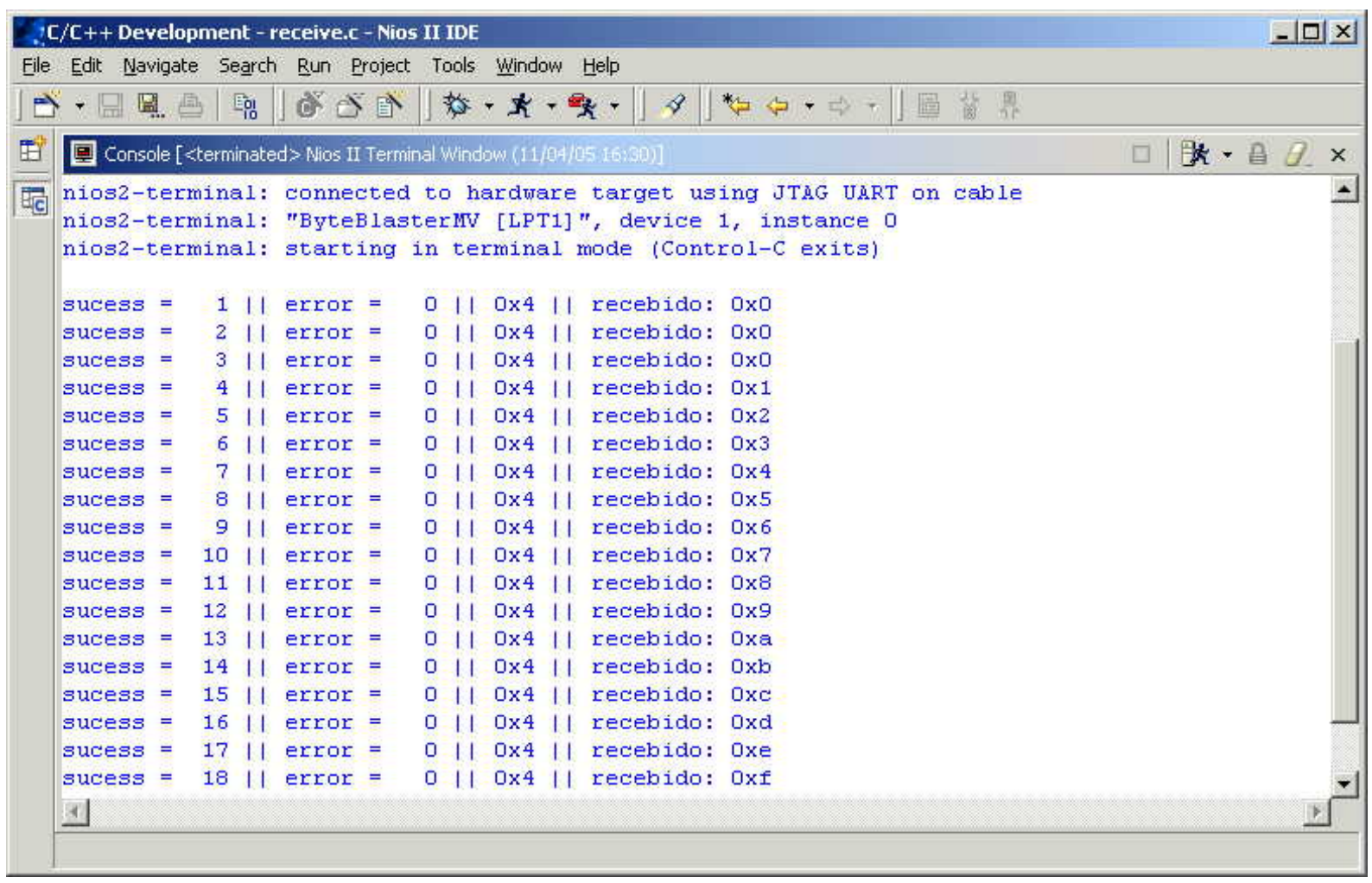

Figura 4.12: Programa recebendo os pacotes Ethernet e mostrando o conteúdo

Durante os primeiros testes foi utilizado um cabo de 40 vias que apresentou erros de comunicação, provavelmente decorrentes de ruídos nos sinais. Os erros eram detectados a partir da interrupção gerada na recepção, como por exemplo pacotes com CRC incorreto. O cabo então foi substituido por outro de 80 vias, que possui um aterramento entre cada sinal de comunicação, e o problema foi resolvido. 


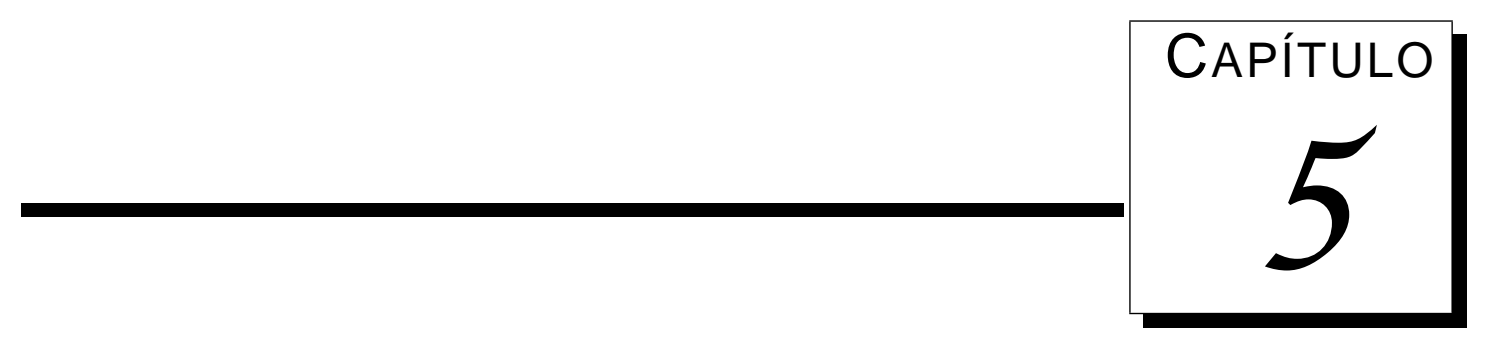

\section{Conclusões}

Este projeto teve como objetivo estudar e implementar um core para uma interface Ethernet em FPGA agregando-o à biblioteca de componentes do SoPC Builder por intermédio da construção de um arquivo PTF para o core. O domínio dessa tecnologia foi importante para o LCR, pois possibilita a aplicação da interface em sistemas embarcados, permitindo a customização e a otimização dos recursos de comunicação de acordo com as necessidades de cada projeto. A interface Ethernet pode ser incorporada a outros projetos em que o hardware necessite de comunicação com o meio externo.

Acredita-se ainda que o domínio da tecnologia Ethernet 802.3 possa contribuir para futuras implementações em hardware reconfigurável dos padrões wireless como o Ethernet 802.11 (Lough et. al., 1999). Ainda que não seja possível a extensão deste projeto para a inclusão no FPGA do padrão 802.11, equipamentos de bridge podem ser facilmente acoplados a esta interface para se obter a comunicação wireless, conforme descrito no Capítulo 1.

Os cores previamente existentes para esse propósito apresentam custos muito altos e são soluções para sistemas específicos. As placas de hardware dedicado dificultam a integração com outros componentes dos sistemas, aumentando o custo e a complexidade de construção das placas de tais sistemas. Assim, a implementação deste módulo em FPGA se mostrou importante 
uma vez que possibilita a customização do hardware de acordo com as necessidades de projeto.

Embora existissem essas soluções Ethernet disponíveis, sistemas embarcados exigem propósitos diferentes da computação tradicional e suas redes, pois são mais integrados com seus ambientes físicos e são mais autônomos. Eles podem operar com um conjunto de restrições em termos de espaço, consumo de energia e outros recursos (Estrin et. al., 2001). A capacidade de reconfiguração dinâmica de alguns FPGAs permite, por exemplo, que se façam estudos posteriores para se alterar dinamicamente as características do módulo de rede, tais como a velocidade de operação, o modo (half-duplex ou full-duplex) e o algoritmo utilizado na operação de backoff, dentre outros.

O Quartus II é um programa que oferece uma solução completa para o desenvolvimento de sistemas baseados em FPGAs, mas a utilização do ModelSim se mostrou fundamental durante o processo de desenvolvimento. O Quartus possibilita a realização de simulações apenas utilizando formas de onda como estímulos de entrada, enquanto o ModelSim possibilita a criação de testbenchs em HDL. Esse recurso permite criar testes mais completos, que respondam aos sinais do módulo testado.

O lançamento de um kit pela empresa Microtronix contendo uma FPGA Altera e um transceiver Ethernet (sem o MAC) reforça a idéia deste projeto de que a integração do MAC ao chip da FPGA é a melhor relação custo-benefício para o desenvolvimento de SoCs que necessitem de rede Ethernet. Embora a Altera tenha optado por colocar ASICs com MAC/PHY em suas placas de desenvolvimento, essa alternativa é confrontada pela Xilinx que está lançando suas placas com FPGAs Virtex-4 apenas com PHY (Xilinx, 2005).

O projeto desenvolvido atende as necessidades de comunicação dos sistemas desenvolvidos no laboratório, indispensável em sistemas embarcados quando se deseja compartilhar recursos ou trabalhar de forma cooperativa. Esses projetos poderão utilizar apenas a interface de rede Ethernet ou combiná-la a soluções wireless para comunicação sem fio.

A integração com o SoPC Builder, disponibilizando o core como um componente da biblioteca, é fundamental para que novos desenvolvedores possam usar a interface de rede da maneira mais fácil possível, sem nenhum trabalho adicional. Finalmente, o trabalho desenvolvido contribuiu de maneira determinante no desenvolvimento do robô permitindo sua comunicação com 
um host.

\subsection{Trabalhos futuros}

Após a aquisição de um kit de desenvolvimento com um transceiver, o módulo Ethernet pode ser utilizado em SoCs para comunicação com outros equipamentos de rede. Adicionalmente, um equipamento de bridge pode ser acoplado para obter comunicação wireless em sistemas móveis, como por exemplo times de robôs atuando de forma cooperativa.

Considerando a quantidade de elementos lógicos utilizados na implementação e o aumento freqüente da quantidade de transistors das FPGAs, é possível colocar vários MACs em um sistema para aumentar a velocidade final da comunicação.

Outra possibilidade de utilização do core é dispensar o transceiver e acoplar um chip para comunicação wireless com uma ligação entre MACs ponto-a-ponto, por meio do bloco RevMII. 


\section{Referências Bibliográficas}

3COM ONline Token Ring Management Module User's Guide. 3Com Corp., 1996.

Disponível em http: / / www. 3com. com (Acessado em 01/2004)

3COM Token Ring-in-Fast Ethernet Server Network Interface Card User Guide. 3Com Corp., 1998.

Disponível em http: / / www. 3com. com (Acessado em 01/2004)

Altera Custom Instructions for the Nios Embedded Processor. Altera Corp., 2002a.

Disponível em http://www.altera.com/literature/an/an188.pdf (Acessado em 02/2004)

Altera Implementing 10 Gigabit Ethernet XAUI in Stratix GX Devices. Altera Corp., 2002b. Disponível em http: / / www.altera.com (Acessado em 01/2004)

Altera MegaCore Function 10/100 Ethernet MAC. Altera Corp., 2002c.

Disponível em http: / / www . altera. com (Acessado em 06/2003)

Altera Nios Custom Instructions Tutorial. Altera Corp., 2002d.

Disponível em http://www.altera.com/literature/tt/tt_nios_ci.pdf (Acessado em 02/2004)

Altera SOPC Builder PTF File. Altera Corp., 2002e.

Disponível em http: / / www . altera. com (Acessado em 01/2004)

Altera The Evolution of High-Speed Transceiver Technology. Altera Corp., 2002f.

Disponível em http: / / www . altera.com (Acessado em 01/2004)

Altera Avalon Bus Specification. Altera Corp., 2003a.

Disponível em http : / / www . altera. com (Acessado em 01/2004)

Altera Nios Embedded Processor System Development. Altera Corp., $2003 \mathrm{~b}$.

Disponível em http://www.altera.com/products/devices/nios/ nio-index.html (Acessado em 01/2004)

Altera Nios Ethernet Development Kit User Guide. Altera Corp., 2003c.

Disponível em http://www.altera.com/literature/lit-nio.html (Acessado em 01/2004)

Altera Stratix Device Handbook. Altera Corp., 2003d.

Disponível em http: / / www . altera . com (Acessado em 01/2004) 
Altera Stratix II Device Handbook. Altera Corp., 2004a.

Disponível em http: / / www . altera. com (Acessado em 02/2004)

Altera Upgrading Nios Processor Systems to the Nios II Processor. Altera Corp., 2004b.

Disponível em http://www.altera.com/literature/an/an350.pdf (Acessado em 01/2005)

AMD Am79c874 NetPHY-1LP Low Power 10/100-TX/FX Ethernet Transceiver. Advanced Micro Devices Inc., 2001.

Disponível em http: / / www . amd. com (Acessado em 08/2003)

ARM AMBA Specification. ARM Limited, 1999.

Disponível em http://www.arm.com/armtech/AMBA_Spec?OpenDocument (Acessado em 02/2004)

BERger, A. Embedded Systems Design: An Introduction to Processes, Tools, and Techniques. CMP Books, 2002.

Bertsekas, D.; Gallager, R. Data Networks, 2nd Ed. Prentice Hall, 1992.

Bout, V. D.; E., D. The Practical Xilinx Designer Lab Book Version 1.5. Prentice Hall, 1999.

Broadcom BCM5221 10/100BASE-TX/FX Mini Transceiver. Broadcom Corp., 2001.

Disponível em http: / / www.broadcom. com (Acessado em 08/2003)

Brown, S.; VRAnesic, Z. Fundamentals of Digital Logic with VHDL Design. McGraw Hill, 2000.

Brown, S.; VRAnesic, Z. Fundamentals of Digital Logic with Verilog Design. McGraw Hill, 2003.

Chan, P. K.; Mourad, S. Digital Design Using Field-Programmable Gate Arrays. Prentice Hall, 1994.

Ciletti, M. D. Modeling, Synthesis, and Rapid Prototyping with the Verilog HDL. Prentice Hall, 1999.

Coffman, K. Real World FPGA Design with Verilog. Prentice Hall, 2000.

COMER, D. E. Internetworking with TCP/IP, Vol. 1: Principles, Protocols and Architecture, 4th Ed. Prentice Hall, 2000.

COMER, D. E. Computer Networks and Internets with Internet Applications, 3rd Ed. Prentice Hall, 2001.

COMER, D. E. Internetworking with TCP/IP, 4th Ed. Prentice Hall, 2002.

Compton, K. Programming Architectures for Run-Time Reconfigurable Systems. Dissertação de mestrado, Northwestern University, 1999.

Compton, K.; Hauck, S. Reconfigurable Computing: A Survey of Systems and Software. ACM Computing Surveys, vol. 34, no. 2, pgs. 171-210, 2002. 
DeHon, A. The Density Advantage of Configurable Computing. IEEE Computer Magazine, pgs. 41-49, 2000.

Elbirt, A.; Yip, W.; Chetwynd, B.; PAar, C. An FPGA-Based Performance Evaluation of the AES Block Cipher Candidate Algorithm Finalists. Em: Proceedings of IEEE Transactions on VLSI Systems, 2001.

Elbirt, A. J.; YiP, W.; Chetwynd, B.; PAAR, C. An FPGA Implementation and Performance Evaluation of the AES Block Cipher Candidate Algorithm Finalists. Em: Proceedings of ACM/SIGDA International Symposium on FPGAs, 2000, pgs. 13-27.

Estrin, D. L.; Borriello, G.; Colwell, R. P.; Fiddler, J.; Horowitz, M.; Kaiser, W. J.; Leveson, N. G.; Liskov, B. H.; Lucas, P.; Maher, D. P.; Mankiewich, P. M.; TAYLOR, R.; WALdO, J. Embedded, Everywhere: A Research Agenda for Network Systems of Embedded Computers. National Academy Press, 2001.

GusEv, D. Reverse Media Independent Interface (RevMII) Block Architecture. STMicroelectronics, 2003.

Disponível em http://www.techonline.com/community/ed_resource/ feature_article/25385?print (Acessado em 03/2005)

Hamblen, J. O.; Furman, M. D. Rapid Prototyping of Digital Systems. Kluwer, 2001.

IBM The CoreConnect Bus Architecture. IBM Corp., 1999.

Disponível em http: / / www. ibm. com (Acessado em 01/2004)

IBM Ethernet and Token Ring Configuration Guide. IBM Corp., 2001.

Disponível em http: / / www. ibm. com (Acessado em 01/2004)

IEEE IEEE 802.2 Std - IEEE Standards for Local Area Networks: Logical Link Control. IEEE, 1985.

IEEE IEEE 802.3 Std 2002 - Carrier Sense Multiple Access with Collision Detection (CSMA/CD) Access Method and Physical Layer Specifications. IEEE, 2002.

Intel LXT971A 3.3V Dual-Speed Fast Ethernet Transceiver. Intel Corp., 2002. Disponível em http: / / www. intel . com (Acessado em 08/2003)

Lough, D. L.; Bankenship, T. K.; Krizman, K. J. A Short Tutorial on Wireless LANs and IEEE 802.11. Virginia Polytechnic Institute and State University, 1999.

Metcalfe, R. M.; Boggs, D. R. Ethernet: Distributed Packet Switching for Local Computer Networks. Communications of the ACM, vol. 19, no. 5, pgs. 395-404, 1976.

Microtronix uKit Development Kit. Microtronix Systems Ltd., 2005.

Disponível em http: / / www.microtronix.com (Acessado em 03/2005)

Mohor, I. Ethernet IP Core Specification. 2002.

Disponível em http://www.opencores.org/projects/ethmac/ (Acessado em 10/2003)

Molle, M. A New Binary Logarithmic Arbitration Method for Ethernet. 1994. 
Murgai, R.; Brayton, R. K.; Sangiovanni-Vincentelli, A. Logic Synthesis for Field-Programmable Gate Arrays. Kluwer Academic, 1995.

NAUGLE, M. G. The Illustrated Network Book. VNR, 1994.

Netgear ME101 802.11b Wireless Ethernet Bridge. Netgear Inc., 2003.

Disponível em http://www.netgear.com/pdf_docs/me101.pdf (Acessado em 02/2004)

Nett, E.; Schemmer, S. Reliable Real-Time Communication in Cooperative Mobile Applications. IEEE Transactions on Computers, vol. 52, no. 2, pgs. 166-180, 2003.

Nicolescu, G.; Yoo, S.; Bouchhima, A.; Jerraya, A. A. Validation in a Component-Based Design Flow for Multicore SoCs. Em: Proceedings of the 15th International Symposium on System Synthesis, ACM Press, 2002, pgs. 162-167.

OldField, J. V.; Dorf, R. C. Field-Programmable Gate Arrays. John Wiley \& Sons Inc., 1995.

Plummer, D. C. RFC 826 - An Ethernet Address Resolution Protocol or Converting Network Protocol Addresses to 48-bit Ethernet Addresses for Transmission on Ethernet Hardware. 1982.

QUeIRoz, D. C. Implementação do barramento on-chip AMBA baseada em computação reconfigurável. Dissertação de mestrado, ICMC/USP, 2005.

Roychoudhury, A.; Mitra, T.; KARRI, S. R. Using formal techniques to Debug the AMBA System-on-Chip Bus Protocol. IEEE/ACM SIGDA Conference Design Automation and Test in Europe, 2003.

SEIFERT, R. The Switch Book: The Complete Guide to LAN Switching Technology. John Wiley \& Sons, 2000.

SMsC LAN91C111: 10/100 Non-PCI Ethernet Single Chip MAC + PHY. Standard Microsystems Corp., 2003.

Disponível em http://www.smsc.com/main/datasheets/91c111.pdf (Acessado em 10/2003)

Song, Y.; KowbaA, A.; Simonot, F. Switched Ethernet for Real-Time Industrial Communication: Modelling and Message Buffering Delay Evaluation. 4th IEEE WFCS 2002, Vasteras (Sweden), 27-30 August, 2002.

Spurgeon, C. E. Ethernet: The Definitive Guide. O'Reilly, 2000.

Spurgeon, C. E. Charles Spurgeon's Ethernet (IEEE 802.3) Web Site. 2004.

Tanenbaum, A. S. Computer Networks, 4th Ed. Prentice Hall, 2003.

TDK 78Q2120C 10/100BASE-TX Transceiver. TDK Semiconductor Corp., 2003.

Disponível em http: / / www.tdk. com (Acessado em 08/2003)

Verbauwhede, I.; Chang, M.-C. F. Reconfigurable Interconnect for Next Generation Systems. Em: Proceedings of the 2002 international workshop on System-level interconnect prediction, 2002, pgs. 71-74. 
Wipro Wipro's IEEE 802.3 Ethernet MAC Layer Synthesizable Core. Wipro Ltd., 2004.

Disponível em http: / /www.wipro.com/ (Acessado em 10/2003)

Xilinx Xilinx Products and Solutions. Xilinx Inc., 2005.

Disponível em http://www.xilinx.com/xlnx/xil_prodcat_landingpage. jsp?sGlobalNavPick=PRODUCTS (Acessado em 03/2005) 


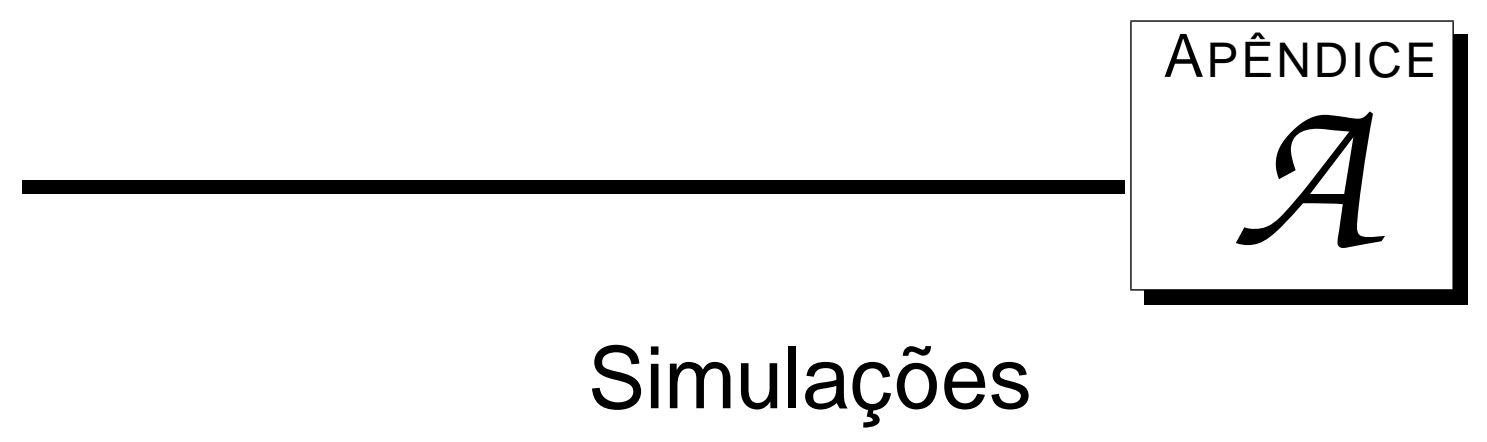

As simulações descritas neste apêndice foram realizadas na ferramenta ModelSim com o core ainda operando no barramento Wishbone. Elas foram utilizadas para entender o funcionamento do core, para futura aplicação ao barramento Avalon e para o possível desenvolvimento de drivers para utilização com diversos sistemas.

O módulo funciona com transferências Direct Memory Access (DMA), por meio de duas interfaces conectadas ao barramento. A interface escrava recebe comandos de leitura que verificam o estado do módulo, além de receber comandos de escrita que alteram seus registradores. A interface mestre transfere dados entre o core e a memória durante as transmissões e recepções de dados pela rede. A descrição completa dos registradores, bem como seu funcionamento pode ser encontrada em Mohor (2002). Alguns registradores não necessitam de alteração, pois possuem um valor inicial que pode ser adequado a tarefa desejada. A Tabela A.1 descreve os principais sinais apresentados nas simulações.

Tabela A.1: Principais sinais do barramento Wishbone apresentados nas simulações

\begin{tabular}{|c|c|c|}
\hline Interface & Sinal & Descrição \\
\hline \hline \multirow{4}{*}{ Escravo } & eth_sl_wb_adr_i & Endereço \\
\cline { 2 - 3 } & eth_sl_wb_dat_o & Saída de dados \\
\cline { 2 - 3 } & eth_sl_wb_dat_i & Entrada de dados \\
\cline { 2 - 3 } & eth_sl_wb_we_i & Leitura/Gravaçao \\
\hline \multirow{4}{*}{ Mestre } & eth_ma_wb_adr_o & Endereço \\
\cline { 2 - 3 } & eth_ma_wb_dat_i & Entrada de dados \\
\cline { 2 - 3 } & eth_ma_wb_dat_o & Saída de dados \\
\cline { 2 - 3 } & eth_ma_wb_we_o & Leitura/Gravaçao \\
\hline
\end{tabular}

Tanto a transmissão quanto a recepção de dados é baseada em descritores de buffers. Estes descritores possuem registradores de configuração e um ponteiro para a memória, indicando a posição dos dados a serem enviados/recebidos.

\section{A.1 Transmissão de dados}

A seguir são descritos alguns passos necessários para realizar uma transmissão de pacotes Ethernet com o core. Muitos dos procedimentos descritos são independentes e podem ser re- 
alizados em qualquer ordem. Além disso, este procedimento não é único, pois existem vários modos de operação possíveis.

Na Figura A.1 é mostrada a gravação do registrador TX_BD_NUM (0x20) que determina a quantidade de buffers de transmissão. O core possui 128 buffers que podem ser utilizados tanto para transmissão quanto para recepção. A quantidade de buffers de recepção é dada por 128 menos TX_BD_NUM.

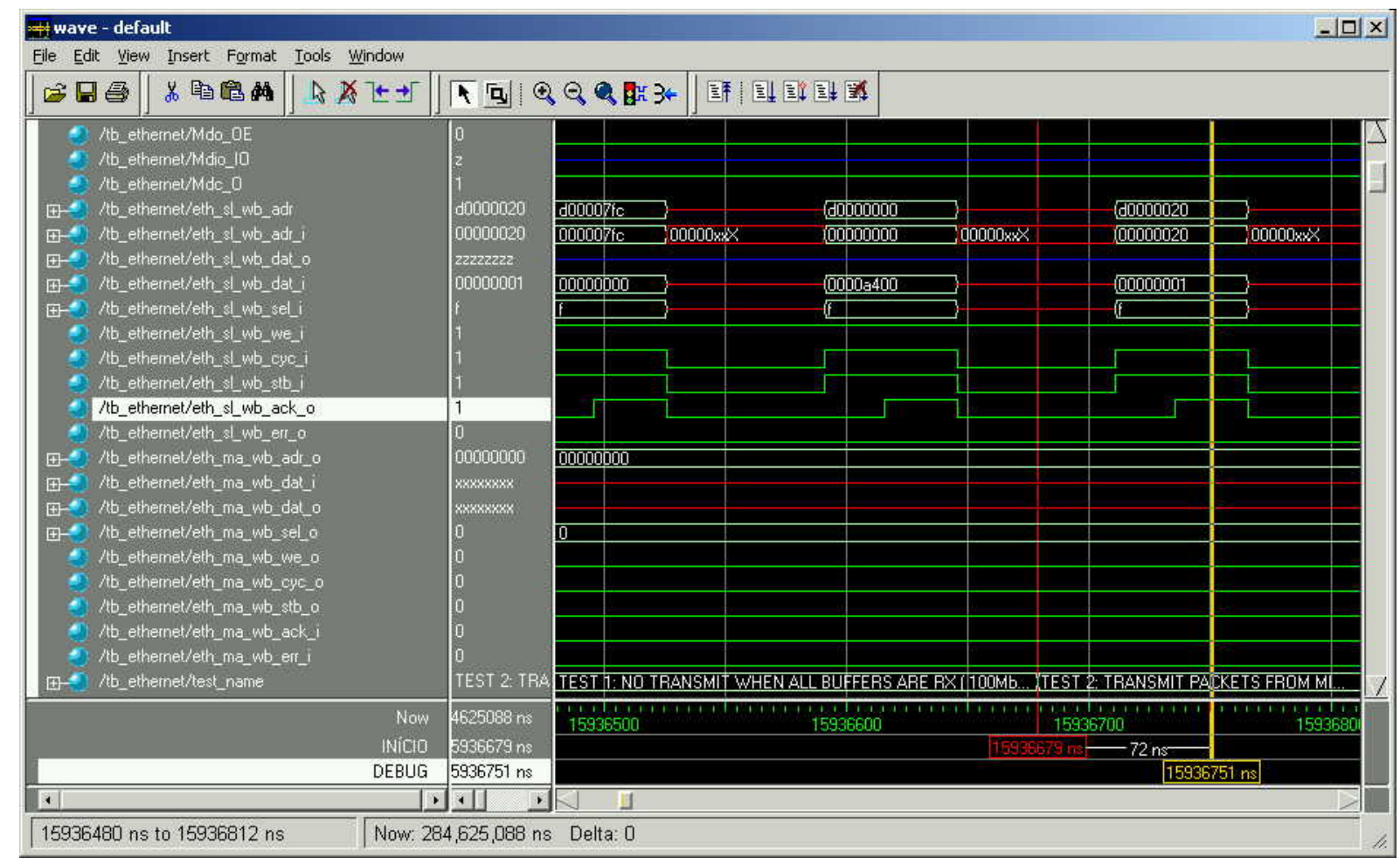

Figura A.1: Gravação do registrador TX_BD_NUM para 1 buffer de transmissão

Posteriormente, é gravado o registrador MODER (0x0) que é o registrador que controla o modo de funcionamento (Figura A.2). São habilitados os bits TXEN, FULLD e CRCEN configurando para a transmissão em modo full-duplex e com geração de CRC.

É realizada uma leitura no registrador PACKETLEN (0x18) para confirmar os tamanhos mínimo e máximo de pacotes, que são respectivamente 64 e 1536 bytes (Figura A.3).

O próximo passo, mostrado da Figura A.4, é configurar um ou mais descritores, localizados a partir do endereço 0x400, para a transmissão de dados. Os bits habilitados são CRC, PAD, IRQ e LEN, sendo que este último é configurado para 60 bytes. Na segunda parte do buffer (endereço mais 0x4) é informada a posição de memória que contém os dados a serem transmitidos (Figura A.5).

Outra configuração realizada é habilitar as interrupções para todos os eventos ocorridos por meio do registrador INT_MASK (0x8). A máscara utilizada está habilitando interrupções tanto para transmissões realizadas com sucesso como para erros de transmissão (Figura A.6). A Figura A.7 mostra mais uma conferência no descritor, após a alteração do ponteiro.

Neste ponto, quase todas as configurações necessárias para realizar um transmissão já foram efetuadas. Por último, é alterado o bit WR do descritor, indicando que este é um último buffer a ser transmitido, já que apenas um buffer está sendo utilizado (Figura A.8) e logo em seguida o mesmo descritor é lido para conferência, como mostrado na Figura A.9.

Uma vez que o descritor está pronto, o bit RD é alterado indicando que o buffer está pronto 


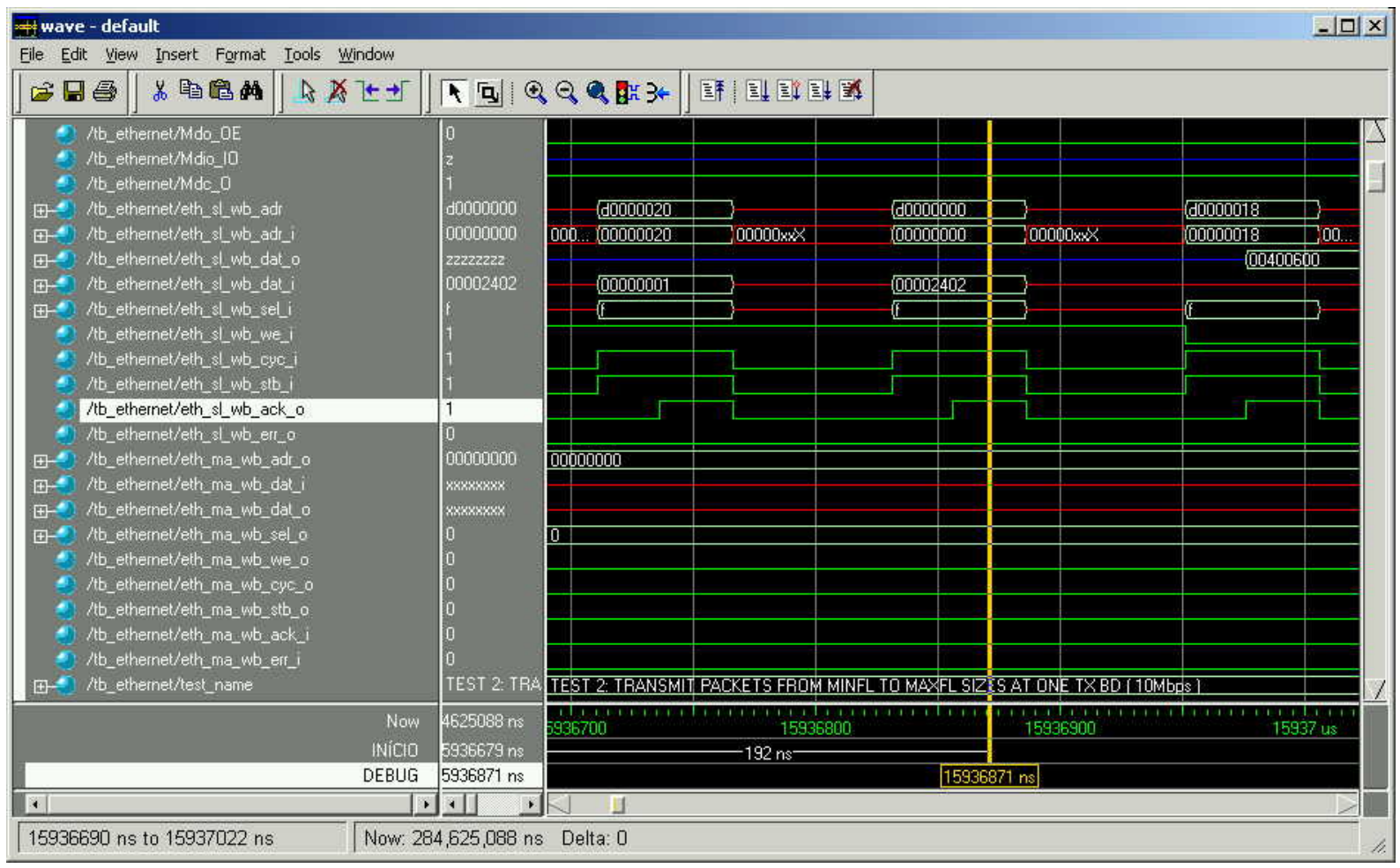

Figura A.2: Gravação do registrador MODER

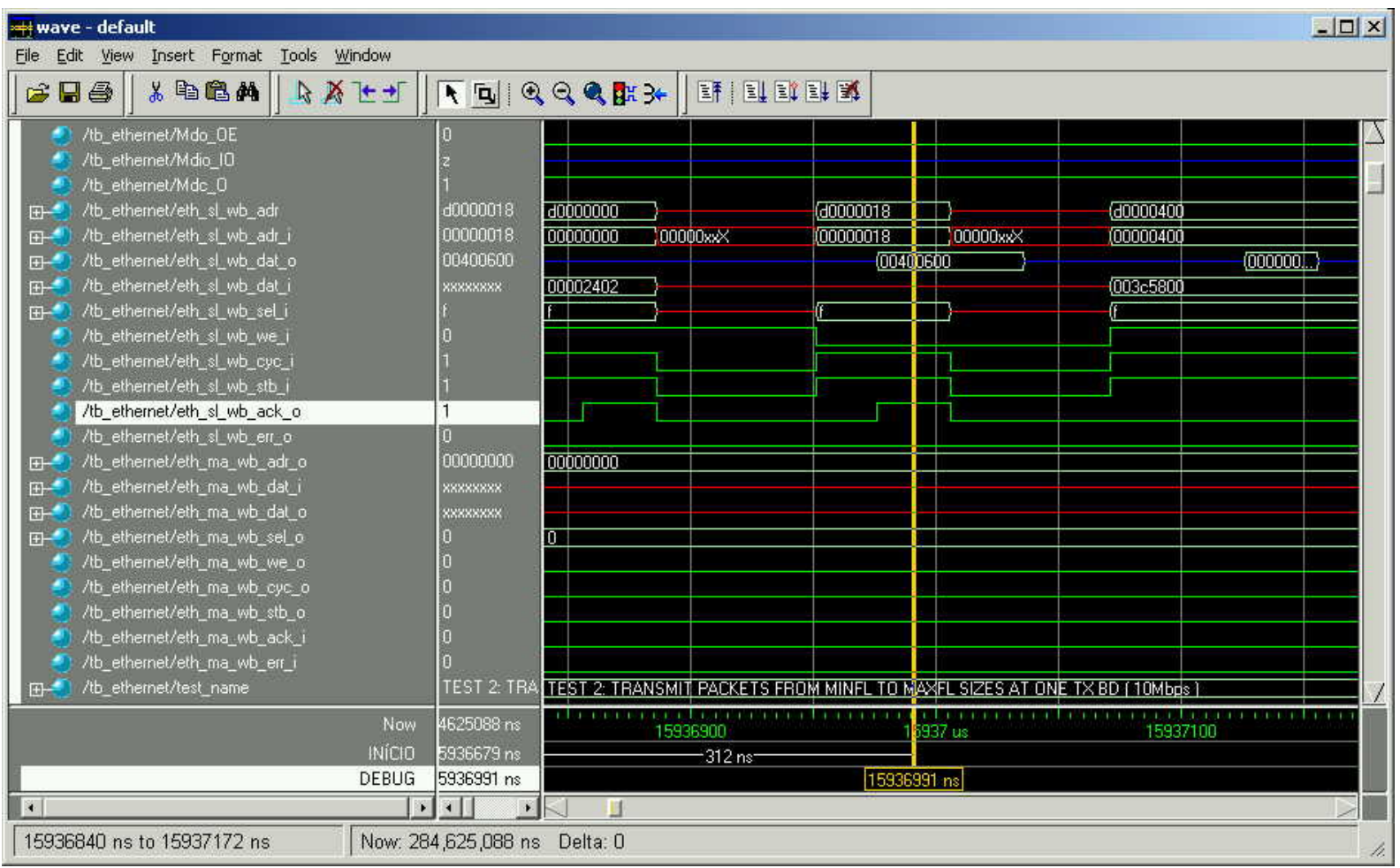

Figura A.3: Lendo os tamanhos mínimo e máximo de pacotes

para ser transmitido (Figura A.10). Após esta alteração, não é possível realizar qualquer modificação no descritor. É realizada ainda uma leitura para conferência, mostrada na Figura A.11.

Após a liberação de pelo menos um buffer, a interface mestre começa a acessar a memória a partir da posição 0x2000, indicada no ponteiro do descritor. Os dados são lidos da memória, 


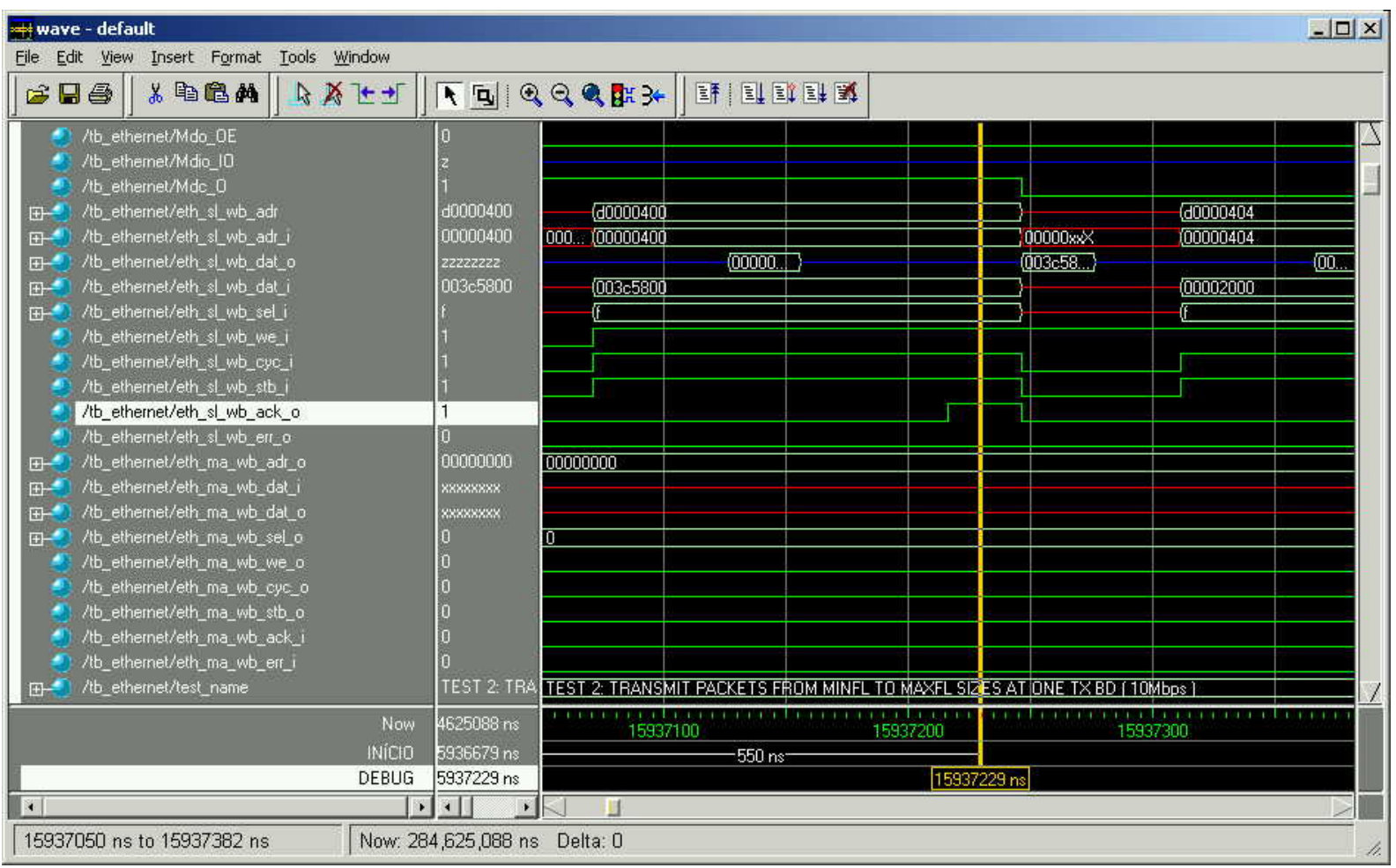

Figura A.4: Configuração de um buffer para transmissão

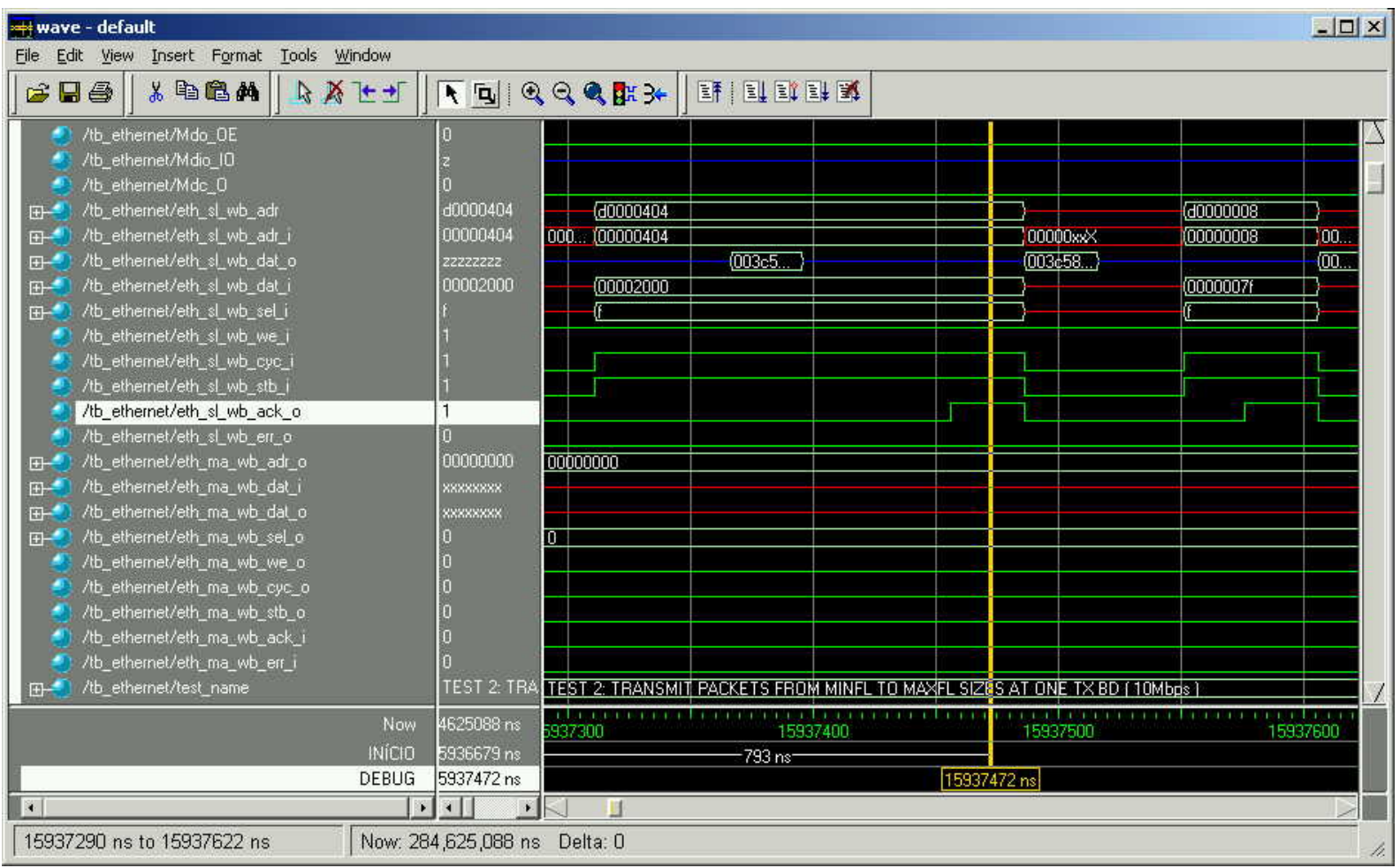

Figura A.5: Configuração do ponteiro de um buffer de transmissão

empacotados e transmitidos em nibbles (conjunto de quatro bits) para a interface MII conectada ao PHY. 


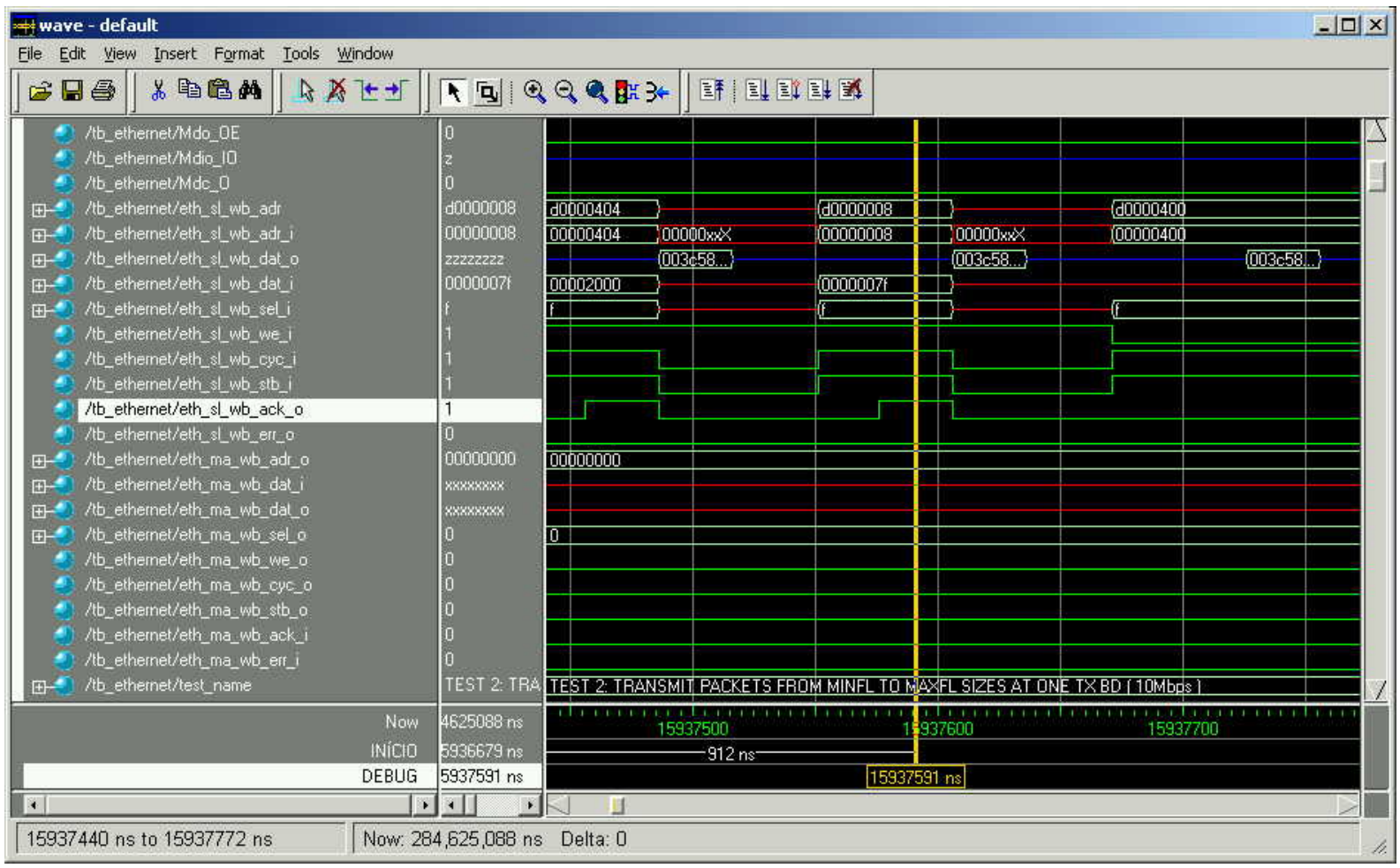

Figura A.6: Configuração da máscara de interrupções

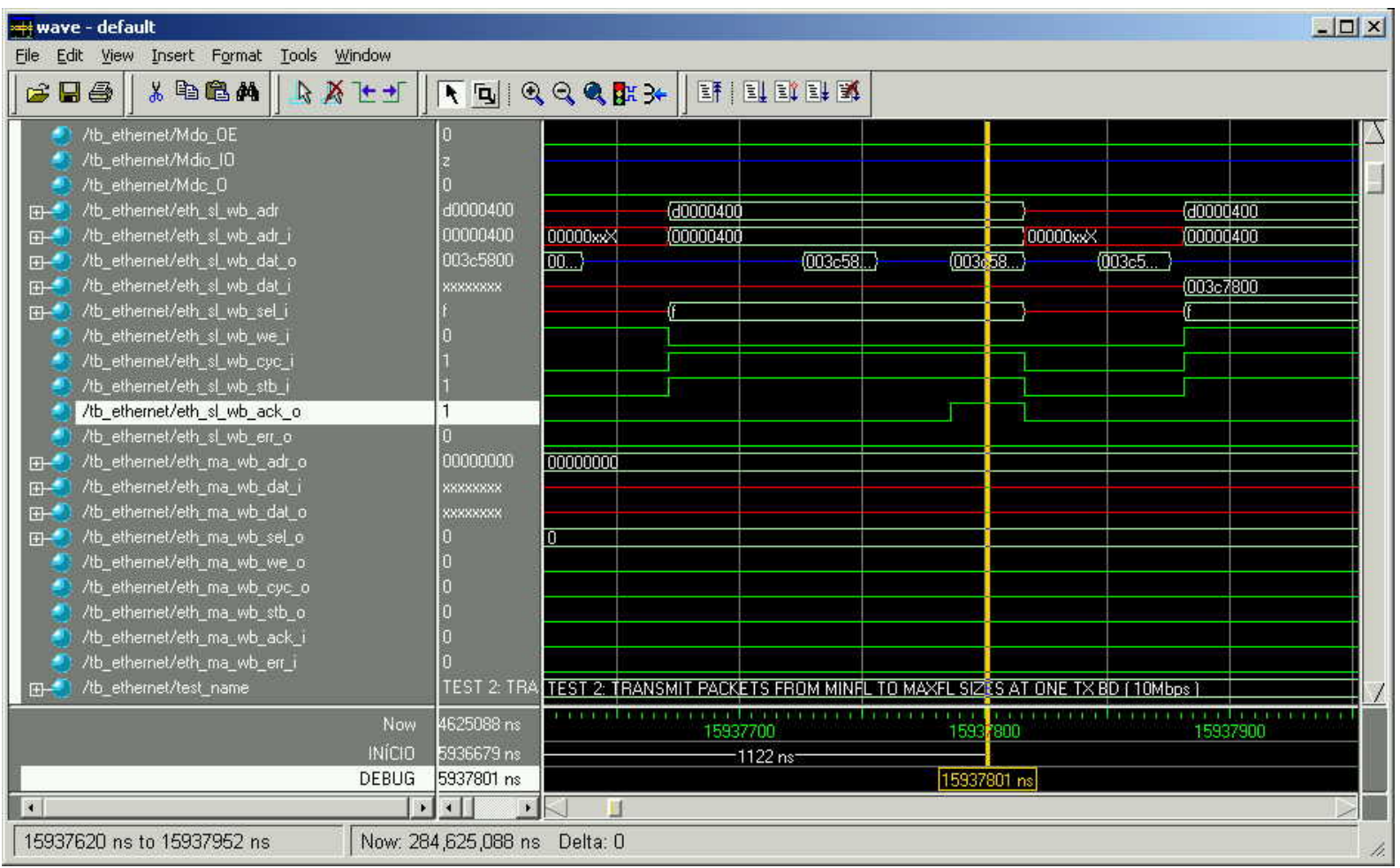

Figura A.7: Leitura do descritor para conferência

\section{A.2 Recepção de dados}

Esta seção descreve alguns procedimentos realizados para recepção de pacotes Ethernet com o core. Assim como na transmissão, o procedimento de recepção não é único, pois esta pode 


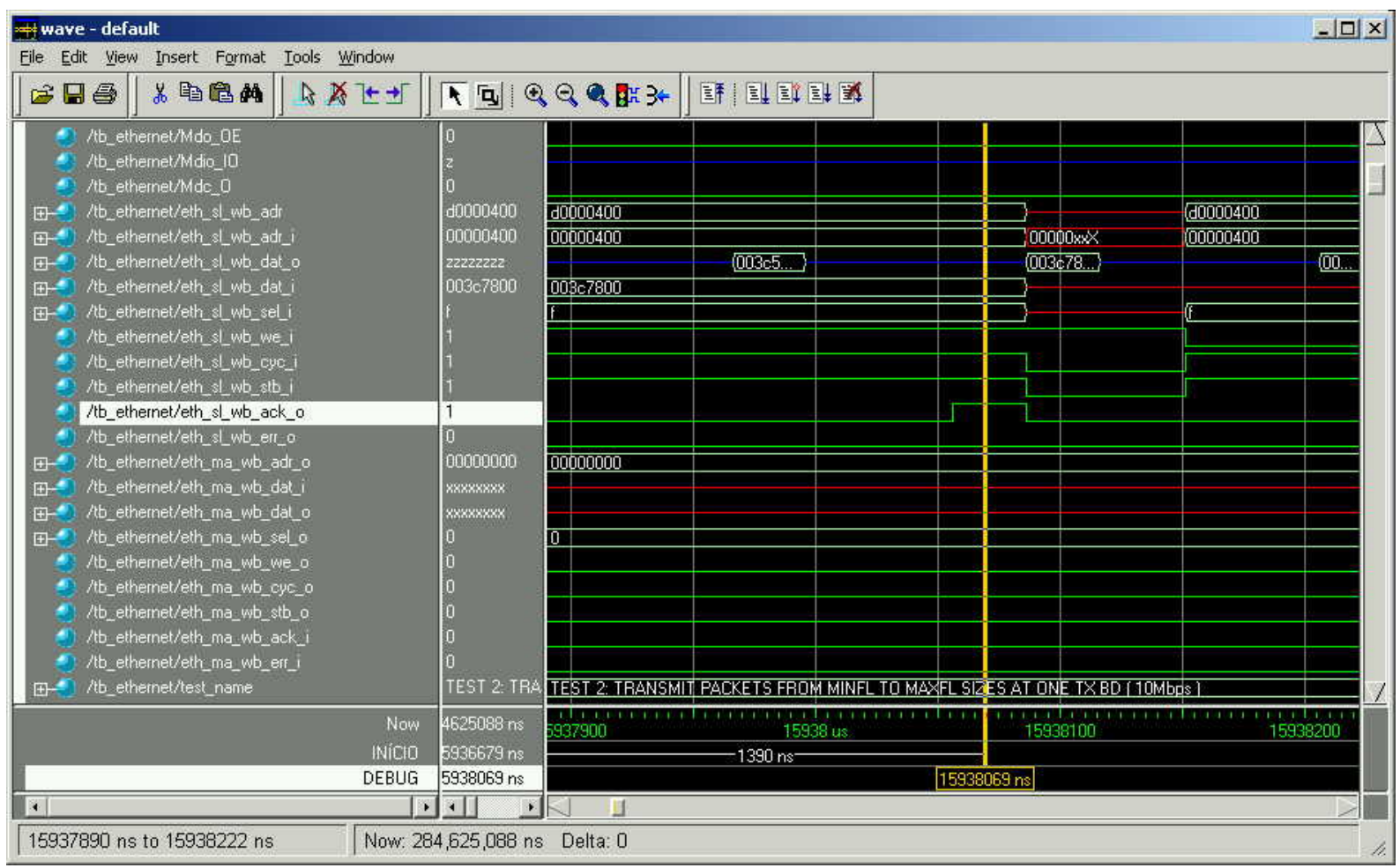

Figura A.8: Gravação do bit WR do descritor

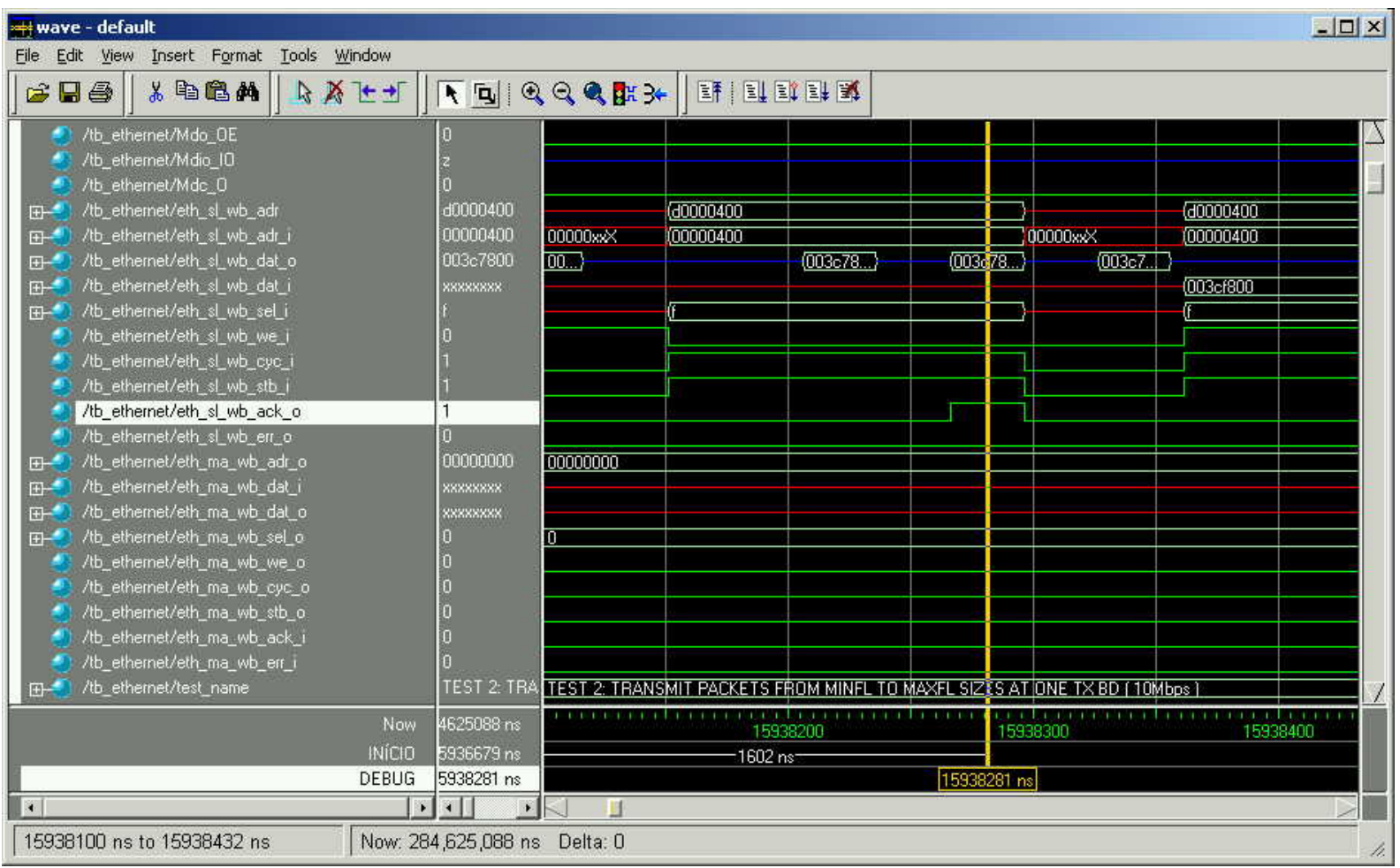

Figura A.9: Leitura do descritor para conferência

ser realizada de diversas formas.

A máscara de interrupções, localizada no registrador INT_MASK (0x8), inclui eventos de transmissão e recepção. A Figura A.13 mostra a gravação da máscara, habilitando interrupções para todos os tipos de eventos. 


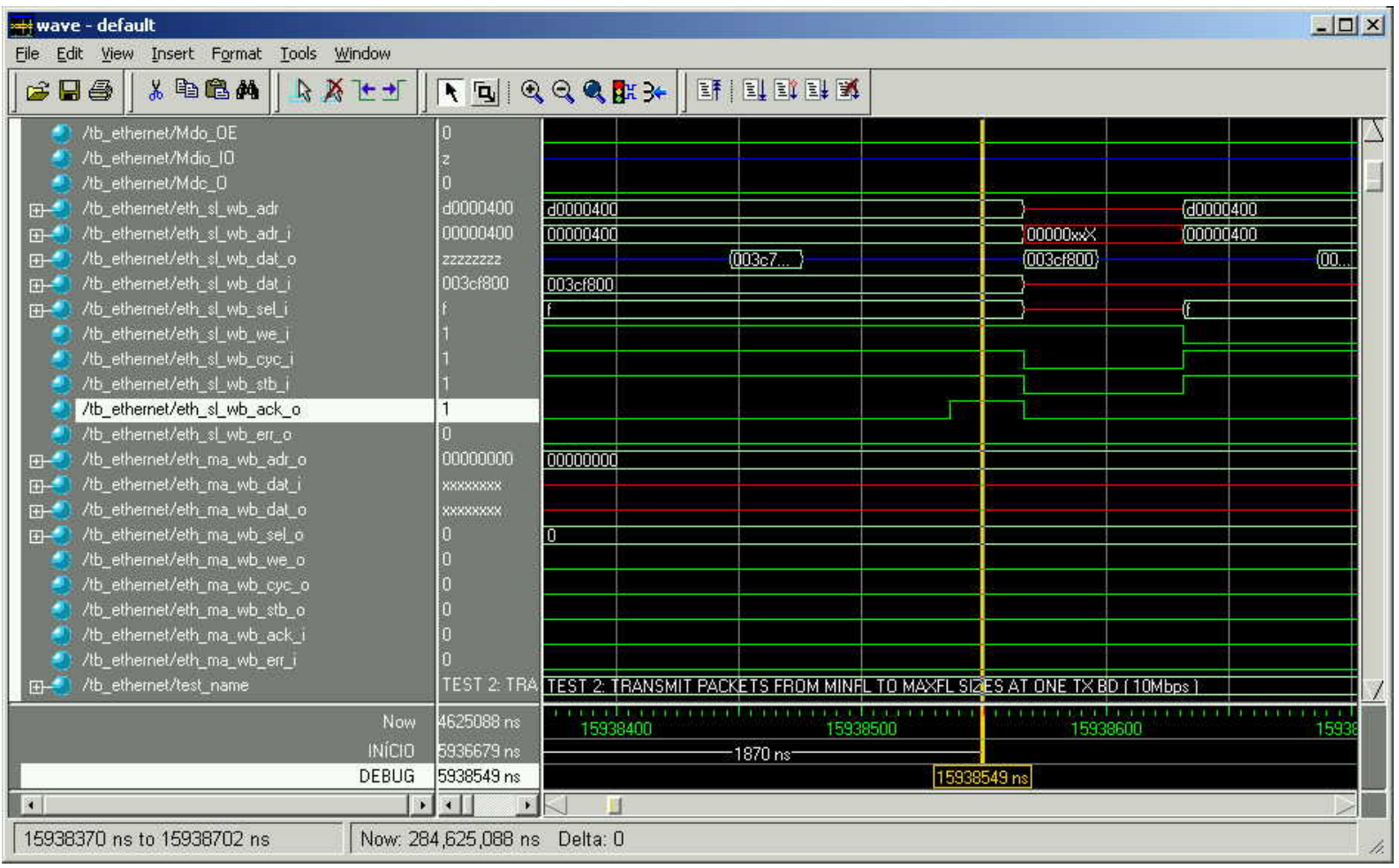

Figura A.10: Gravação do bit RD, informado que o buffer está pronto

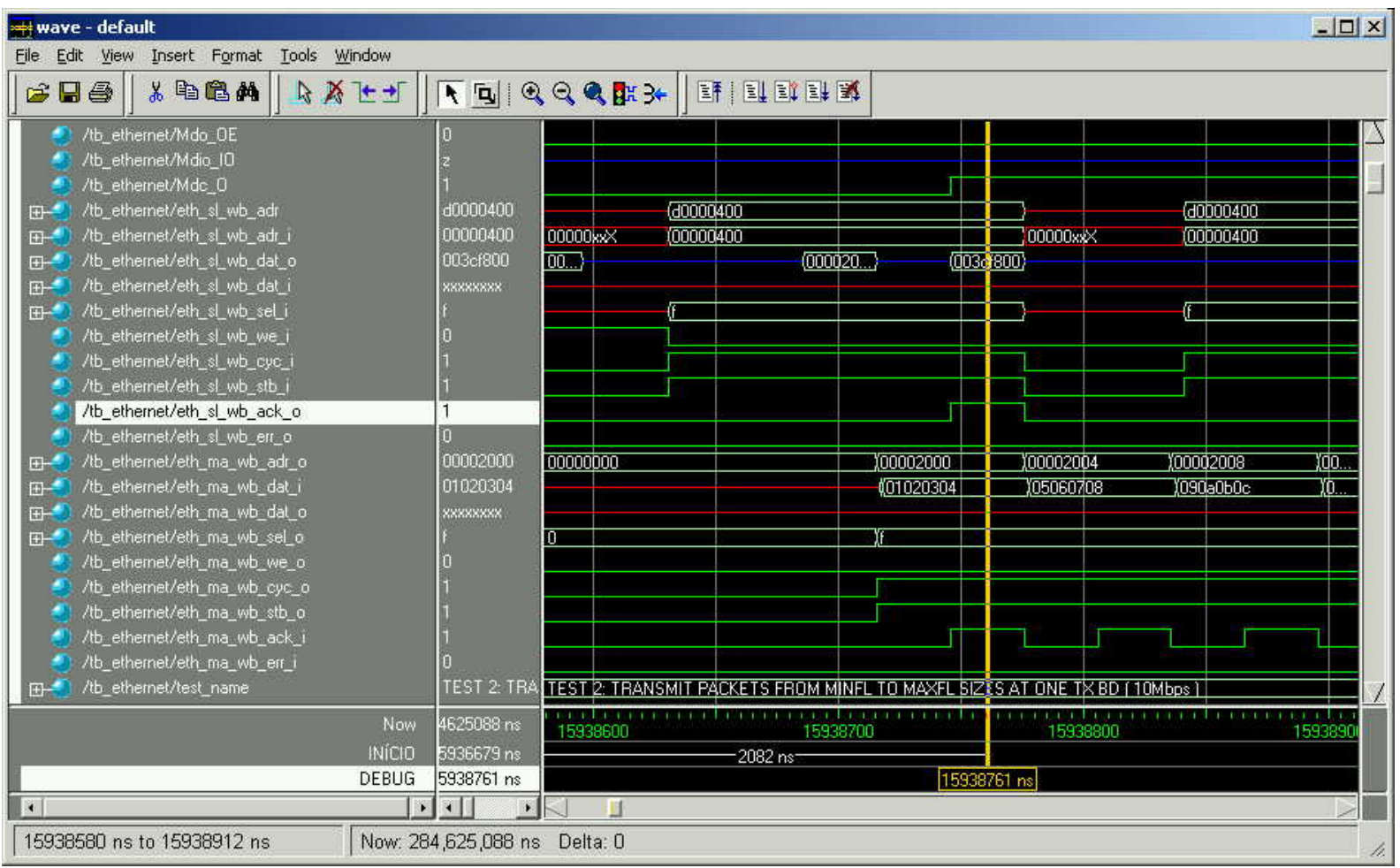

Figura A.11: Leitura do descritor para conferência

São definidos 118 buffers de transmissão (0x76), sobrando 20 buffers para recepção, conforme mostrado na Figura A.14. Com esta configuração o primeiro descritor de transmissão passa a ser o de endereço 0x7b0. Para se obter este endereço basta somar o endereço inicial dos descritores $(0 x 400)$ com a quantidade de descritores de transmissão (0x76) multiplicados por 8 


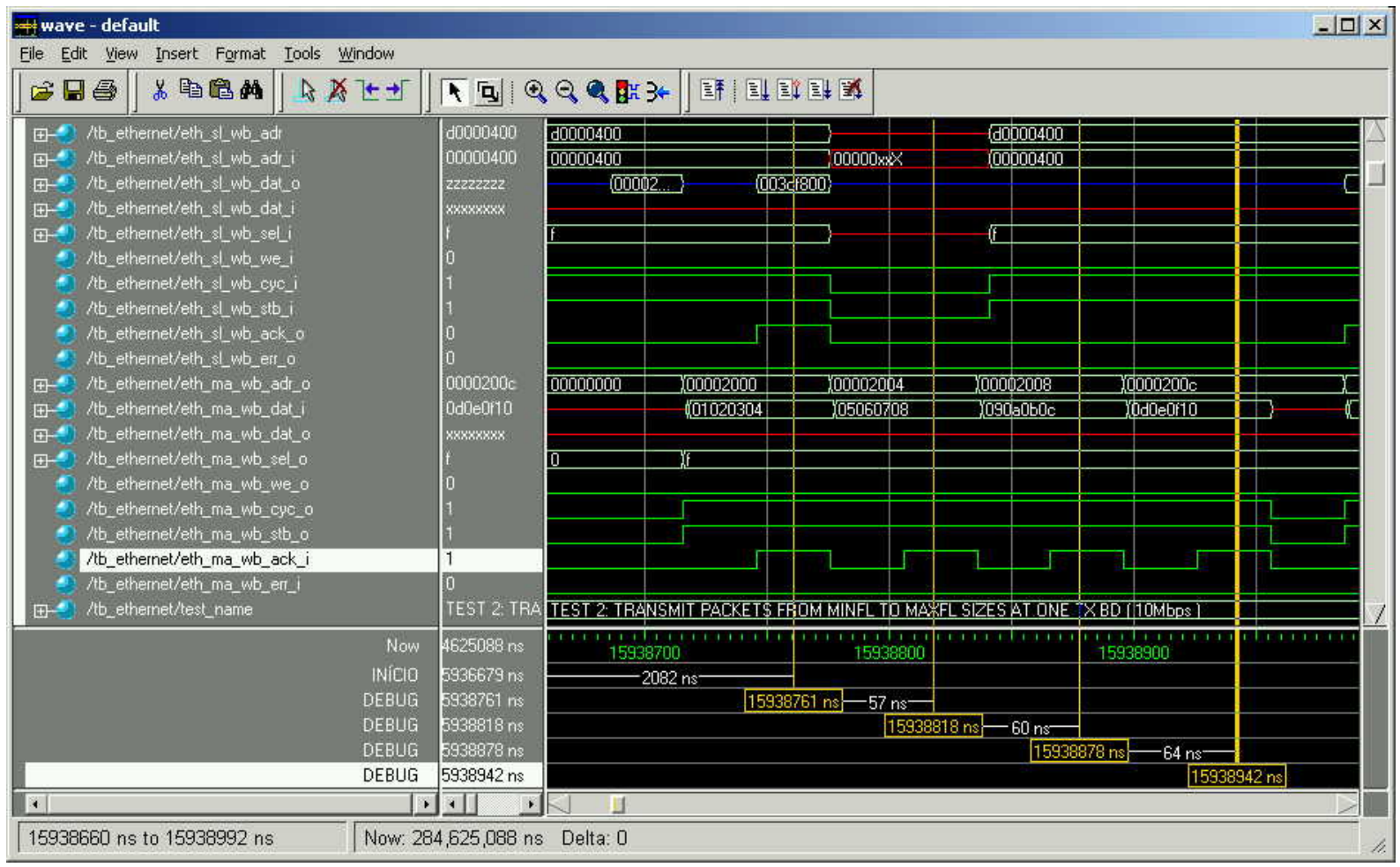

Figura A.12: Interface mestre busca dados na memória

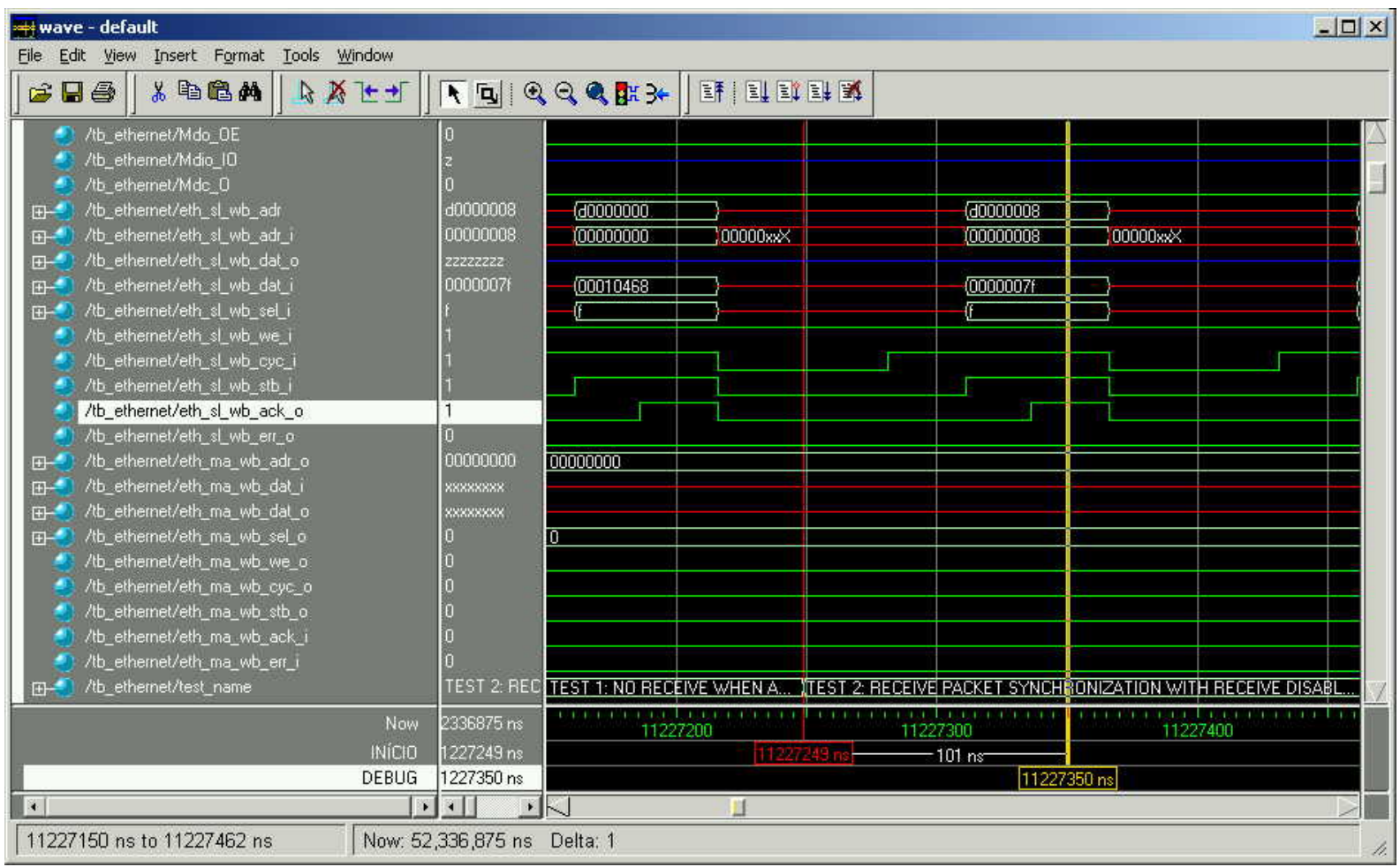

Figura A.13: Configuração da máscara de interrupções

que é o espaço ocupado por cada descritor.

Posteriormente, o registrador MODER é gravado, alterando o modo de funcionamento do core (Figura A.15). As principais modificações são os bits PRO, que coloca a interface de rede em modo promíscuo e FULLD, para operação em modo full-duplex. 


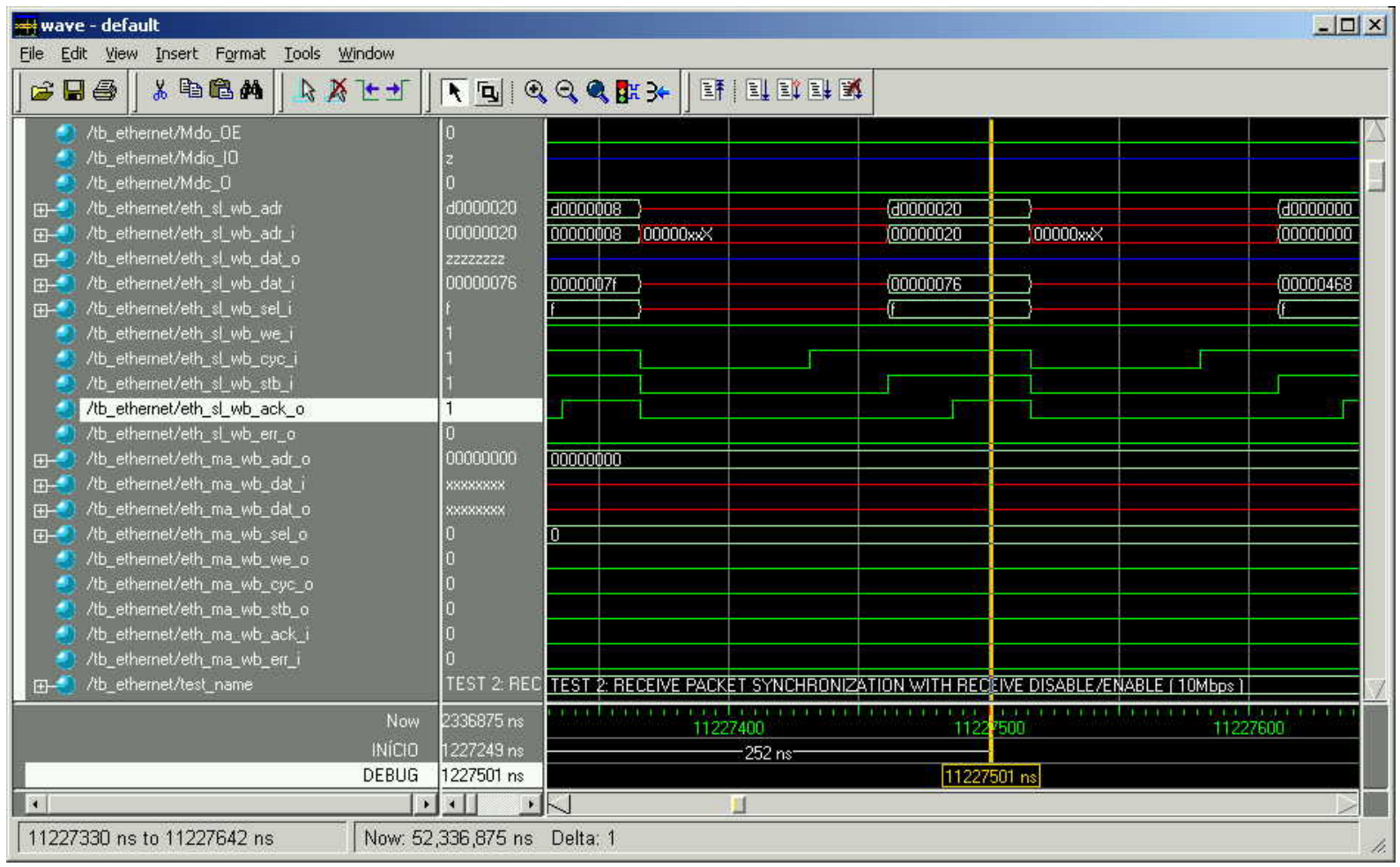

Figura A.14: Gravação do registrador TX_BD_NUM para 118 buffers de transmissão

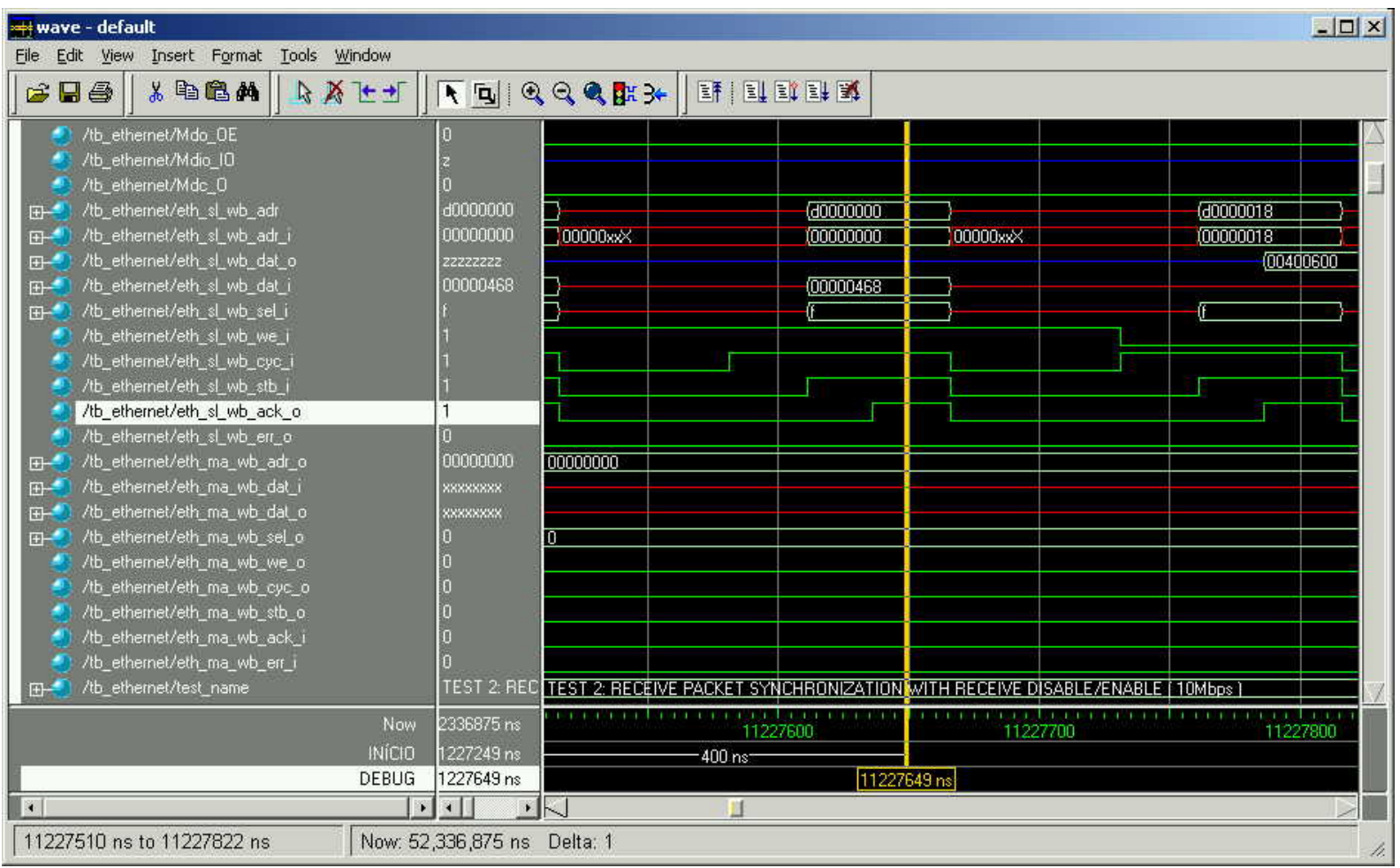

Figura A.15: Gravação do registrador MODER

Como na transmissão, é realizada uma leitura no registrador PACKETLEN (0x18) para confirmar os tamanhos mínimo e máximo de pacotes, que são respectivamente 64 e 1536 bytes (Figura A.16).

A seguir é habilitada a interrupção para o descritor de recepção, conforme a Figura A.17. 


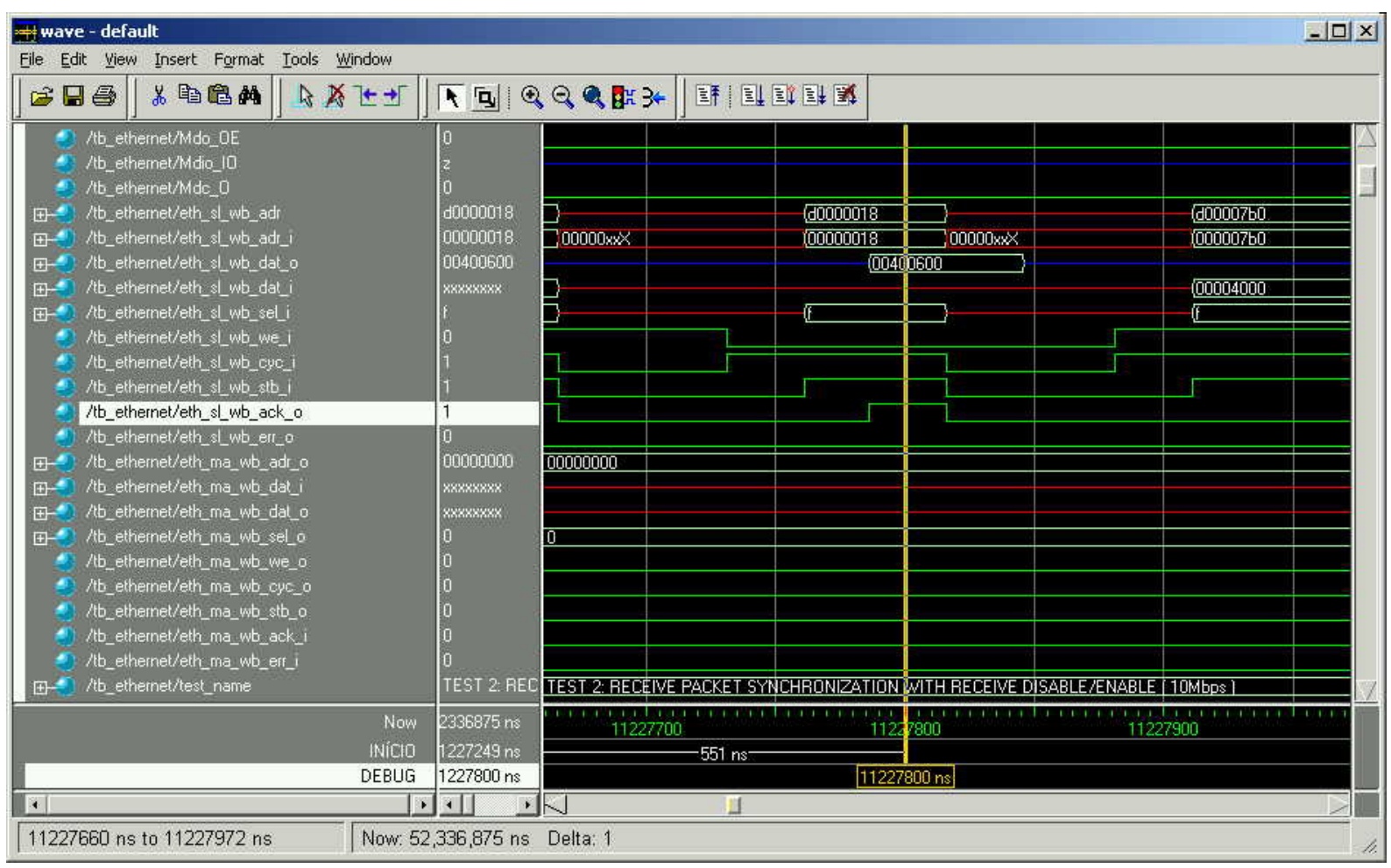

Figura A.16: Lendo os tamanhos mínimo e máximo de pacotes

Os tipos de interrupções configurados no registrador MODER servem para todos os buffers, mas é possível determinar se um buffer específico irá gerar ou não a interrupção. Na segunda parte do buffer (endereço mais 0x4) é informada a posição de memória que contém os dados a serem transmitidos (Figura A.18).

A Figura A.19 demonstra a leitura do descritor para conferência dos parâmetros utilizados. Estas operações são feitas com freqüência, para garantir que o parâmetro foi alterado.

O próximo passo é alterar o bit WRAP do descritor, indicando que ele é o último disponível (Figura A.20). Quando o core utiliza o último descritor ele retorna ao primeiro da lista.

Novamente o descritor é lido para conferência da alteração (Figura A.21).

Após todas as configurações no descritor, o registrador MODER é alterado novamente, gravando agora o bit RXEN que habilita a interface de rede para recepção. Esta última modificação é mostrada na Figura A.22.

A medida em que os dados são recebidos o core irá gravá-los na memória a partir do endereço 0x2000, indicado no ponteiro do descritor. Esta operação é realizada pela interface mestre do barramento, conforme a Figura A.23. A operação é realizada nos endereços seguintes até que todo o pacote seja recebido, conforme a Figura A.24.

Após a recepção do pacote completo o core irá atualizar os registradores do descritor utilizado. O bit $\mathbf{E}$ indica que este buffer não está mais vazio e o registrador LEN armazena a quantidade de bytes recebidos.

Com estes testes e muitos outros não descritos aqui, verificou-se por simulação, o funcionamento correto do core e sua viabilidade para utilização no projeto. 


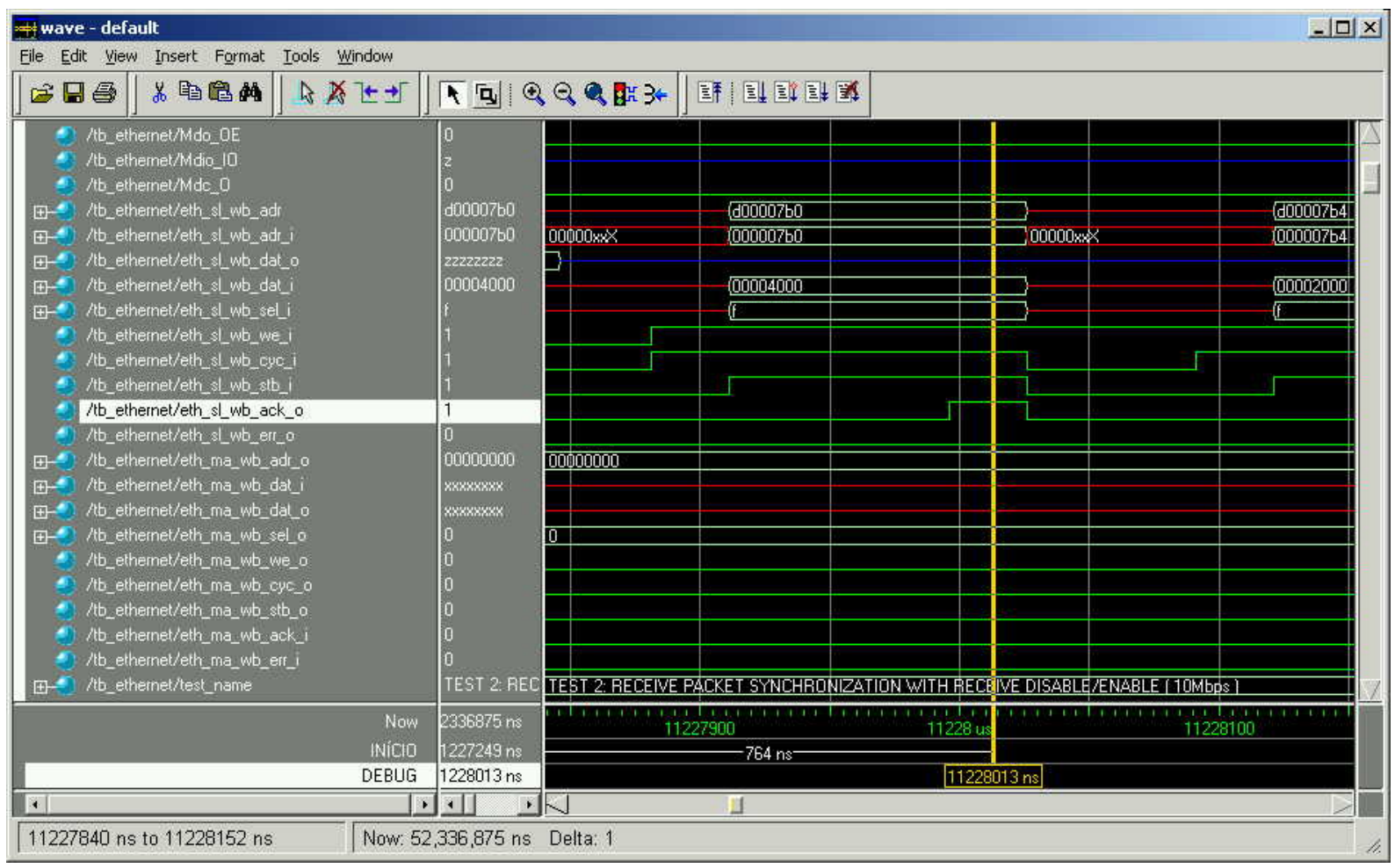

Figura A.17: Habilitando a interrupção para o descritor de recepção

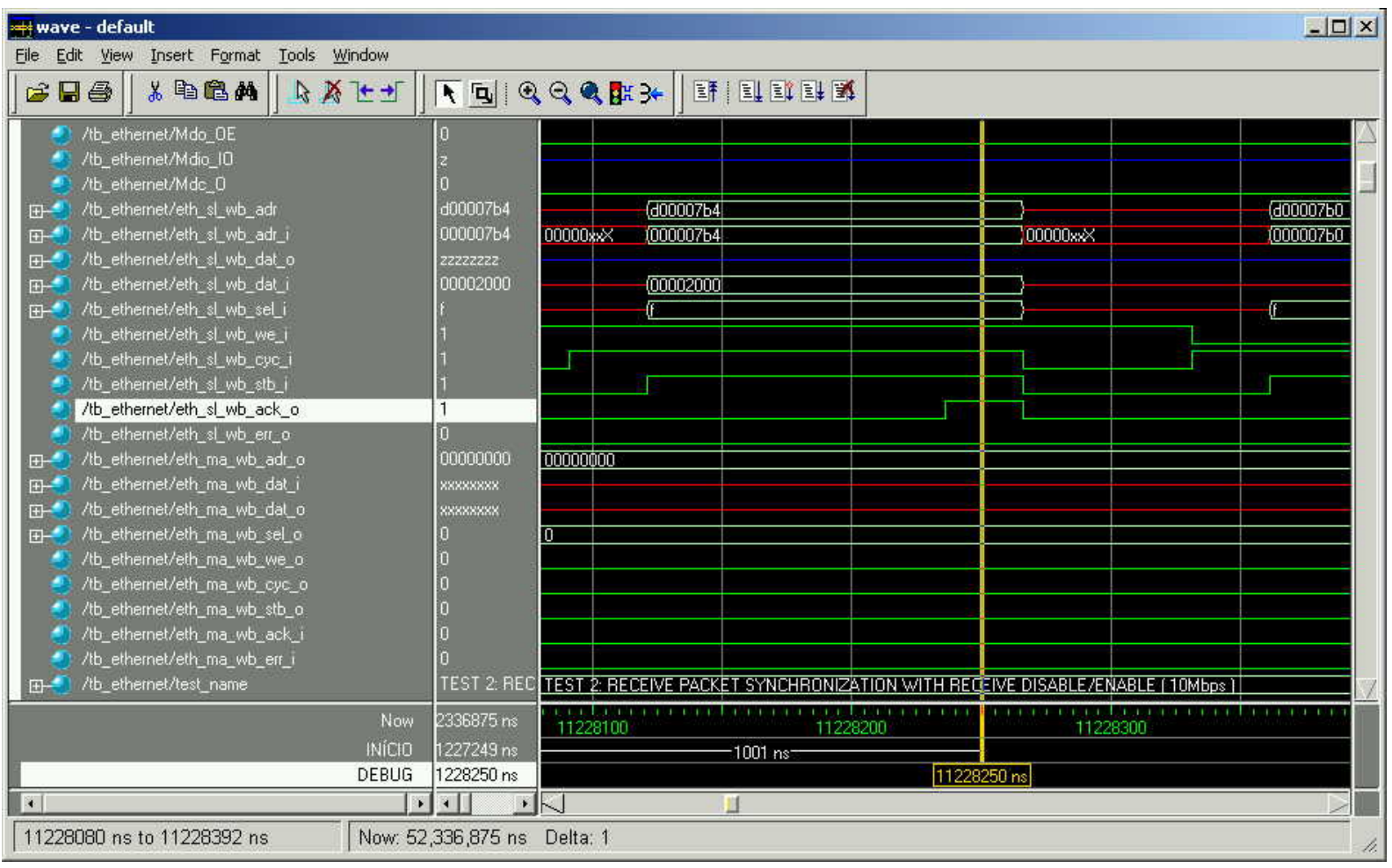

Figura A.18: Configuração do ponteiro de um buffer de recepção 


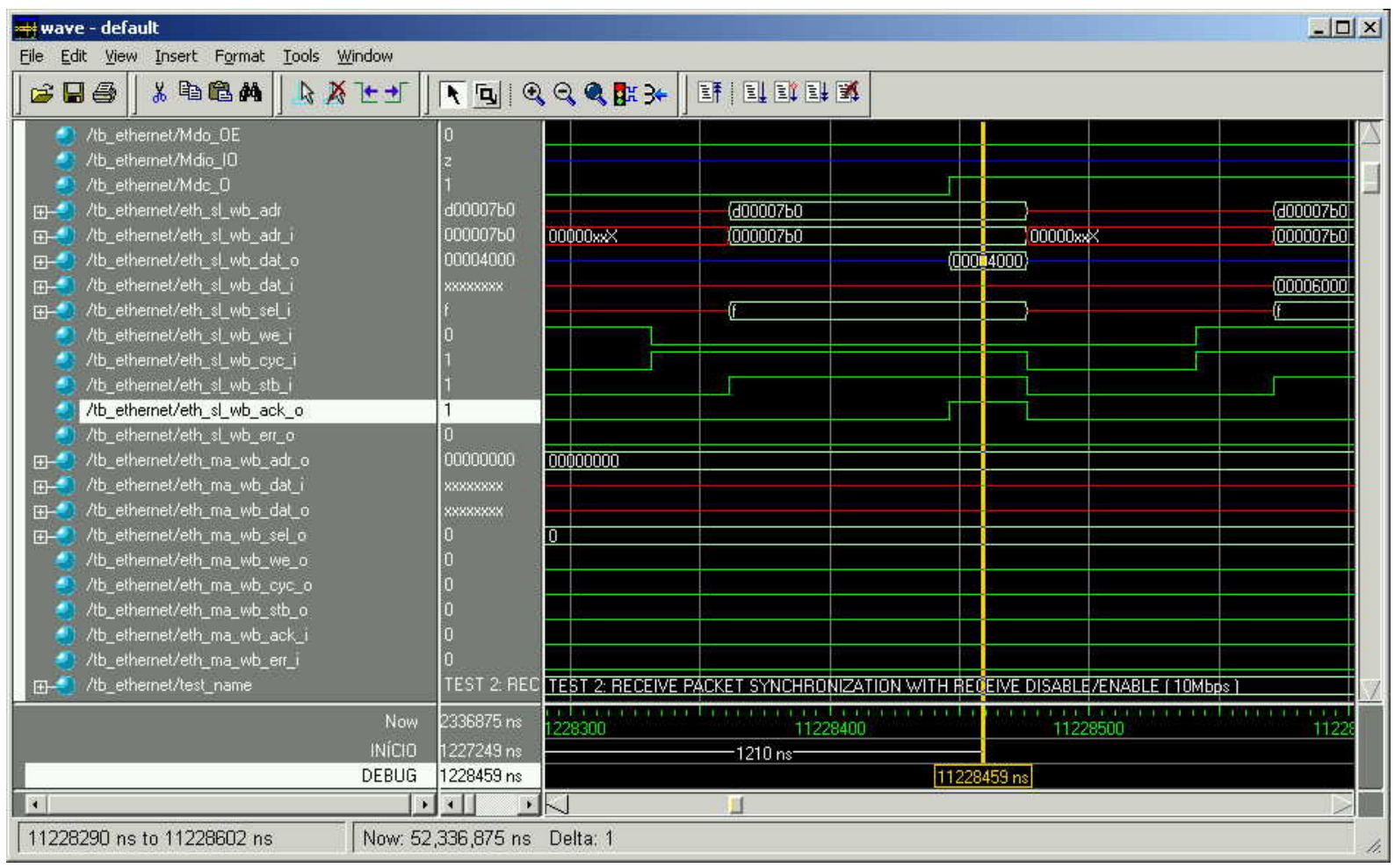

Figura A.19: Leitura do descritor para conferência

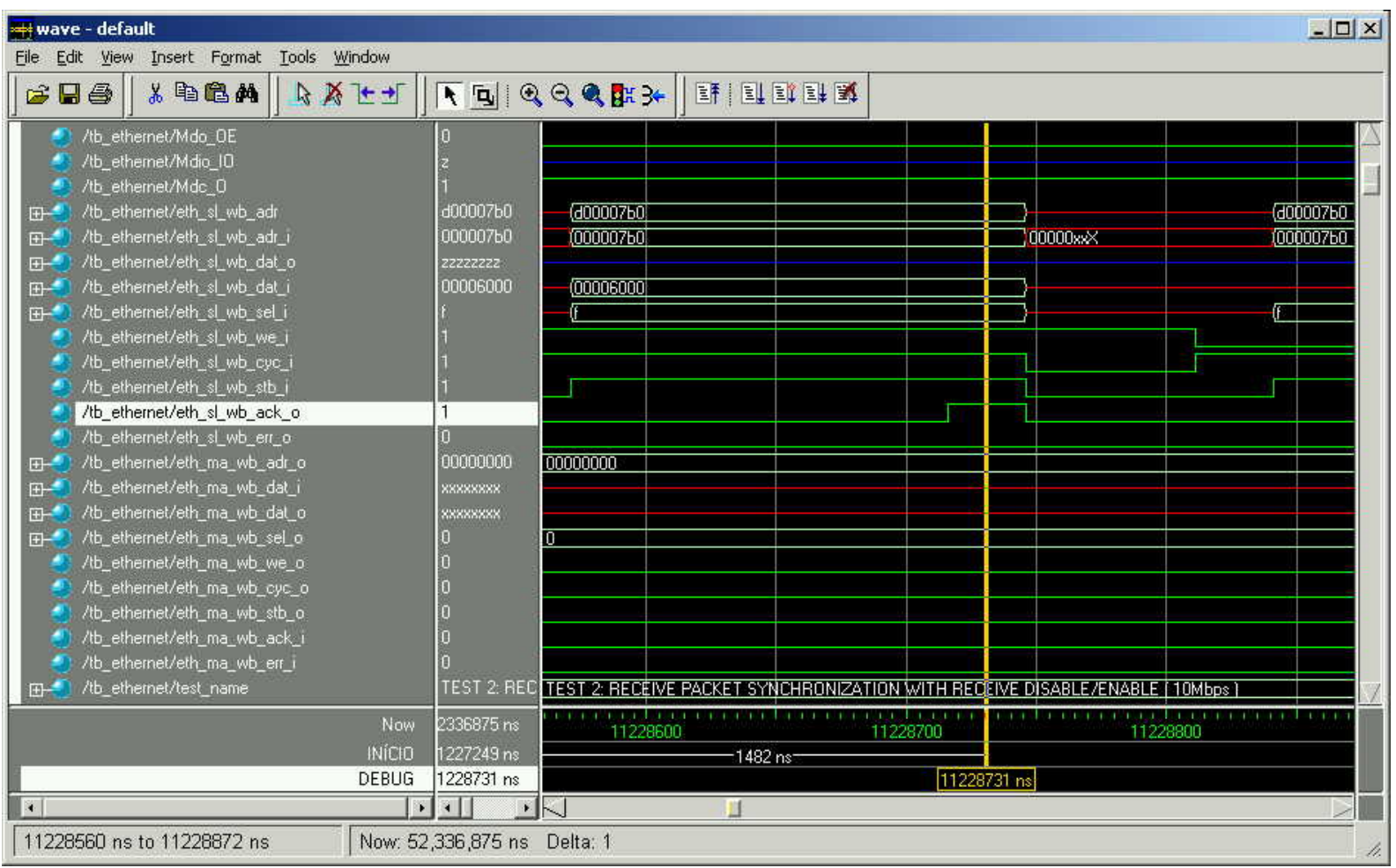

Figura A.20: Gravação do bit WRAP do descritor 


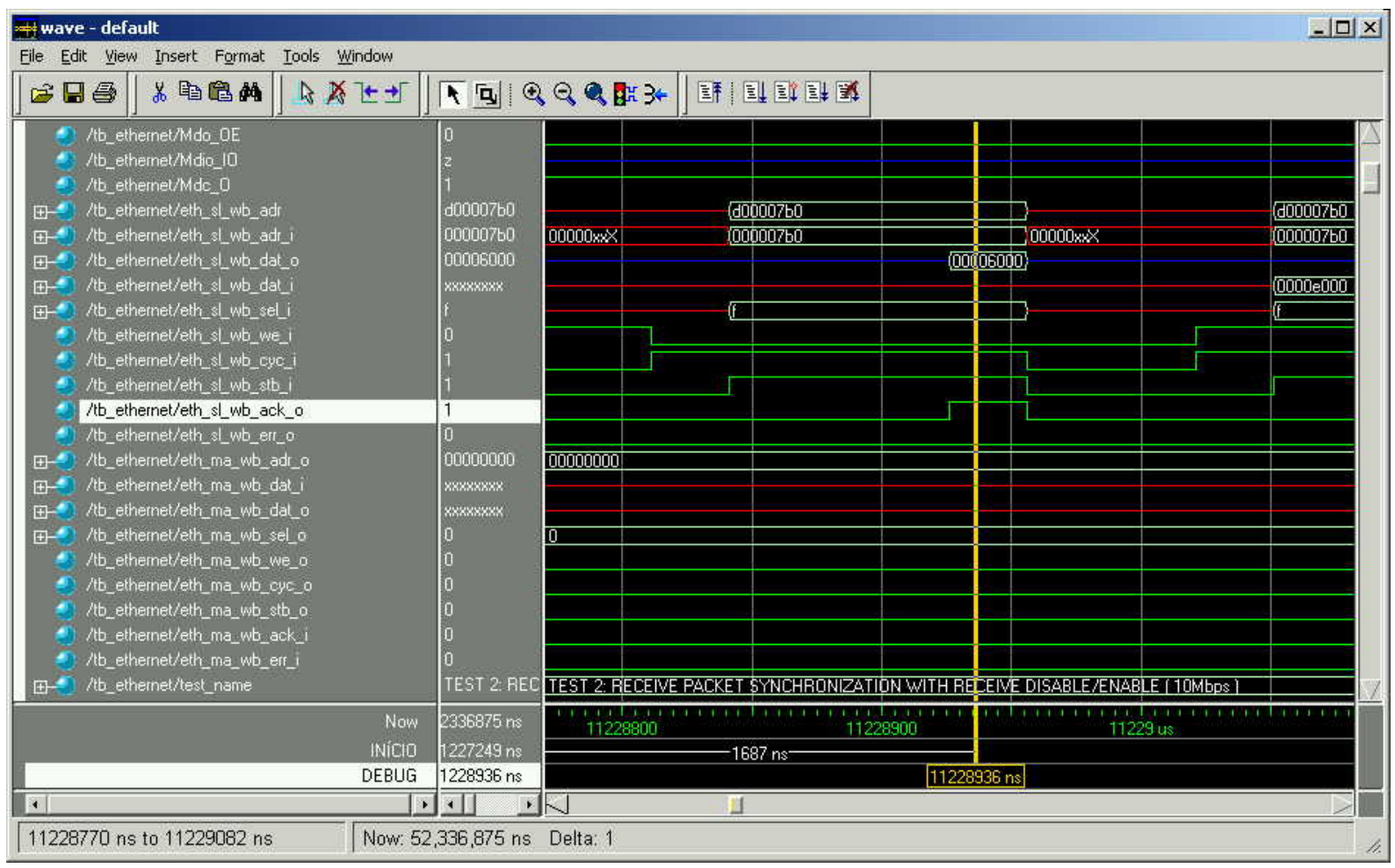

Figura A.21: Leitura do descritor para conferência

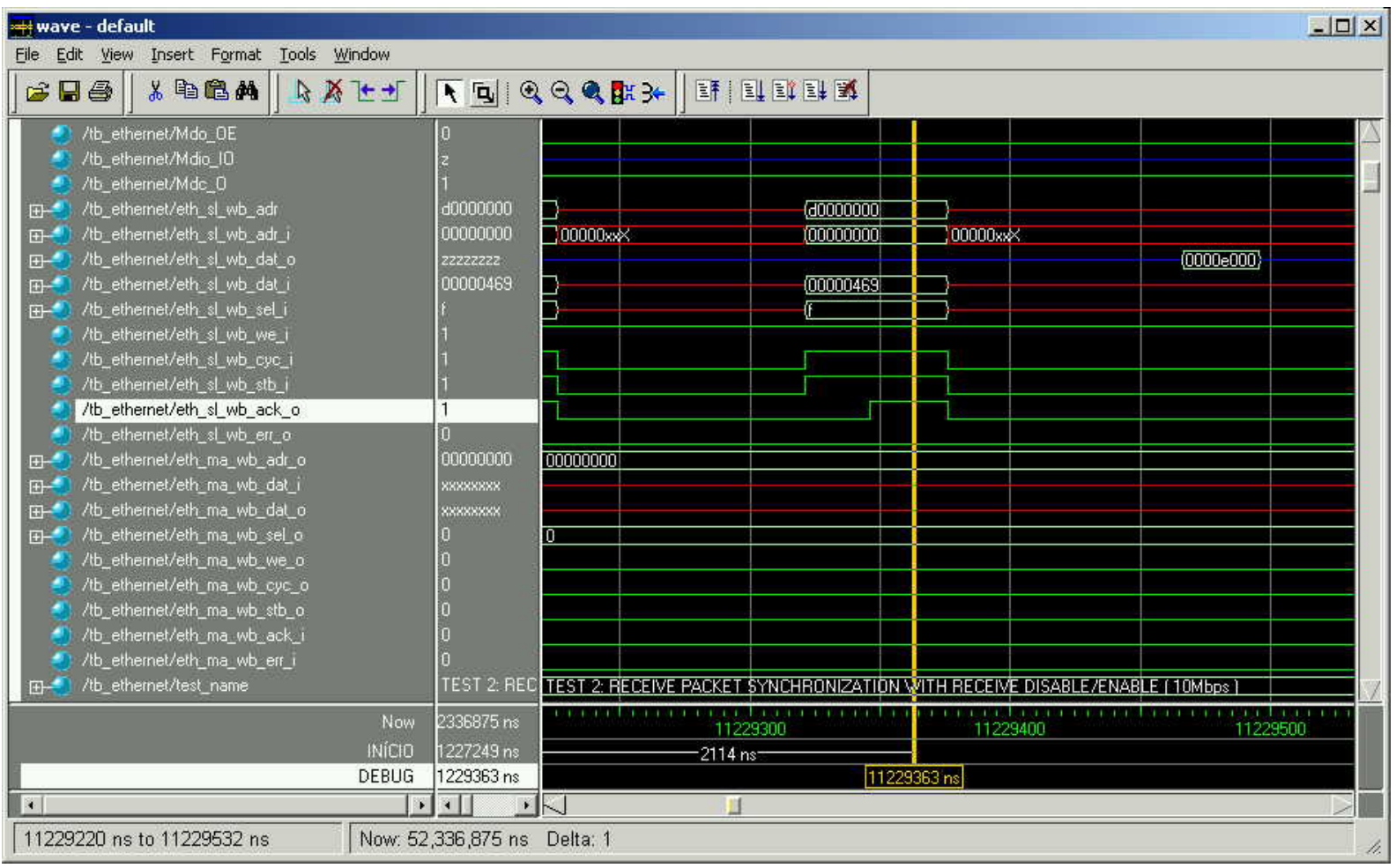

Figura A.22: Gravação do registrador MODER, habilitando a recepção 


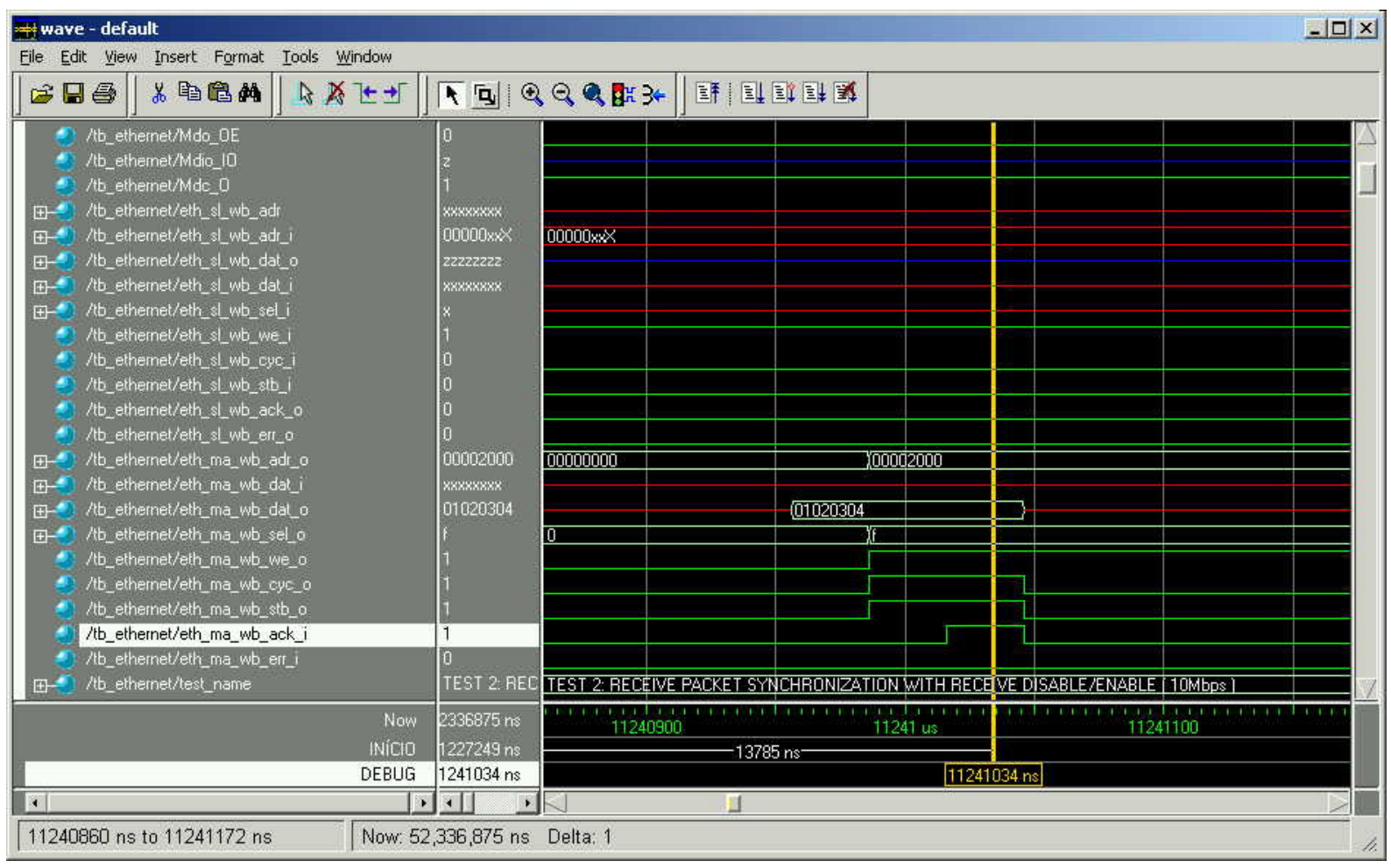

Figura A.23: Interface mestre grava dados na memória

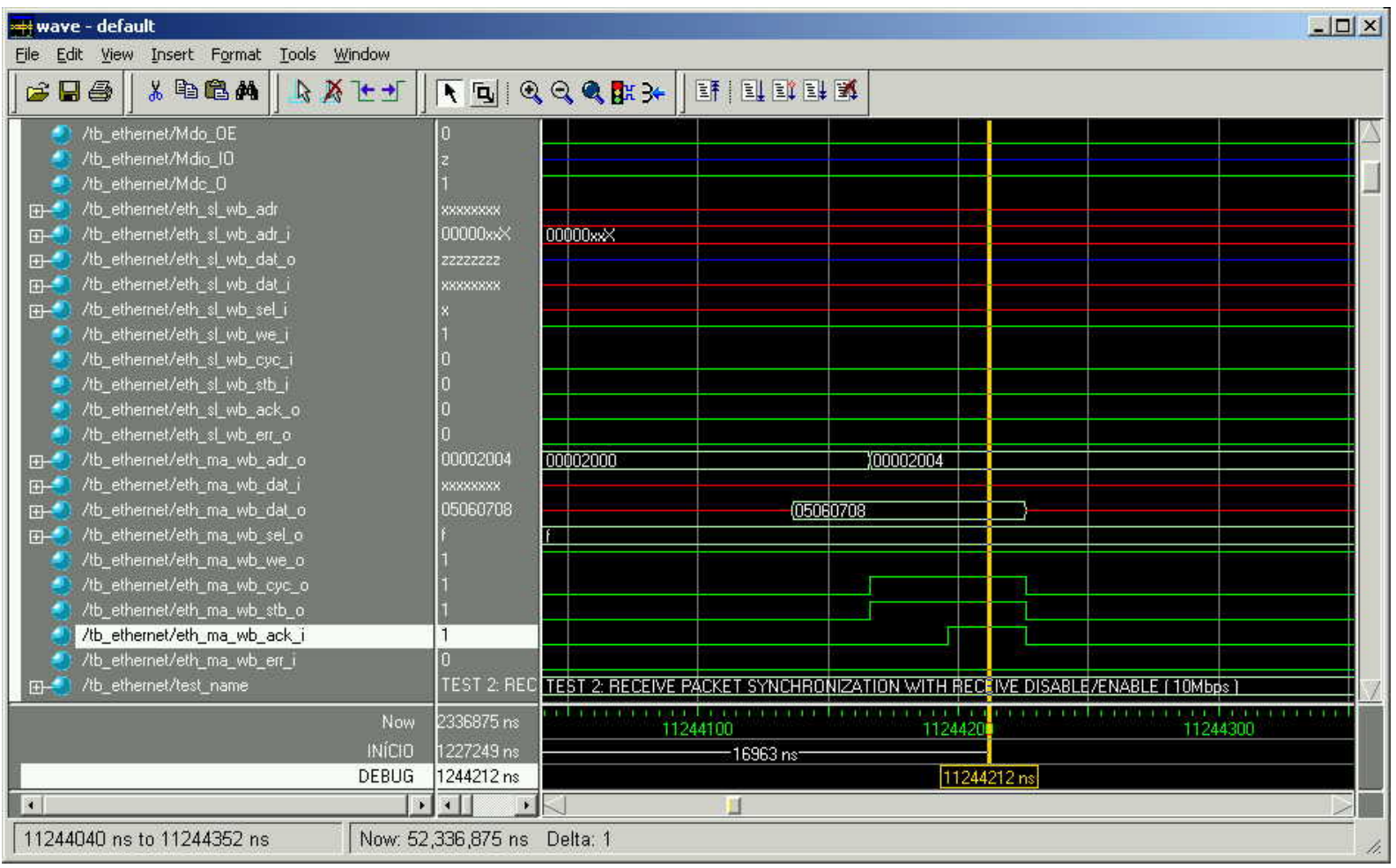

Figura A.24: Endereços consecutivos são utilizados 